\title{
Acid Catalyzed Activation of Peroxyketals: Tunable Radical Initiation at Ambient Temperature and Below
}

Bertrand Schweitzer-Chaput, Esther Boess, and Martin Klussmann

\section{Supporting Information}

\section{Table of Contents}

1 EXPERIMENTAL DETAILS ......................................................................................................

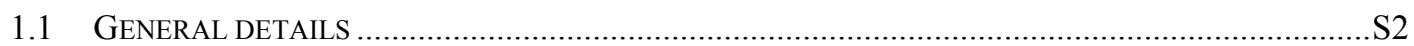

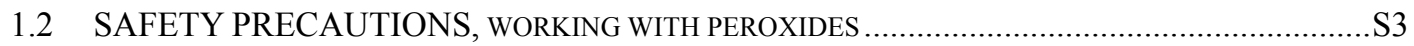

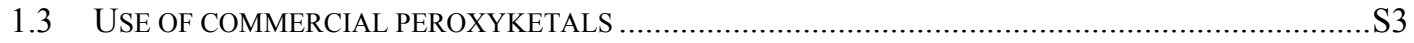

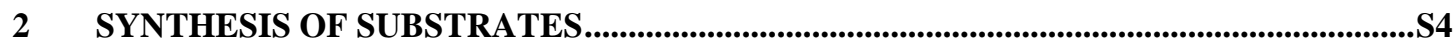

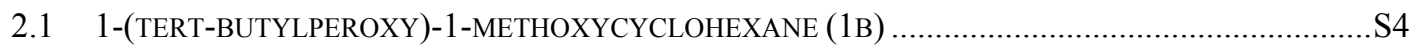

2.2 1-AZIDO-1-(TERT-BUTYLPEROXY)CYCLOHEXANE (1C) …………........................................

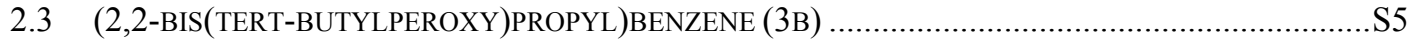

$2.4 \quad(1,1$-BIS(TERT-BUTYLPEROXY)ETHANE-1,2-DIYL)DIBENZENE (3C) ……………………….......S5

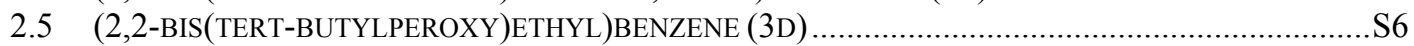

$2.6 \quad 2,2$-BIS(TERT-BUTYLPEROXY)-2,3-DIHYDRO-1H-INDENE (6A) ……………………...............S7

2.7 2,2-BIS(TERT-BUTYLPEROXY)-1,2,3,4-TETRAHYDRONAPHTHALENE (6B) ………….................S7

2.8 O-((3AR,6S,6AR)-5-((R)-2,2-DIMETHYL-1,3-DIOXOLAN-4-YL)-2,2-

DIMETHYLTETRAHYDROFURO[2,3-D][1,3]DIOXOL-6-YL) O-PHENYL CARBONOTHIOATE (14) ............S8

3 WOHL-ZIEGLER BROMINATION OF FLUORENE.............................................................S9

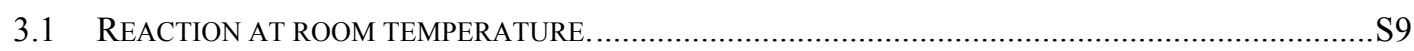

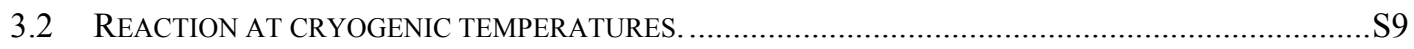

$4 \quad$ SYNTHESIS OF PRODUCTS.....................................................................................................

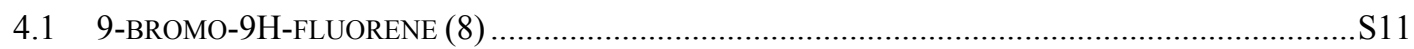

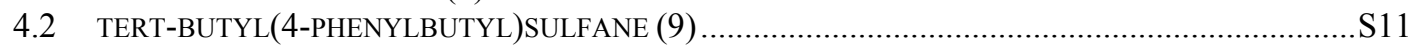

$4.3 \quad(3,5,5,5$-TETRACHLOROPENTYL)BENZENE (10) ............................................................. 12

4.4 PHENANTHRENE (11) ............................................................................................. 12

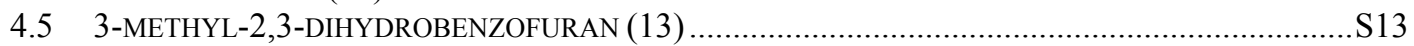

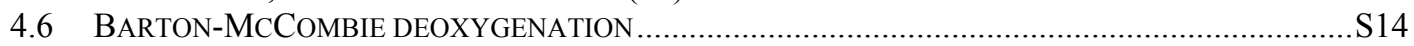

5 TRAPPING OF GENERATED RADICALS WITH STYRENE ...........................................S16

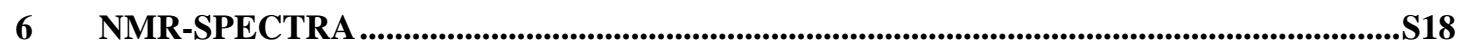

7 SUPPORTING REFERENCES.................................................................................... 


\section{Experimental details}

\subsection{General details}

Unless otherwise indicated, all reagents and solvents were purchased from commercial distributors and used as received. For details concerning the peroxyketals, see below.

Solvents (pentane, hexanes, ethyl acetate, dichloromethane, methanol) used for column chromatography were of technical grade and used after distillation in a rotary evaporator.

Air sensitive reactions were performed using classical Schlenk line techniques under an atmosphere of argon (Air Liquide, $>99.5 \%$ ).

TLC was used to check the reactions for full conversion and was performed on Macherey-Nagel Polygram Sil G/UV 254 thin layer plates. TLC spots were visualized by UV-light irradiation and/or staining with solutions of $\mathrm{KMnO}_{4}$ or anisaldehyde.

Flash column chromatography was carried out using Merck Silica Gel 60 (40-63 $\mu \mathrm{m})$. Yields refer to pure isolated compounds.

${ }^{1} \mathrm{H}$ and ${ }^{13} \mathrm{C}$ NMR spectra were measured with Bruker AV 600, AV 500 and AV 400 spectrometers. All chemical shifts are given in ppm downfield relative to TMS and were referenced to the solvent residual peaks. ${ }^{1}{ }^{1} \mathrm{H}$ NMR chemical shifts are designated using the following abbreviations as well as their combinations: $\mathrm{s}=$ singlet, $\mathrm{d}=$ doublet, $\mathrm{t}=$ triplet, $\mathrm{q}=$ quartet, $\mathrm{m}=$ multiplet, $\mathrm{br}=$ broad signal, app. $=$ apparent. For ${ }^{13} \mathrm{C}$ NMR data the following abbreviations are used: $\mathrm{p}=$ primary $\left(\mathrm{CH}_{3}\right)$, $\mathrm{s}=$ secondary $\left(\mathrm{CH}_{2}\right), \mathrm{t}=$ tertiary $(\mathrm{CH}), \mathrm{q}=$ quaternary $(\mathrm{C})$.

High resolution mass spectra were recorded with a Bruker APEX III FTICR-MS or a Finnigan SSQ 7000 quadrupole MS or a Finnigan MAT 95 double focusing sector field MS instrument.

Abbreviations: $\mathrm{MsOH}$ : methane sulfonic acid; pTsOH: paratoluene sulfonic acid; Me: methyl; tBu: tertbutyl; Ph: phenyl; DCM: dichloromethane; AcOEt: ethyl acetate; $\mathrm{MeOH}$ : methanol; MeCN: acetonitrile; NBS: N-bromosuccinimide; TMS: trimethylsilyl. 


\subsection{SAFETY PRECAUTIONS, working with peroxides}

Although we never experienced any problems in the experiments as described in this work, precautions should be taken when working with peroxides. In particular, it should be avoided as much as possible to expose neat peroxides or even the commercial solutions to heat or to mix them undiluted with reactive compounds. Performing such reactions behind a blast shield is recommended. In this report, the peroxides were generally added to the reagents in solvent and the catalyst was added last; we did not encounter any problems using this approach. Pure peroxides were only synthesized on relatively small scale, as described below, and were stored in the dark in a fridge.

\subsection{Use of commercial peroxyketals}

Peroxide 1a (Trigonox 22, $50 \%$ solution in mineral oil) was purchased from Acros Organics (catalog $\left.n^{\circ} 361310100\right)$

Peroxide 3a (Trigonox D, 50\% solution in aromatic free mineral spirit) was purchased from Acros Organics (catalog $n^{\circ} 349830100$ )

Peroxide 4 (Trigonox 301, 41\% solution in aromatic free mineral spirit) was purchased from Acros Organics (catalog n 349940050)

Peroxide 5 (Luperox DHD-9, 32\% solution in phthalate-free plasticizer mixture) was purchased from Sigma-Aldrich (catalog $n^{\circ} 524670$ )

\section{General note on using the commercial mineral oil solutions}

Use of the commercial solutions of peroxides in mineral oil often leads to a biphasic system with the mineral oil floating on top, especially in acetonitrile. This can also happen in other solvents, especially when the peroxide solution is used in larger amounts. In our hands, this never seemed to cause problems: results with the pure peroxide 1a, synthesized according to a literature procedure, ${ }^{2}$ gave essentially identical results as with the use of the commercial solution of 1a. Reactions with such biphasic systems were always stirred at high speed $(\sim 700 \mathrm{rpm})$ to ensure optimal mixing, just in case. 


\section{Synthesis of substrates}

\subsection{1-(tert-butylperoxy)-1-methoxycyclohexane (1b)}<smiles>CCOC1(OCC)CCCCC1</smiles>

Synthesized according to the report of Matsuyama and Minoshima. ${ }^{3}$

In a $25 \mathrm{~mL}$ round bottom flask, 1,1-dimethoxycyclohexane ( $1 \mathrm{~g}, 6.94 \mathrm{mmol}$, 1 eq) was dissolved in DMSO $(5 \mathrm{~mL})$ and $\mathrm{tBuOOH}(5.5 \mathrm{M}$ solution in decane, $1 \mathrm{eq})$ was added followed by $p \mathrm{TsOH}(400 \mathrm{mg}, 0.3 \mathrm{eq})$ and the resulting mixture stirred at room temperature for 3 hours. Pentane $(15 \mathrm{ml})$ was then added, followed by aqueous $\mathrm{NaOH}$ $(2 \mathrm{M}, 10 \mathrm{~mL})$. Phases were separated and the organic phase washed with distilled water $(2 \times 15 \mathrm{~mL})$, dried over $\mathrm{Na}_{2} \mathrm{SO}_{4}$ and evaporated to dryness. The resulting clear oil was purified by flash chromatography on silica gel (prewashed with pentane containing 1\% $\mathrm{NEt}_{3}$ ) and pentane as eluant to afford $\mathbf{1 b}$ as a clear oil (544 mg, 2.69 mmol, $39 \%$ yield)

${ }^{1}$ H NMR (500 MHz, d6-DMSO): 3.15 (s, 3H); 1.63-1.56 (m, 4H); 1.52-1.31 (m, $6 \mathrm{H}) ; 1.20(\mathrm{~s}, 9 \mathrm{H})$

${ }^{13}$ C NMR (125 MHz, d6-DMSO): 102.77 (q); 78.23 (q); $47.36\left(\mathrm{CH}_{3}\right) ; 31.28\left(\mathrm{CH}_{2}\right)$; $26.40\left(3 \mathrm{x} \mathrm{CH}_{3}\right) ; 25.00\left(\mathrm{CH}_{2}\right) ; 22.31\left(\mathrm{CH}_{2}\right)$

MS (EI): 197 (2); 145 (27); 129 (73); 113 (30); 97 (85); 87 (50); 69 (80); 57 (100); 41

HRMS (ESI): calculated for $\mathrm{C}_{11} \mathrm{H}_{22} \mathrm{O}_{3} \mathrm{Na}$ : 225.1461; found: 225.1460

\subsection{1-Azido-1-(tert-butylperoxy)cyclohexane (1c)}

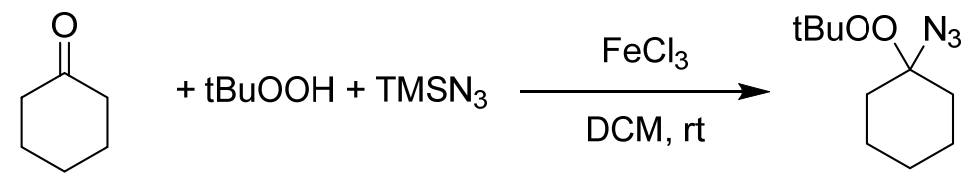

Synthesized according to the procedure of Ghorai. ${ }^{4}$

In a $25 \mathrm{~mL}$ round bottom flask, cyclohexanone $(103 \mu \mathrm{L}, 1 \mathrm{mmol})$ was dissolved in $\mathrm{DCM}(10 \mathrm{~mL})$ and cooled to $0^{\circ} \mathrm{C}$ in an ice bath. $t \mathrm{BuOOH}(5.5 \mathrm{M}$ solution in decane, $182 \mu \mathrm{L}, 1 \mathrm{mmol})$ and $\mathrm{TMSN}_{3}(330 \mu \mathrm{L}, 2.5 \mathrm{mmol})$ was added followed by $\mathrm{FeCl}_{3}(16$ $\mathrm{mg}, 0.1 \mathrm{mmol})$. The ice bath was removed and the reaction mixture stirred at room temperature for 30 minutes. The mixture was filtered over a pad of silica to remove the iron catalyst and the solvent removed under reduced pressure. The resulting clear oil was purified by flash chromatography on silica gel (hexanes as eluant) to afford 1c as a clear oil (166 mg, $0.78 \mathrm{mmol}, 78 \%$ yield)

${ }^{1}$ H NMR (500 MHz, d6-DMSO): 1.75 (t, J=5.9 Hz, 4H); 1.60-1.50 (m, 2H); 1.48$1.34(\mathrm{~m}, 4 \mathrm{H}) ; 1.24(\mathrm{~s}, 9 \mathrm{H})$ 
${ }^{13}$ C NMR (125 MHz, d6-DMSO):96.54 (C); 79.69 (C); $32.09\left(\mathrm{CH}_{2}\right) ; 26.03\left(\mathrm{CH}_{3}\right)$; $24.27\left(\mathrm{CH}_{2}\right) ; 21.99\left(\mathrm{CH}_{2}\right)$

MS (ESI-pos): 409 (100); 320 (76); 236 (M+Na, 32); 213 (32)

HRMS (ESI-pos): calculated for $\mathrm{C}_{10} \mathrm{H}_{19} \mathrm{~N}_{3} \mathrm{O}_{2} \mathrm{Na}_{1}$ : 236.1369; found: 236.1370

\section{3 (2,2-bis(tert-butylperoxy)propyl)benzene (3b)}

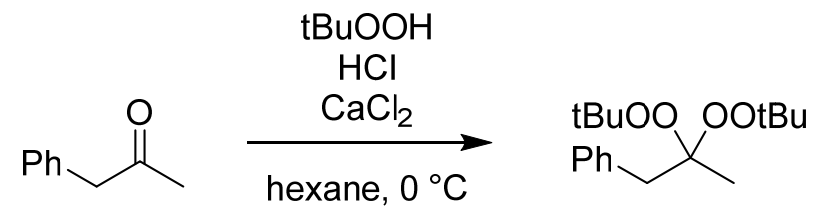

Synthesized according to a reported method. ${ }^{5}$

In a $50 \mathrm{~mL}$ round bottom flask, phenyl acetone $(1 \mathrm{~g}, 7.46 \mathrm{mmol})$ was dissolved in hexanes $(6 \mathrm{~mL})$ and cooled to $0^{\circ} \mathrm{C}$ (ice bath). Ground calcium chloride $(500 \mathrm{mg})$ was added followed by $\mathrm{tBuOOH}(70 \%$ solution in water, $4 \mathrm{~mL})$ and concentrated hydrochloric acid $(0.5 \mathrm{~mL})$, making sure the temperature does not exceed $5^{\circ} \mathrm{C}$. The resulting mixture was vigorously stirred at $0^{\circ} \mathrm{C}$ for 4 hours. Hexane $(30 \mathrm{~mL})$ was added and the phases separated. The organic phase was then successively washed with an aqueous $\mathrm{NaOH}$ solution $(2 \mathrm{M}, 15 \mathrm{~mL})$ and distilled water $(2 \mathrm{x} 15 \mathrm{~mL})$, dried over $\mathrm{Na}_{2} \mathrm{SO}_{4}$ and evaporated to dryness. The resulting clear liquid was purified by flash chromatography on silica gel (prewashed with hexane containing $1 \% \mathrm{NEt}_{3}$ ) and hexane as eluant to afford $3 \mathbf{b}$ as white solid (1.846 $\mathrm{g}, 6.23 \mathrm{mmol}, 83 \%$ yield).

${ }^{1}$ H NMR (500 MHz, d6-DMSO): 7.31-7.26 (m, 4H); 7.25-7.19 (m, 1H) 3.03 (s, 2H); $1.19(\mathrm{~s}, 18 \mathrm{H})$

${ }^{13}$ C NMR (125 MHz, d6-DMSO): 136.29 (Ar C); 130.62 (Ar CH); 127.74 (Ar CH); $126.34(\mathrm{Ar} \mathrm{CH}) ; 107.95(\mathrm{C}) ; 79.13(\mathrm{C}) ; 40.73\left(\mathrm{CH}_{2}\right) ; 26.37\left(\mathrm{CH}_{3}\right) ; 18.99\left(\mathrm{CH}_{3}\right)$

MS (EI): 207 (3); 91 (18); 73 (100); 57 (8); 43 (18)

HRMS (ESI): calculated for $\mathrm{C}_{17} \mathrm{H}_{28} \mathrm{O}_{4} \mathrm{Na}$ : 319.1880 ; found: 319.1878

\section{4 (1,1-bis(tert-butylperoxy)ethane-1,2-diyl)dibenzene (3c)}

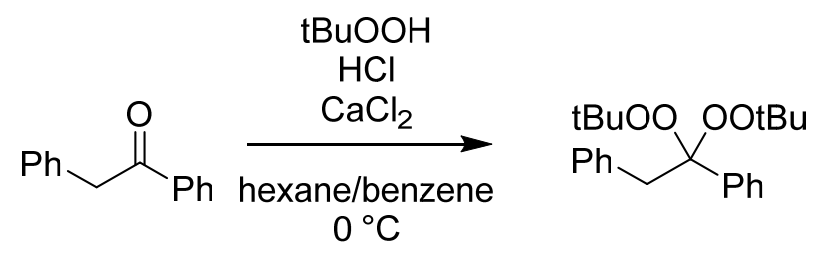

Synthesized in analogy to a reported method. ${ }^{5}$

In a $50 \mathrm{~mL}$ round bottom flask, deoxybenzoin $(1 \mathrm{~g}, 5.1 \mathrm{mmol})$ was dissolved in a 1:1 mixture of benzene and hexanes $\left(6 \mathrm{~mL}\right.$ in total) and cooled to $0^{\circ} \mathrm{C}$ (ice bath). Ground calcium chloride $(500 \mathrm{mg})$ was added followed by $\mathrm{tBuOOH}(70 \%$ solution in water, 4 $\mathrm{mL})$ and concentrated hydrochloric acid $(0.5 \mathrm{~mL})$, making sure the temperature did 
not exceed $5^{\circ} \mathrm{C}$. The resulting mixture was vigorously stirred at $0^{\circ} \mathrm{C}$ for 4 hours. Hexane $(30 \mathrm{~mL})$ was added and the phases separated. The organic phase was then successively washed with an aqueous $\mathrm{NaOH}$ solution $(2 \mathrm{M}, 15 \mathrm{~mL})$ and distilled water ( $2 \times 15 \mathrm{~mL}$ ), dried over $\mathrm{Na}_{2} \mathrm{SO}_{4}$ and evaporated to dryness. The resulting clear liquid was purified by flash chromatography on silica gel (prewashed with hexane containing 1\% $\left.\mathrm{NEt}_{3}\right)$ and hexane as eluant to afford $3 \mathrm{c}$ as white solid $(217 \mathrm{mg}, 0.60$ mmol, 11\% yield).

${ }^{1}$ H NMR (500 MHz, d6-DMSO): 7.24-7.16 (m, 3H); 7.16-7.10 (m, 2H); 7.09-7.03 (m, 3H); 6.84-6.78 (m, 2H); 3.29 (s, 3H); 1.29 (s, 18H)

${ }^{13}$ C NMR (125 MHz, d6-DMSO): 137.46 (Ar C); 135.08 (Ar C); 130.56 (Ar CH); 127.69 (Ar CH); $127.22(\mathrm{Ar} \mathrm{CH}) ; 127.09(\mathrm{Ar} \mathrm{CH}) ; 126.91(\mathrm{Ar} \mathrm{CH}) ; 126.09(\mathrm{Ar} \mathrm{CH})$; $108.51(\mathrm{C}) ; 79.45(\mathrm{C}) ; 42.10\left(\mathrm{CH}_{2}\right) ; 26.55\left(\mathrm{CH}_{3}\right)$

MS (EI): 269 (4); 197 (3); 105 (34); 91 (19); 73 (100)

HRMS (ESI): calculated for $\mathrm{C}_{22} \mathrm{H}_{30} \mathrm{O}_{4} \mathrm{Na}$ : 381.2036; found: 381.2034

\section{5 (2,2-bis(tert-butylperoxy)ethyl)benzene (3d)}

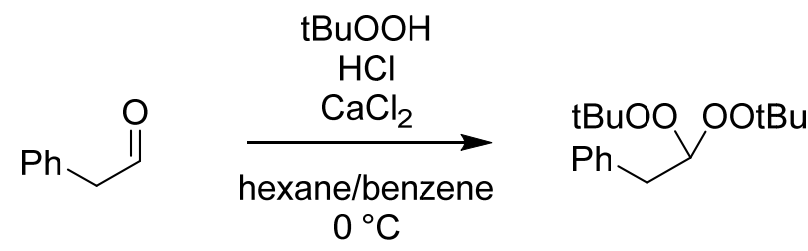

Synthesized according to a reported method. ${ }^{5}$

In a $50 \mathrm{~mL}$ round bottom flask, phenylacetaldehyde $(1 \mathrm{~g}, 8.33 \mathrm{mmol})$ was dissolved in a 1:1 mixture of benzene and hexanes $\left(6 \mathrm{~mL}\right.$ in total) and cooled to $0^{\circ} \mathrm{C}$ (ice bath). Ground calcium chloride $(500 \mathrm{mg})$ was added followed by $\mathrm{tBuOOH}(70 \%$ solution in water, $4 \mathrm{~mL})$ and concentrated hydrochloric acid $(0.5 \mathrm{~mL})$, making sure the temperature did not exceed $5^{\circ} \mathrm{C}$. The resulting mixture was vigorously stirred at $0^{\circ} \mathrm{C}$ for 4 hours. Hexane $(30 \mathrm{~mL})$ was added and the phases separated. The organic phase was then successively washed with an aqueous $\mathrm{NaOH}$ solution $(2 \mathrm{M}, 15 \mathrm{~mL})$ and distilled water $(2 \times 15 \mathrm{~mL})$, dried over $\mathrm{Na}_{2} \mathrm{SO}_{4}$ and evaporated to dryness. The resulting clear liquid was purified by flash chromatography on silica gel (prewashed with hexane containing $\left.1 \% \mathrm{NEt}_{3}\right)$ and hexane as eluant to afford $\mathbf{3 d}$ as clear oil $(1.3 \mathrm{~g}$, $4.60 \mathrm{mmol}, 55 \%$ yield).

${ }^{1}$ H NMR (500 MHz, d6-DMSO): 7.35-7.18 (m, 5H); 5.34 (t, J=6.2 Hz, 1H); 2.97 (d, $\mathrm{J}=6.2 \mathrm{~Hz}, 2 \mathrm{H}) ; 1.10(\mathrm{~s}, 18 \mathrm{H})$

${ }^{13}$ C NMR (125 MHz, d6-DMSO): 136.23 (Ar q); 129.58 (Ar CH); 128.13 (Ar CH); $126.48(\mathrm{Ar} \mathrm{CH}) ; 108.39(\mathrm{CH}) ; 80.13(\mathrm{C}) ; 36.47\left(\mathrm{CH}_{2}\right) ; 26.07\left(3 \mathrm{x} \mathrm{CH}_{3}\right)$

MS (EI): 193 (3); 91 (31); 73 (100); 57 (11); 43 (8)

HRMS (ESI): calculated for $\mathrm{C}_{16} \mathrm{H}_{26} \mathrm{O}_{4} \mathrm{Na}$ : 305.1723 ; found: 305.1722 


\subsection{2,2-bis(tert-butylperoxy)-2,3-dihydro-1H-indene (6a)}

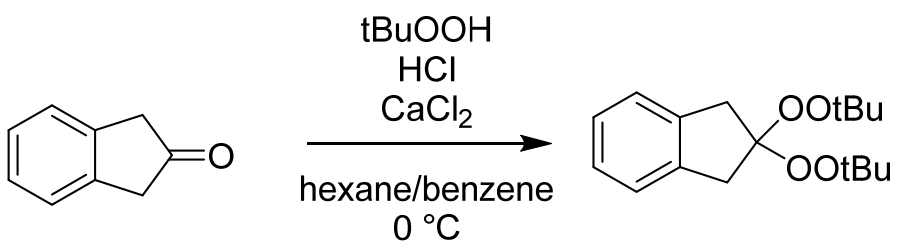

Synthesized according to the method by Colombo et al. ${ }^{6}$

In a $50 \mathrm{~mL}$ round bottom flask, 2-indanone $(1 \mathrm{~g}, 7.57 \mathrm{mmol})$ was dissolved in a $6: 1$ mixture of benzene and hexanes $\left(6 \mathrm{~mL}\right.$ in total) and cooled to $0^{\circ} \mathrm{C}$ (ice bath). Ground calcium chloride $(500 \mathrm{mg})$ was added followed by $\mathrm{tBuOOH}(70 \%$ solution in water, 4 $\mathrm{mL}$ ) and concentrated hydrochloric acid $(0.5 \mathrm{~mL})$, making sure the temperature did not exceed $5^{\circ} \mathrm{C}$. The resulting mixture was vigorously stirred at $0^{\circ} \mathrm{C}$ for 5 hours. Hexane $(30 \mathrm{~mL})$ was added and the phases separated. The organic phase was then successively washed with an aqueous $\mathrm{NaOH}$ solution $(2 \mathrm{M}, 15 \mathrm{~mL})$ and distilled water (2x $15 \mathrm{~mL}$ ), dried over $\mathrm{Na}_{2} \mathrm{SO}_{4}$ and evaporated to dryness. The resulting clear liquid was purified by flash chromatography on silica gel (prewashed with hexane containing $\left.1 \% \mathrm{NEt}_{3}\right)$ and hexane as eluant to afford $\mathbf{6 a}$ as white solid $(1.176 \mathrm{~g}, 4.055$ mmol, $53 \%$ yield).

${ }^{1}$ H NMR (500 MHz, d6-DMSO): 7.22-7.12 (m, 4H); 3.25 (s, 4H); 1.19 (s, 18H)

${ }^{13}$ C NMR (125 MHz, d6-DMSO): 139.19 ( $\left.\mathrm{Ar} \mathrm{C}\right) ; 126.57(\mathrm{Ar} \mathrm{CH}) ; 124.55(\mathrm{Ar} \mathrm{CH})$; $116.45(\mathrm{C}) ; 79.56(\mathrm{C}) ; 39.63\left(\mathrm{CH}_{2}\right) ; 26.36\left(\mathrm{CH}_{3}\right)$

MS (EI): 205 (4); 104 (16); 73 (100); 57 (5); 43 (7)

HRMS (ESI): calculated for $\mathrm{C}_{17} \mathrm{H}_{26} \mathrm{O}_{4} \mathrm{Na}$ : 317.1723 ; found: 317.1721

\subsection{2,2-bis(tert-butylperoxy)-1,2,3,4-tetrahydronaphthalene (6b)}

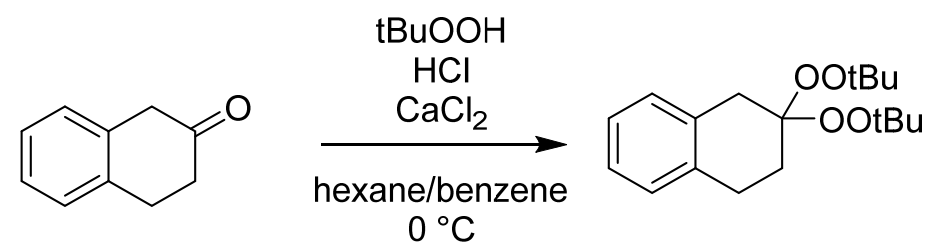

Synthesized according to the method by Colombo et al. ${ }^{6}$

In a $50 \mathrm{~mL}$ round bottom flask, 2-tetralone $(1 \mathrm{~g}, 6.85 \mathrm{mmol})$ was dissolved in a 2:4 mixture of benzene and hexanes $\left(6 \mathrm{~mL}\right.$ in total) and cooled to $0^{\circ} \mathrm{C}$ (ice bath). Ground calcium chloride $(500 \mathrm{mg})$ was added followed by $\mathrm{tBuOOH}(70 \%$ solution in water, 4 $\mathrm{mL})$ and concentrated hydrochloric acid $(0.5 \mathrm{~mL})$, making sure the temperature did not exceed $5^{\circ} \mathrm{C}$. The resulting mixture was vigorously stirred at $0^{\circ} \mathrm{C}$ for 5 hours. Hexane $(30 \mathrm{~mL})$ was added and the phases separated. The organic phase was then successively washed with an aqueous $\mathrm{NaOH}$ solution $(2 \mathrm{M}, 15 \mathrm{~mL})$ and distilled water (2x $15 \mathrm{~mL}$ ), dried over $\mathrm{Na}_{2} \mathrm{SO}_{4}$ and evaporated to dryness. The resulting clear liquid was purified by flash chromatography on silica gel (prewashed with hexane 
containing $\left.1 \% \mathrm{NEt}_{3}\right)$ and hexane as eluant to afford $\mathbf{6 b}$ as white solid (1.512 g, 4.909 mmol, $71 \%$ yield).

${ }^{1}$ H NMR (500 MHz, d6-DMSO): 7.14-7.03 (m, 4H); 3.07 (s, 2H); 2.80 (t, J=6.7 Hz, $2 \mathrm{H}) ; 2.05(\mathrm{t}, \mathrm{J}=6.7 \mathrm{~Hz}, 2 \mathrm{H}) ; 1.17(\mathrm{~s}, 18 \mathrm{H})$

${ }^{13}$ C NMR (125 MHz, d6-DMSO): 135.68 (Ar C); 133.42 (Ar C); 128.79 (Ar CH); 127.94 (Ar CH); 125.76 (Ar CH); 125.68 (Ar CH); 106.78 (C); 79.12 (C); 34.74 $\left(\mathrm{CH}_{2}\right): 27.62\left(\mathrm{CH}_{2}\right) ; 26.38\left(\mathrm{CH}_{3}\right) ; 26.31\left(\mathrm{CH}_{2}\right)$

MS (EI): 219 (12); 104 (8); 73 (100)

HRMS (ESI): calculated for $\mathrm{C}_{18} \mathrm{H}_{28} \mathrm{O}_{4} \mathrm{Na}$ : 331.1880; found: 331.1879

\subsection{O-((3aR,6S,6aR)-5-((R)-2,2-dimethyl-1,3-dioxolan-4-yl)-2,2-} dimethyltetrahydrofuro[2,3-d][1,3]dioxol-6-yl) 0-phenyl carbonothioate (14)<smiles>CC1(C)C[C@@H](C2O[C@@H]3OC(C)(C)O[C@@H]3C2O)CO1</smiles>

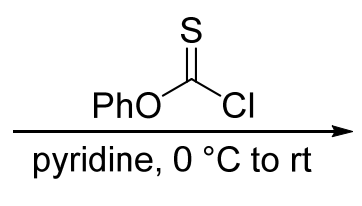<smiles>C[C@H]1COC(C)(C)[C@@H]1OC(=S)Oc1ccccc1</smiles>

Synthesized according to the method by Roy et al., ${ }^{7}$ in $94 \%$ yield as a colorless solid.

${ }^{1}$ H NMR (500 MHz, d6-DMSO): 7.51-7.46 (m, 2H), 7.37-7.32 (m, 1H), 7.24-7.20 $(\mathrm{m}, 2 \mathrm{H}), 5.99(\mathrm{~d}, \mathrm{~Hz}=1.96,1 \mathrm{H}), 5.48(\mathrm{~d}, \mathrm{~Hz}=1.50,1 \mathrm{H}), 4.85(\mathrm{~d}, \mathrm{~Hz}=1.96,1 \mathrm{H}), 4.28-$ $4.20(\mathrm{~m}, 2 \mathrm{H}), 4.05-4.00(\mathrm{~m}, 1 \mathrm{H}), 3.86-3.84(\mathrm{~m}, 1 \mathrm{H}), 1.46(\mathrm{~s}, 3 \mathrm{H}), 1.35(\mathrm{~s}, 3 \mathrm{H}), 1.29$ $(\mathrm{s}, 3 \mathrm{H}), 1.28(\mathrm{~s}, 3 \mathrm{H})$

${ }^{13}$ C NMR (125 MHz, d6-DMSO):193.15, 152.80, 129.82, 126.87, 121.63, 111.52, $108.54,104.57,85.10,82.21,78.72,71.85,65.89,26.56,26.28,25.99,29.10$

HRMS (ESIpos): calculated for $\mathrm{C}_{19} \mathrm{H}_{24} \mathrm{O}_{7} \mathrm{SNa}$ : 419.1135; found: 419.1134 


\section{Wohl-Ziegler bromination of fluorene.}

\subsection{Reaction at room temperature.}

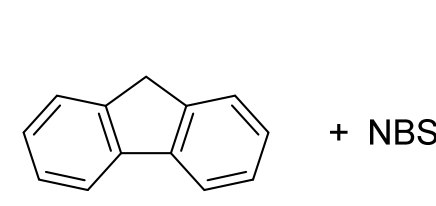

7

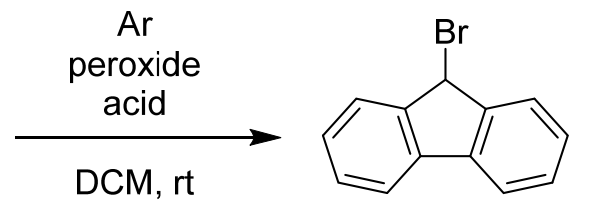

8

In an oven-dried Schlenk flask was fluorene 7 (83 mg, $0.5 \mathrm{mmol}, 1 \mathrm{eq}), \mathrm{N}$ bromosuccinimide ( $98 \mathrm{mg}, 0.55 \mathrm{mmol}, 1.1 \mathrm{eq})$ were dissolved in DCM $(5 \mathrm{~mL})$. The desired peroxide $(0.025 \mathrm{mmol}, 5 \mathrm{~mol} \%)$ was introduced and the resulting mixture was degassed by the freeze-pump-thaw method (3 cycles). After warming to room temperature, the acid catalyst was added under a stream of argon and after the desired reaction time, the reaction mixture was quenched with $\mathrm{NEt}_{3}(250 \mu \mathrm{L}), \mathrm{CH}_{2} \mathrm{Br}_{2}(0.5$ mmol) added as a standard and an aliquot taken for direct ${ }^{1} \mathrm{H}$ NMR analysis. Yield was determined by integrating a reference peak of $8(5.9 \mathrm{ppm}, \mathrm{s}, 1 \mathrm{H}$; determined from an authentic sample) relative to the peak of $\mathrm{CH}_{2} \mathrm{Br}_{2}$.

Results are presented in table 1 of the main text.

\subsection{Reaction at cryogenic temperatures.}

Using the same experimental procedure, the reaction was evaluated at low temperature (Table S1).

Table S1: Wohl-Ziegler bromination of fluorene at cryogenic temperatures.

$\begin{array}{cccccc}\text { entry } & \text { temp. }\left({ }^{\circ} \mathbf{C}\right) & \text { peroxide } & \text { MsOH } & \text { additive } & \text { yield (\%) } \\ 1 & 0 & \mathbf{1 a}(5 \%) & 5 \text { mol \% } & / & 30 \% \\ 2 & -10 & \mathbf{1 a}(5 \%) & 5 \text { mol \% } & / & \text { trace } \\ 3 & -10 & \text { 1a }(1 \text { equiv) } & 1 \text { equiv } & / & 60 \\ 4 & -10 & t \text { BuOOH } & 1 \text { equiv } & \begin{array}{c}\text { cyclohexanone } \\ (1 \text { equiv) }\end{array} & 17 \\ & & t \text { BuOOH } & 1 \text { equiv } & / & 0 \\ 5 & -10 & (2 \text { equiv }) & 1 \text { equiv } & / & \text { trace } \\ 6 & -20 & \mathbf{1 a}(1 \text { equiv) } & 1 \text { equiv } & / & 25 \\ 7 & -20 & \mathbf{6 b}(1 \text { equiv) } & 1 \text { equiv } & \text { trace } \\ 8 & -30 & \mathbf{6 b}(1 \text { equiv) } & 1 \text { equiv } & / & \end{array}$

First the reaction was performed under the same reaction conditions than at room temperature (i.e. $5 \mathrm{~mol} \% \mathbf{1 a}$ and $\mathrm{MsOH}$ ) to give $30 \%$ of $\mathbf{8}$ after 24 hours (entry 1). Lowering the temperature to $-10^{\circ} \mathrm{C}$, only trace amount of $\mathbf{8}$ could be detected (entry2). Using stoichiometric amounts of $1 \mathrm{a}$ and $\mathrm{MsOH}$, a satisfying $60 \%$ yield of 2 was obtained after 24 hours (entry 3). This was directly compared with our previous method of generating radicals by using the ketone (cyclohexanone in this case) and tBuOOH. Although 8 was still obtained in 17\% yield (entry 4), it was considerably less efficient than to use 1a preformed (17\% Vs 60\%). A control experiment was 
performed excluding cyclohexanone and no trace of 8 was detected after 24 hours, excluding any background reaction from the combination of $\mathrm{tBuOOH}$ and $\mathrm{MsOH}$ (entry 5). Lowering the temperature further to $-20^{\circ} \mathrm{C}$ led to only traces of 2 after 24 hours (entry 6). Using $\mathbf{6 b}$, more reactive than $\mathbf{1 a}, 25 \%$ of $\mathbf{8}$ was formed at $-20^{\circ} \mathrm{C}$ (entry 7) but only traces if the temperature was further lowered to $-30^{\circ} \mathrm{C}$ (entry 8 ).

Note: Care was taken to exclude light in order to avoid potential photochemical initiation. The reactions were carried out in a fume hood with the lights switched off and the Schlenk flask was wrapped in aluminium foil after the reaction mixture was degassed and warmed to the desired temperature.

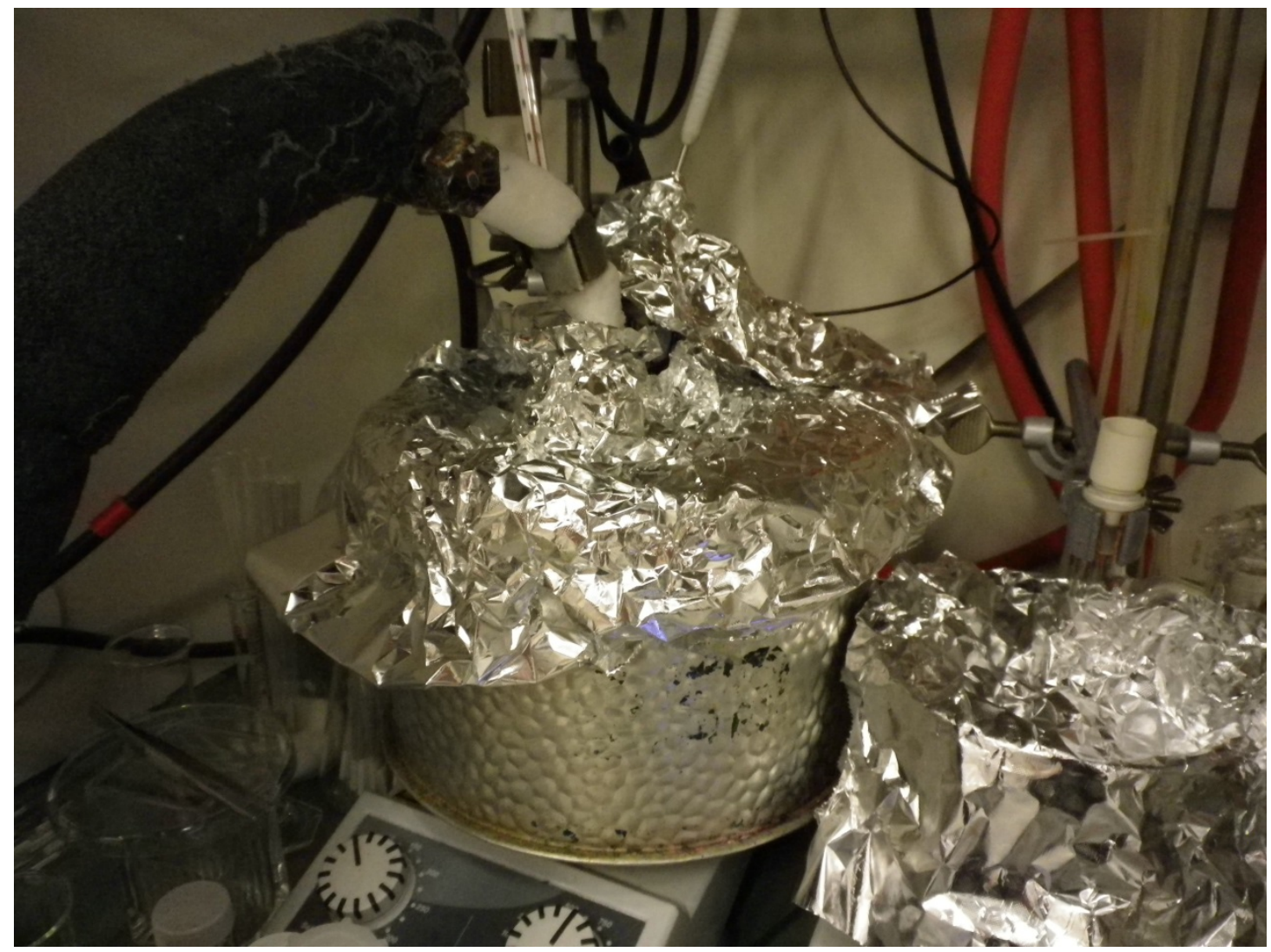

Figure S1: picture of the experimental set-up used. Left stirring plate: reaction performed at cryogenic temperature using a cryostat and an ethanol bath. Right stirring plate: reaction performed at room temperature $\left(22-23^{\circ} \mathrm{C}\right)$ using an oil bath as temperature regulator. 


\section{Synthesis of products.}

\subsection{9-bromo-9H-fluorene (8)}

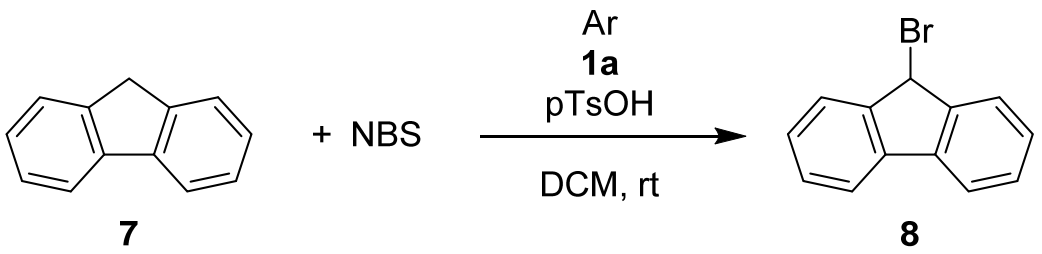

In an oven-dried Schlenk flask was fluorene 7 (166 mg, $1 \mathrm{mmol}, 1 \mathrm{eq}), \mathrm{N}$ bromosuccinimide (195 mg, $1.1 \mathrm{mmol}, 1.1 \mathrm{eq})$ were dissolved in DCM (10 mL). 1a (50\% solution, $52 \mathrm{mg}, 0.05 \mathrm{mmol}$ ) was introduced and the resulting mixture was degassed by the freeze-pump-thaw method (3 cycles). After warming to room temperature, para-toluenesulfonic acid $(9.5 \mathrm{mg} ; 0.05 \mathrm{mmol})$ was added under a stream of argon and after three hours, a small amount of silica was added, the solvent was removed under vacuo and the resulting white powder was purified by flash chromatography on silica gel (Hex/AcOEt 99:1 as eluent) to afford 2 as a white solid (237mg, 96\% yield). Analytical data was in accordance with reported values. ${ }^{8}$

${ }^{1}$ H NMR (500 MHz, CDCl3): 7.68 (br t, J=7.5 Hz, 4H); 7.41 (td, J=7.5 and $1 \mathrm{~Hz}$; $2 \mathrm{H}) ; 7.35$ (td, $\mathrm{J}=7.5$ and $1 \mathrm{~Hz}, 2 \mathrm{H}) ; 6.01(\mathrm{~s}, 1 \mathrm{H})$

${ }^{13}$ C NMR (125 MHz, CDCl3): 144.17 (Ar C); 139.80 (Ar C); 129.24 (Ar CH); $128.11(\mathrm{Ar} \mathrm{CH}) ; 126.38(\mathrm{Ar} \mathrm{CH}) ; 120.30(\mathrm{Ar} \mathrm{CH}) ; 46.08(\mathrm{CH})$

MS (EI): 246 (7); 244 (7); 165 (100)

HRMS (ESI): calculated for $\mathrm{C}_{13} \mathrm{H}_{9} \mathrm{Br}$ : 243.9888; found: 243.9889

\section{2 tert-butyl(4-phenylbutyl)sulfane (9)}

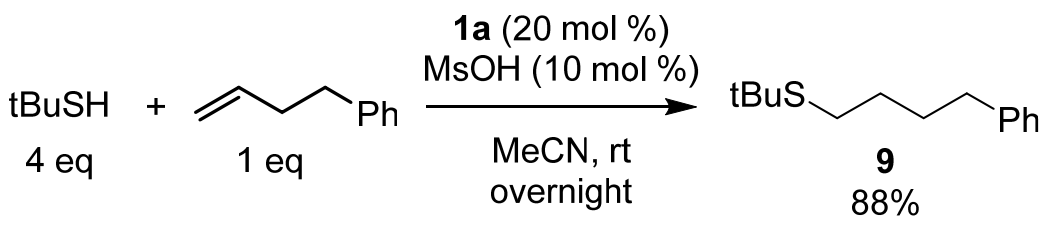

In an oven dried Schlenk tube, $\mathrm{tBuSH}(225 \mu \mathrm{L}, 2 \mathrm{mmol})$, 4-phenyl butane $(75 \mu \mathrm{L}, 0.5$ $\mathrm{mmol})$ and $1 \mathrm{a}(50 \%$ solution, $52 \mathrm{mg}, 0.1 \mathrm{mmol})$ were dissolved in acetonitrile $(5 \mathrm{~mL})$. The resulting mixture was degassed (Freeze-Pump-Thaw technique, 3 cycles), brought to room temperature and methane sulfonic acid $(3.5 \mu \mathrm{L}, 0.05 \mathrm{mmol})$ was added and the mixture left to react overnight. The mixture was transferred to an extraction funnel, diluted with ethyl acetate $(20 \mathrm{~mL})$ and washed with $\mathrm{NaOH}(2 \mathrm{M}, 2 \mathrm{x}$ $10 \mathrm{~mL})$ and distilled water $(2 \times 10 \mathrm{~mL})$. The organic phase was dried over Na2SO4, evaporated to dryness and the resulting oil was purified by flash chromatography on silica gel (Hex/AcOEt 99:1 as eluent) to afford 9 as a clear oil (98mg, 88\% yield)

${ }^{1}$ H NMR (500 MHz, CDCl3): 7.31-7.25 (m, 2H); 7.21-7.15 (m, 2H); 2.64 (t, J=7.6 $\mathrm{Hz}, 2 \mathrm{H}) ; 2.55$ (t, J=7.4 Hz, 2H); 1.78-1.70 (m, 2H); 1.67-1.59 (m, 2H); $1.32(\mathrm{~s}, 9 \mathrm{H})$ 
${ }^{13}$ C NMR (125 MHz, CDCl3): 142.30 ( $\left.\mathrm{Ar} \mathrm{C}\right) ; 128.43$ ( $\left.\mathrm{Ar} \mathrm{CH}\right) ; 128.31(\mathrm{Ar} \mathrm{CH})$; $125.74(\mathrm{Ar} \mathrm{CH}) ; 41.83(\mathrm{C}) ; 35.60\left(\mathrm{CH}_{2}\right) ; 31.01\left(\mathrm{CH}_{3}\right) ; 29.46\left(\mathrm{CH}_{2}\right) ; 29.44\left(\mathrm{CH}_{2}\right)$; $28.15\left(\mathrm{CH}_{2}\right)$

MS (EI): 222 (32); 166 (29); 165 (33); 164 (21); 131 (25); 104 (36); 91 (63); 87 (22); $57(100)$

HRMS (ESI): calculated for $\mathrm{C}_{14} \mathrm{H}_{22} \mathrm{~S}$ : 222.1442; found: 222.1444

\section{$4.3 \quad(3,5,5,5$-tetrachloropentyl)benzene (10)}

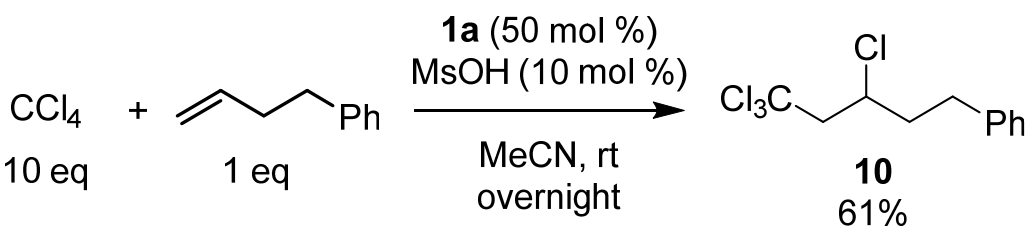

In an oven dried Schlenk tube, $\mathrm{CCl}_{4}(962 \mu \mathrm{L}, 10 \mathrm{mmol})$, 4-phenyl butane $(150 \mu \mathrm{L}, 1$ $\mathrm{mmol})$ and 1a (50\% solution, $260 \mathrm{mg}, 0.5 \mathrm{mmol})$ were dissolved in acetonitrile (1 $\mathrm{mL}$ ). The resulting mixture was degassed (Freeze-Pump-Thaw technique, 3 cycles), brought to room temperature and methane sulfonic acid $(7 \mu \mathrm{L}, 0.1 \mathrm{mmol})$ was added and the mixture left to react overnight. The mixture was evaporated to dryness and the resulting oil was purified by flash chromatography on silica gel (hexane as eluent) to afford 10 as a clear oil $\left(172 \mathrm{mg}, 60 \%\right.$ yield). Analytical data of ${ }^{13} \mathrm{C}-\mathrm{NMR}$ was in accordance with reported values. ${ }^{9}$

${ }^{1}$ H NMR (500 MHz, CDCl3): 7.25-7.19 (m, 2 H); 7.16-7.11 (m, 3 H); 4.20-4.14 (m, $1 \mathrm{H}) ; 3.23(\mathrm{dd}, \mathrm{J}=5.5$ and $15.6 \mathrm{~Hz}, 1 \mathrm{H}) ; 3.06(\mathrm{dd}, \mathrm{J}=4.6$ and $15.6 \mathrm{~Hz}, 1 \mathrm{H}) ; 2.86$ (ddd, $\mathrm{J}=4.8,9.6$ and $14 \mathrm{~Hz}, 1 \mathrm{H}) ; 2.72(\mathrm{ddd}, \mathrm{J}=6.8,9.5$ and $13.8 \mathrm{~Hz}, 1 \mathrm{H}) ; 2.24-2.16(\mathrm{~m}, 1 \mathrm{H})$; 2.10-2.01 (m, 1H)

${ }^{13}$ C NMR (125 MHz, CDCl3): 140.29 (Ar C); 128.62 (Ar CH); $128.52(\mathrm{Ar} \mathrm{CH})$; $126.35(\mathrm{Ar} \mathrm{CH}) ; 96.76(\mathrm{C}) ; 62.26\left(\mathrm{CH}_{2}\right) ; 57.11(\mathrm{CH}) ; 40.57\left(\mathrm{CH}_{2}\right) ; 32.33\left(\mathrm{CH}_{2}\right)$

MS (EI): 286 (10); 284 (8); 92 (60); 91 (100); 65 (11)

HRMS (ESI): calculated for $\mathrm{C}_{11} \mathrm{H}_{12} \mathrm{Cl}_{4}$ : 283.9693; found: 283.9695

\subsection{Phenanthrene (11)}<smiles>Ic1cc2ccccc2c2ccccc12</smiles>

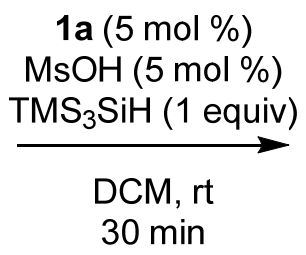<smiles>c1ccc2c(c1)ccc1ccccc12</smiles>

In an oven dried Schlenk tube, 9-iodophenanthrene (304 mg, $1 \mathrm{mmol}$ ), was dissolved in dichloromethane $(10 \mathrm{~mL})$. The resulting solution was degassed (Freeze-PumpThaw technique, 3 cycles), brought to room temperature and 1a (50\% solution, 26 $\mathrm{mg}, 0.05 \mathrm{mmol})$ and $\mathrm{TMS}_{3} \mathrm{SiH}(308 \mu \mathrm{L}, 1 \mathrm{mmol})$ were added. The mixture was degassed once more and after being brought back to room temperature, methane sulfonic acid $(3.5 \mu \mathrm{L}, 0.05 \mathrm{mmol})$ was added and the mixture left to react for 30 
minutes. The mixture was evaporated to dryness and the resulting slightly yellow oil was purified by flash chromatography on silica gel (hexane as eluent) to afford $\mathbf{1 1}$ as a white solid (168 mg, 94\% yield).

${ }^{1}$ H NMR (500 MHz, CDCl3): 8.75 (br d, J=8.1 Hz, 2H); 7.96 (dd, J=1 and $7.8 \mathrm{~Hz}$, $2 \mathrm{H}) ; 7.80$ (s, 2H); 7.74-7.64 (m, 4H);

${ }^{13}$ C NMR (125 MHz, CDCl3): $132.16(\mathrm{C}) ; 130.41(\mathrm{C}) ; 128.68(\mathrm{CH}) ; 127.03(\mathrm{CH})$; $126.67(\mathrm{CH}) ; 122.78(\mathrm{CH})$

MS (EI): 178 (100)

HRMS (ESI): calculated for $\mathrm{C}_{14} \mathrm{H}_{10}$ : 178.0783; found: 178.0781

\subsection{3-methyl-2,3-dihydrobenzofuran (13)}

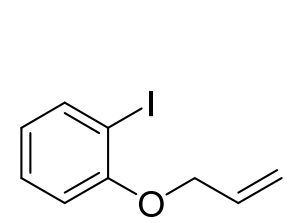

12

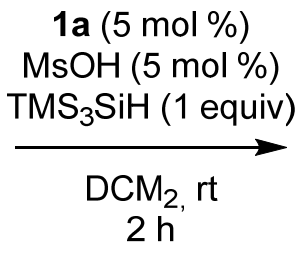

$\mathrm{MsOH}(5 \mathrm{~mol} \%)$

$\mathrm{TMS}_{3} \mathrm{SiH}$ (1 equiv)

$2 \mathrm{~h}$<smiles>CC1COc2ccccc21</smiles>

13

$79 \%$

Note: 12 was synthesized according to a reported procedure. ${ }^{10}$

In an oven dried Schlenk tube, 12 (259 $\mathrm{mg}, 1 \mathrm{mmol})$, was dissolved in dichloromethane $(10 \mathrm{~mL})$. The resulting solution was degassed (Freeze-Pump-Thaw technique, 3 cycles), brought to room temperature and 1a (50\% solution, $26 \mathrm{mg}, 0.05$ mmol) and $\mathrm{TMS}_{3} \mathrm{SiH}(308 \mu \mathrm{L}, 1 \mathrm{mmol})$ were added. The mixture was degassed once more and after being brought back to room temperature, methane sulfonic acid (3.5 $\mu \mathrm{L}, 0.05 \mathrm{mmol}$ ) was added and the mixture left to react for 2 hours. The mixture was evaporated to dryness and the resulting slightly yellow oil was purified by flash chromatography on silica gel (pentane as eluent) to afford $\mathbf{1 3}$ as a clear oil (106 mg, $79 \%$ yield). Analytical data was in accordance with reported values. ${ }^{11}$

${ }^{1}$ H NMR (500 MHz, $\mathbf{C D C l}_{3}$ ): 7.16 (br d, J=7.5 Hz, 1H); 7.12 (br t, J=7.8 Hz, 1H); $6.88(\mathrm{td}, \mathrm{J}=7.5$ and $1 \mathrm{~Hz}, 1 \mathrm{H}) ; 6.79(\mathrm{br} \mathrm{d}, \mathrm{H}=7.8 \mathrm{~Hz}, 1 \mathrm{H}) ; 4.68(\mathrm{t}, \mathrm{J}=8.8 \mathrm{~Hz}, 1 \mathrm{H}) ; 4.07$ (dd, $\mathrm{J}=7.5$ and $8.8 \mathrm{~Hz}, 1 \mathrm{H}) ; 3.55(\mathrm{~m}, 1 \mathrm{H}) ; 1.34(\mathrm{~d}, \mathrm{~J}=7 \mathrm{~Hz}, 3 \mathrm{H})$

${ }^{13}$ C NMR (125 MHz, $\left.\mathbf{C D C l}_{3}\right)$ : $159.82(\mathrm{Ar} \mathrm{C}) ; 132.38(\mathrm{Ar} \mathrm{C}) ; 128.11(\mathrm{Ar} \mathrm{CH})$; 123.93 (Ar CH); 120.55 (Ar CH); $109.58(\mathrm{Ar} \mathrm{CH}) ; 78.47\left(\mathrm{CH}_{2}\right) ; 36.60(\mathrm{CH}) ; 19.33$ $\left(\mathrm{CH}_{3}\right)$

MS (EI): 134 (72); 119 (100); 91 (94)

HRMS (ESI): calculated for $\mathrm{C}_{9} \mathrm{H}_{10} \mathrm{ONa}$ : 157.0624; found: 157.0624 


\subsection{Barton-McCombie deoxygenation}
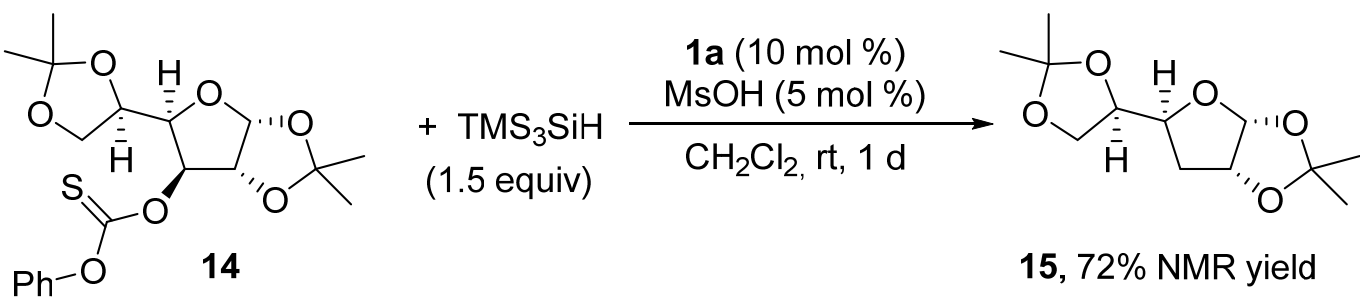

15, $72 \%$ NMR yield

Representative procedure, used for initial isolation and characterization of $\mathbf{1 5}$, on the basis of a reported method: ${ }^{12}$

In an oven dried Schlenk tube, 14 (198.23 mg, $0.5 \mathrm{mmol})$, was dissolved in $\mathrm{CH}_{2} \mathrm{Cl}_{2}$ (5 $\mathrm{mL}$ ). The resulting solution was degassed (Freeze-Pump-Thaw technique, 3 cycles), brought to room temperature and $1 \mathrm{a}(50 \%$ solution, $13 \mathrm{mg}, 0.05 \mathrm{mmol})$ and $\mathrm{TMS}_{3} \mathrm{SiH}$ (153.49 $\mu \mathrm{L}, 1 \mathrm{mmol})$ were added. The mixture was degassed once more and after being brought back to room temperature, methane sulfonic acid $(1.62 \mu \mathrm{L}, 0.05 \mathrm{mmol})$ was added and the mixture left to react for 2 days. The mixture was evaporated to dryness and the resulting slightly yellow oil was purified by flash chromatography on silica gel (pentane as eluent) to afford $133 \mathrm{aR}, 6 \mathrm{aR})-5-((\mathrm{R})-2,2$-dimethyl-1,3-dioxolan4-yl)-2,2-dimethyltetrahydrofuro[2,3-d][1,3]dioxole (15) as a clear oil $(34.2 \mathrm{mg}, 28 \%$ yield). The analytical data was in accordance with literature data. ${ }^{12}$

${ }^{1}$ H NMR (500 MHz, d6-DMSO): $5.74\left(\mathrm{~d},{ }^{3} J=1.83 \mathrm{~Hz}, 1 \mathrm{H}\right), 4.75-4.72(\mathrm{~m}, 1 \mathrm{H})$, 4.07-3.98 (m, 3H), 3.69-3.65 (m, 1H), 2.03-1.98 (m, 1H), 1.68-1.60 (m, 1H), $1.39(\mathrm{~s}$, $3 \mathrm{H}), 1.32(\mathrm{~s}, 3 \mathrm{H}), 1.26(\mathrm{~s}, 3 \mathrm{H}), 1.23(\mathrm{~s}, 3 \mathrm{H})$

${ }^{13}$ C NMR (125 MHz, d6-DMSO):110.23, 108.61, 105.07, 79.85, 77.92, 76.18, 66.09, $34.64,26.63,26.30,26.05,25.16$

HRMS (ESIpos): calculated for $\mathrm{C}_{12} \mathrm{H}_{20} \mathrm{O}_{5} \mathrm{Na}$ : 267.1203; found: 267.1200

The reaction conditions were then varied to improve the product yield and study the effect of acid and peroxide loading. For this purpose, 1.0 equivalents (relative to 14) of internal standard 1,4-dimethoxybenzene were added to the reaction before addition of dichloromethane. Aliquots of $0.1 \mathrm{~mL}$ were then taken at the time indicated in the table below, mixed with $0.4 \mathrm{~mL}$ of DMSO- $\mathrm{d}_{6}$, which was found to effectively quench the reaction, and analyzed by ${ }^{1} \mathrm{H}-\mathrm{NMR}$.

\begin{tabular}{|c|c|c|c|c|c|c|}
\hline entry & $\mathrm{TMS}_{3} \mathrm{SiH}$ & peroxide & MsOH & solvent & yield SM/P (\%) & time \\
\hline $1 \mathrm{a}$ & 1 equiv & $1 \mathbf{a}(5 \%)$ & $5 \mathrm{~mol} \mathrm{\%}$ & DCM & $61.3 / 32.4$ & $2 \mathrm{~h}$ \\
\hline $1 b$ & 1 equiv & $1 \mathbf{a}(5 \%)$ & $5 \mathrm{~mol} \mathrm{\%}$ & DCM & $54.8 / 42.9$ & $1 \mathrm{~d}$ \\
\hline $2 a$ & 1 equiv & 1a $(10 \%)$ & $10 \mathrm{~mol} \%$ & DCM & $52.5 / 41.1$ & $2 \mathrm{~h}$ \\
\hline $2 b$ & 1 equiv & $1 \mathbf{a}(10 \%)$ & $10 \mathrm{~mol} \mathrm{\%}$ & DCM & $53.4 / 15.8$ & $1 \mathrm{~d}$ \\
\hline 3 & 1 equiv & $1 \mathbf{a}(5 \%)$ & $5 \mathrm{~mol} \mathrm{\%}$ & toluene & - & $1 \mathrm{~d}$ \\
\hline 4 & 1 equiv & $1 \mathrm{a}(5 \%)$ & $5 \mathrm{~mol} \%$ & acetonitrile & - & $1 \mathrm{~d}$ \\
\hline $5 a$ & 1 equiv & $1 \mathrm{a}(10 \%)$ & $5 \mathrm{~mol} \mathrm{\%}$ & DCM & $57.7 / 43.5$ & $2 \mathrm{~h}$ \\
\hline $5 b$ & 1 equiv & $1 \mathbf{a}(10 \%)$ & $5 \mathrm{~mol} \mathrm{\%}$ & DCM & $54.9 / 45.1$ & $1 \mathrm{~d}$ \\
\hline $6 a$ & 1.5 equiv & $1 \mathbf{a}(10 \%)$ & $5 \mathrm{~mol} \mathrm{\%}$ & DCM & $27.6 / 72.1$ & $1 \mathrm{~d}$ \\
\hline $6 b$ & 1.5 equiv & 1a $(10 \%)$ & $5 \mathrm{~mol} \%$ & DCM & $19.5 / 66.6$ & $2 d$ \\
\hline
\end{tabular}


Common entry numbers indicate a single experiment from which two samples $(a, b)$ were taken for analysis.

An increased amount of acid catalyst doesn't increase conversion of substrate significantly while it enhances decomposition of the product over time (cf. entries 1a, $1 \mathrm{~b}$ and entries $2 \mathrm{a}, 2 \mathrm{~b}$ ). Similarly, the product yield goes down if the reaction is allowed to take place for too long, most likely by acid-catalyzed cleavage of the ketal groups (entries 6a, 6b).

An increase of the amount of peroxide initiator leads to a small increase in conversion and product yield (cf. entries 1a and 5a). Excess of silane (1.5 equiv vs. 1.0 equiv) leads to an increase of conversion as well as of product yield (cf. entries 5a and 6a). 


\section{Trapping of generated radicals with styrene}

In order to support the presumed structure of the radicals generated, the acid-mediated decomposition of perketal 1a was performed in the presence of styrene:<smiles>CCCOC1(OCCC)CCCCC1</smiles>

1a, 2 equiv

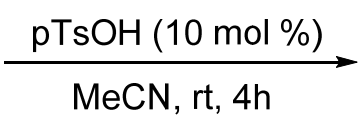

$\mathrm{MeCN}, \mathrm{rt}, 4 \mathrm{~h}$<smiles>CCOC(CC1CCCCC1=O)c1ccccc1</smiles>

$65 \%$

The resulting $\gamma$-peroxyketone (2-(2-(tert-butylperoxy)-2-phenylethyl)cyclohexan-1one) was received in $65 \%$ isolated yield after 4 hours of reaction time at ambient temperature. The product was found to be identical with the one previously synthesized from cyclohexanone, tert-butylhydroperoxide and styrene, ${ }^{13}$ according to the characterization data. In contrast to this three-component reaction, the reaction time was shorter and the required reaction temperature lower.

This supports the proposed in situ generation of alkenyl peroxides and the corresponding radicals generated thereof by homolytic O-O bond cleavage. The formation of the peroxyl radical is explained by a fast hydrogen atom transfer between the initially formed oxyl radical and tert-butylhydroperoxide: ${ }^{13-14}$<smiles>CCCCOC1(OCCCC)CCCCC1=O</smiles>

\section{Synthetic procedure:}

In an oven dried Schlenk tube, 1a (50\% solution, $520 \mathrm{mg}, 1 \mathrm{mmol})$ and styrene (58 $\mu \mathrm{L}, 0.5 \mathrm{mmol})$ were dissolved in acetonitrile $(2 \mathrm{~mL})$. The resulting solution was degassed (Freeze-Pump-Thaw technique, 3 cycles), brought to room temperature and paratoluene sulfonic acid $(9.5 \mathrm{mg}, 0.05 \mathrm{mmol})$ was added and the mixture left to react for 2 hours. The mixture was diluted, a small amount of silica added and evaporated to dryness and the resulting slightly yellow powder was purified by flash chromatography on silica gel (hexane/AcOEt 95/5 as eluent) to afford 2-(2-(tertbutylperoxy)-2-phenylethyl)cyclohexan-1-one as a clear oil (94 mg, 65\% yield). Analytical data was found to be consistent with previously reported data. ${ }^{13}$

${ }^{1} \mathbf{H}$ NMR: $\left(\mathrm{CDCl}_{3} ; 500 \mathrm{MHz}, 2\right.$ diastereoisomers): 7.42-7.22 (m, 5H); 5.02-4.96 (m, $1 \mathrm{H}) ; 2.62-2.53(\mathrm{~m}, 1 \mathrm{H}$, major); 2.51-2.43 (m, 1H, minor); 2.44-2.38 (m, 1H); 2.38$2.14(\mathrm{~m}, 3 \mathrm{H}) ; 2.12-2.01(\mathrm{~m}, 1 \mathrm{H}) ; 1.91-1.81(\mathrm{~m}, 1 \mathrm{H}) ; 1.74-1.57(\mathrm{~m}, 3 \mathrm{H}) ; 1.53-1.35(\mathrm{~m}$, $2 \mathrm{H}) ; 1.21$ (s, 9H, minor); 1.18 (s, 9H, major) 
${ }^{13}$ C NMR: $\left(\mathrm{CDCl}_{3} ; 125 \mathrm{MHz} ; 2\right.$ diastereoisomers): 212.63 (C); 141.83 (Ar q, major); 141.48 (Ar q, minor); 128.21 (Ar CH, major); 128.17 (Ar CH, minor); 127.63 (Ar $\mathrm{CH}$, minor); 127.53 (Ar CH; major); 126.94 (Ar CH, major); 126.72 (Ar CH; minor); 84.01 (CH, major); $83.05(\mathrm{CH}$, minor); $80.08(\mathrm{C}) ; 47.65(\mathrm{CH}$, minor $) ; 47.26(\mathrm{CH}$, major); $42.28\left(\mathrm{CH}_{2}\right.$, major); $42.11\left(\mathrm{CH}_{2}\right.$, minor $) ; 35.60\left(\mathrm{CH}_{2}\right.$, minor $) ; 35.06\left(\mathrm{CH}_{2}\right.$, major); $34.93\left(\mathrm{CH}_{2}\right.$, major); $34.41\left(\mathrm{CH}_{2}\right.$, minor $) ; 28.26\left(\mathrm{CH}_{2}\right.$, minor $) ; 28.08\left(\mathrm{CH}_{2}\right.$, major); 26.50 (3x $\mathrm{CH}_{3}$, major); 26.49 (3x $\mathrm{CH}_{3}$, minor); $25.33\left(\mathrm{CH}_{2}\right.$, major); 25.00 $\left(\mathrm{CH}_{2}\right.$, minor)

MS (EI): 217 (3.8); 201 (100); 105 (16); 91 (26)

HRMS (ESI): Calculated for $\left[\mathrm{C}_{18} \mathrm{H}_{26} \mathrm{O}_{3} \mathrm{Na}\right]^{+}\left(\mathrm{M}+\mathrm{Na}^{+}\right)$: 313.1774 ; found: 313.1775 


\section{NMR-spectra}

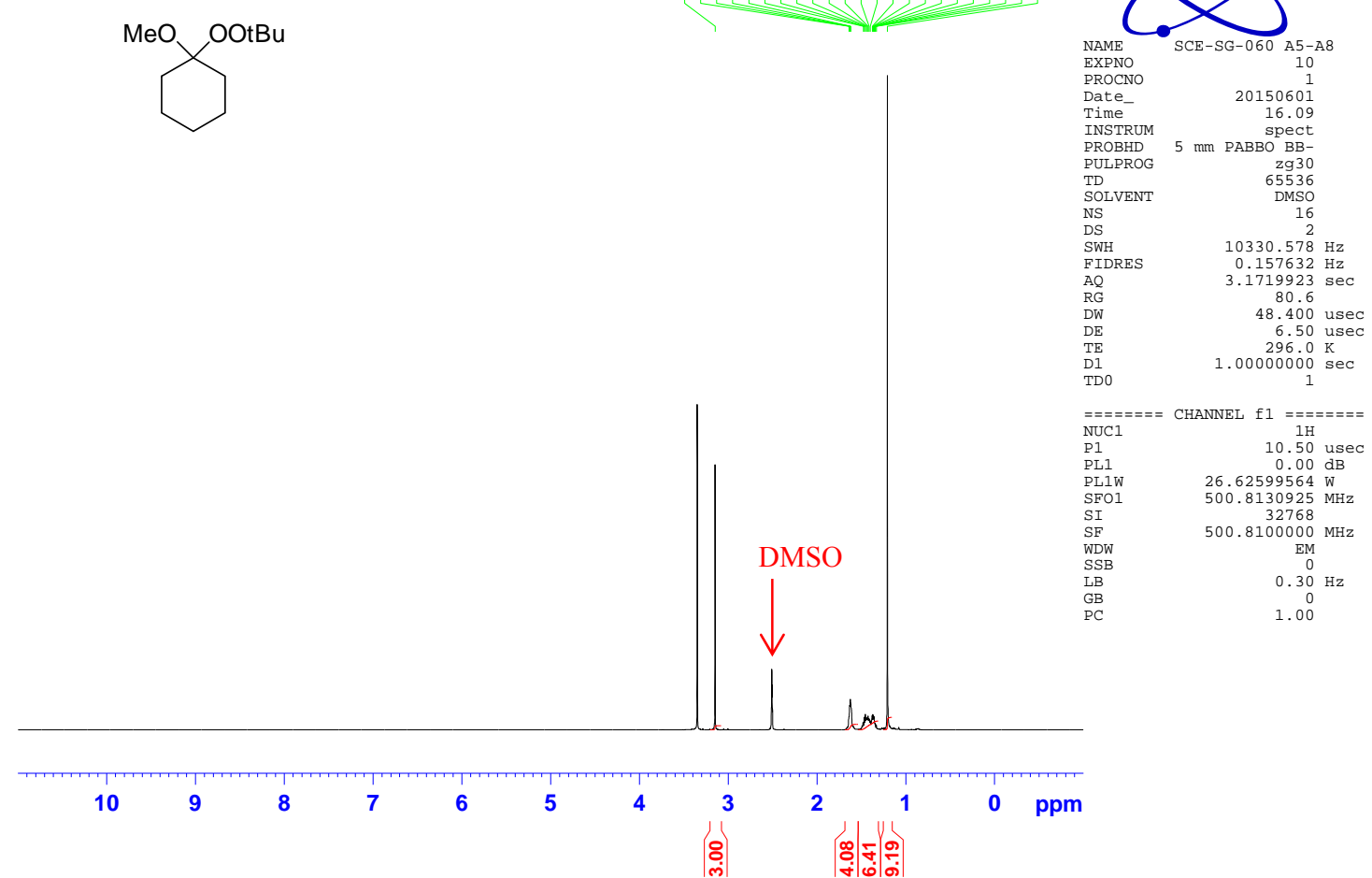

Figure S2: ${ }^{1} \mathrm{H}-\mathrm{NMR}$ (DMSO-d ${ }_{6}, 500 \mathrm{MHz}$ ) of compound $1 \mathrm{~b}$.

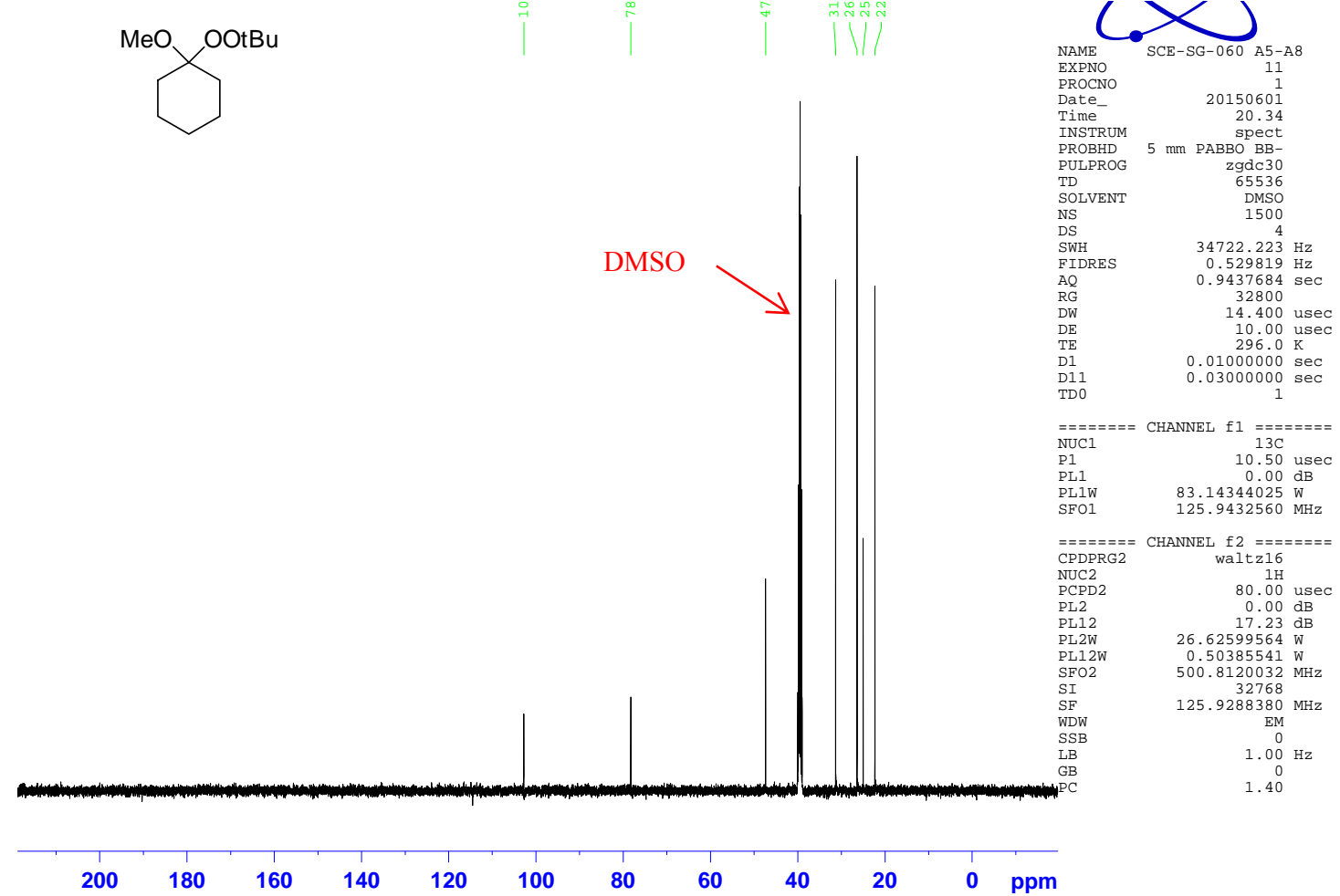

Figure S3: ${ }^{13} \mathrm{C}-\mathrm{NMR}$ (DMSO-d $\mathrm{d}_{6}, 125 \mathrm{MHz}$ ) of compound $1 \mathrm{~b}$. 


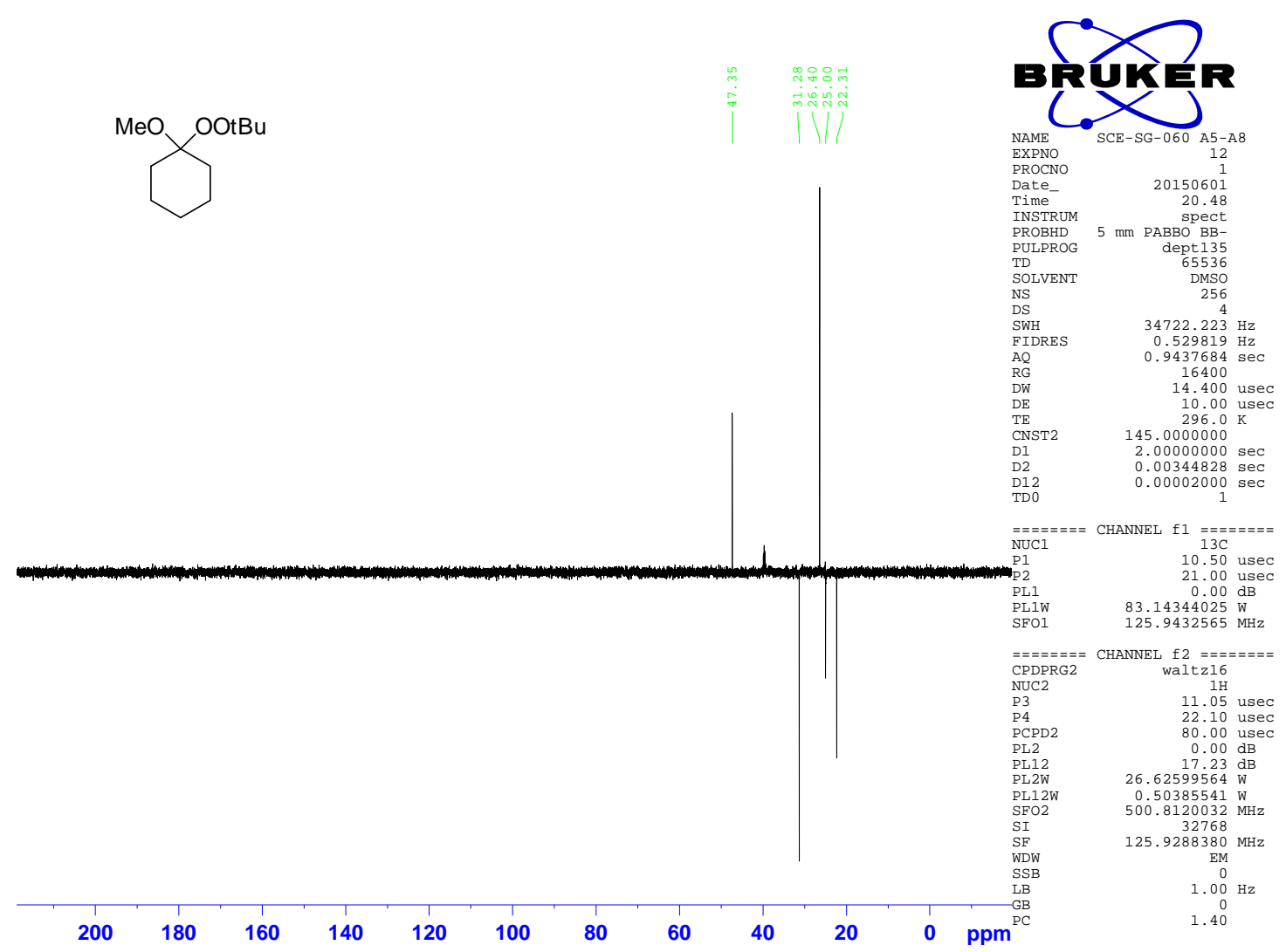

Figure S4: DEPT 135-NMR (DMSO-d ,, $125 \mathrm{MHz}$ ) of compound $1 \mathrm{~b}$.

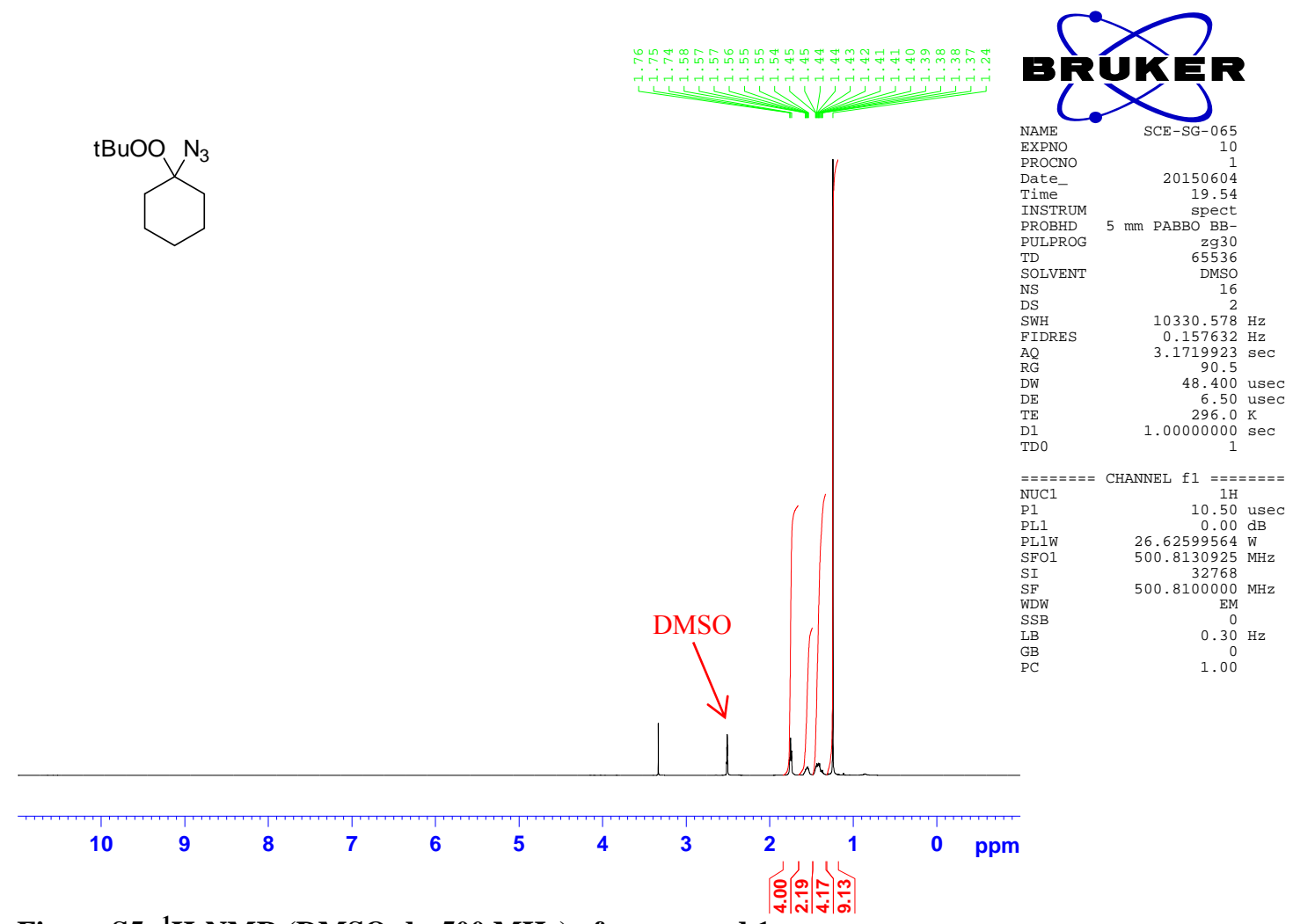

Figure S5: ${ }^{1} \mathrm{H}-\mathrm{NMR}$ (DMSO-d 6 , $500 \mathrm{MHz}$ ) of compound 1c. 


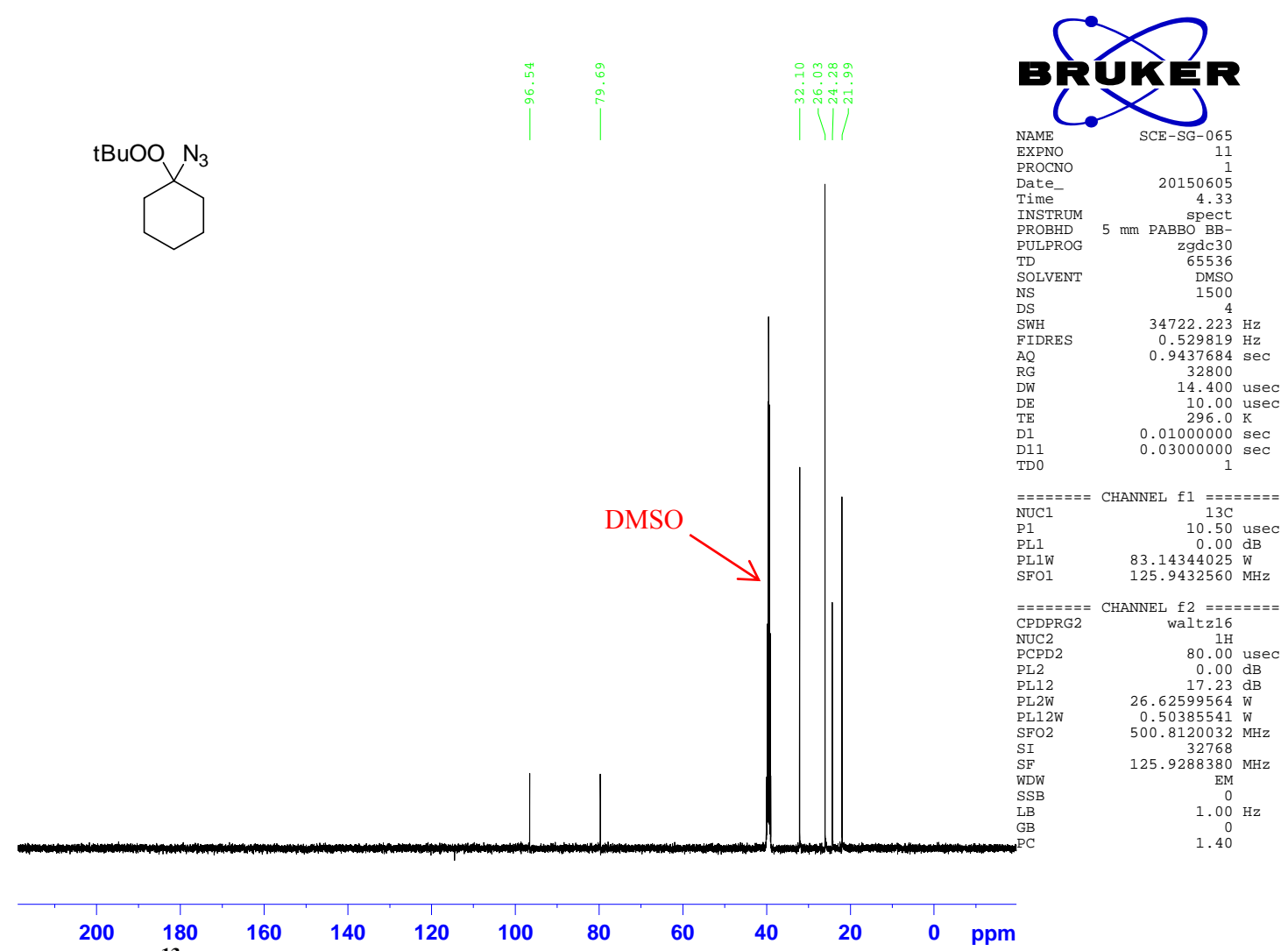

Figure S6: ${ }^{13} \mathrm{C}-\mathrm{NMR}$ (DMSO- $\mathrm{d}_{6}, 125 \mathrm{MHz}$ ) of compound 1c.

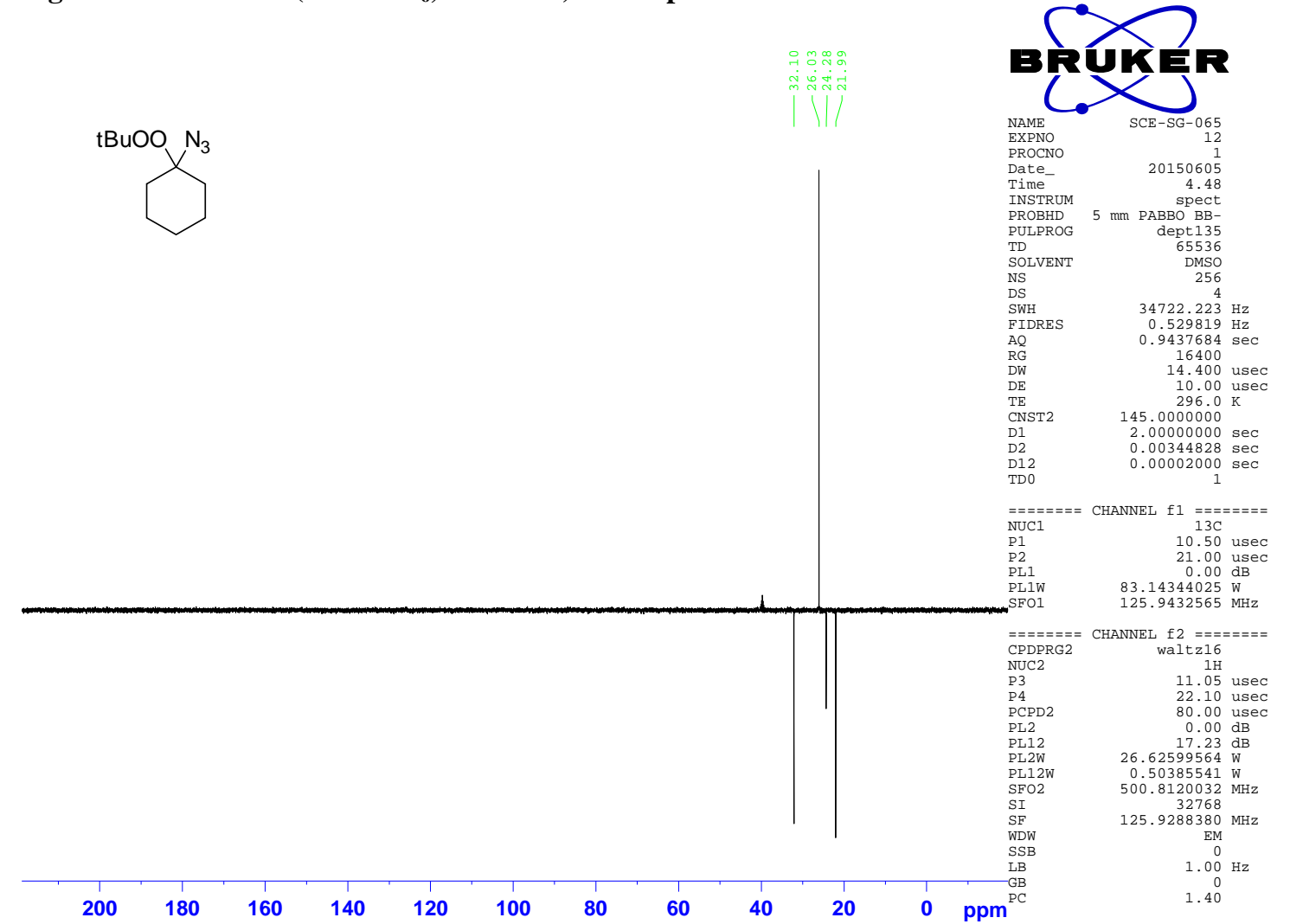

Figure S7: DEPT 135-NMR (DMSO-d 6 , $125 \mathrm{MHz}$ ) of compound 1c. 


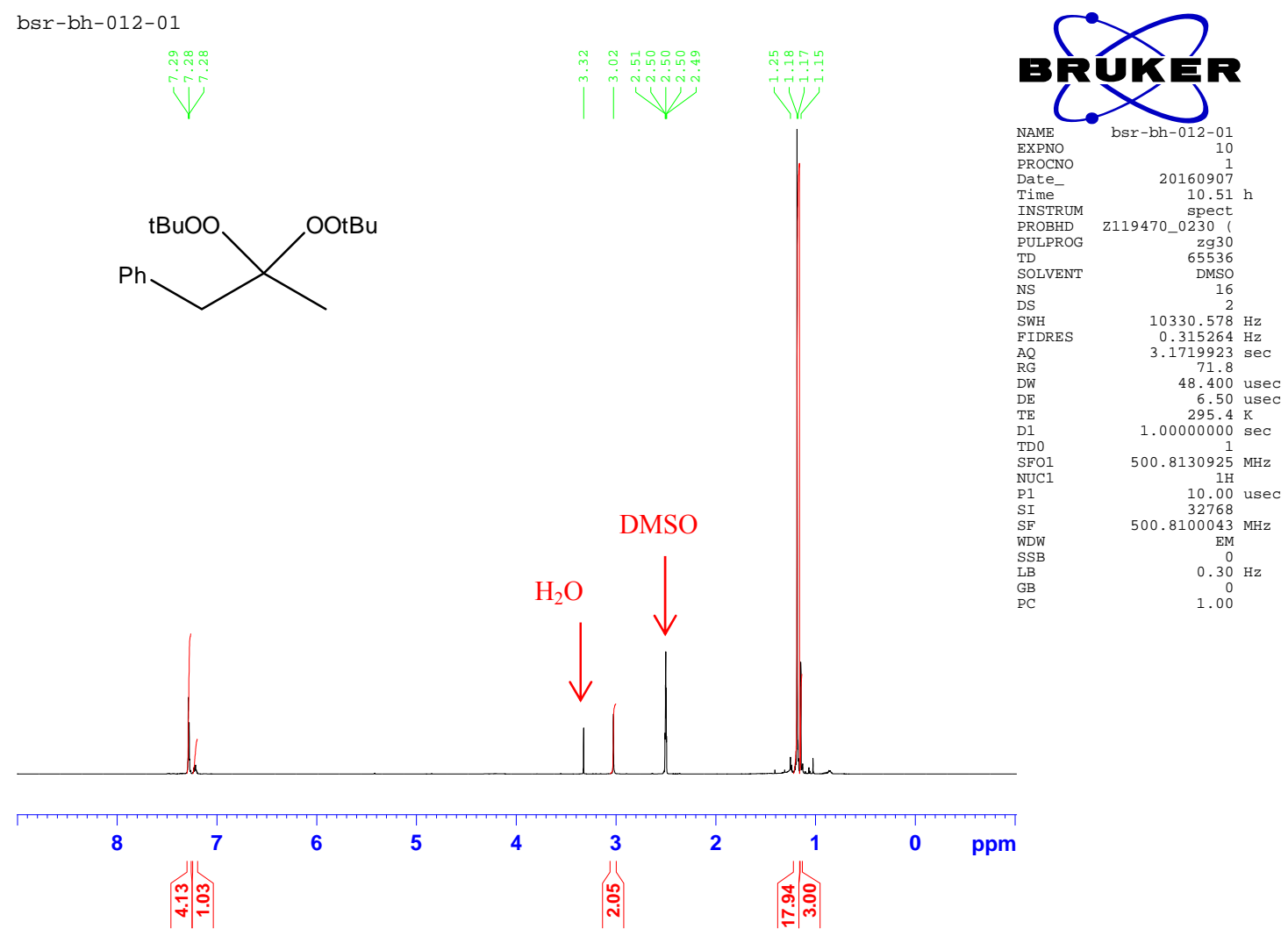

Figure S8: ${ }^{1} \mathrm{H}-\mathrm{NMR}$ (DMSO-d $\mathrm{d}_{6}, 500 \mathrm{MHz}$ ) of compound $3 \mathrm{~b}$.

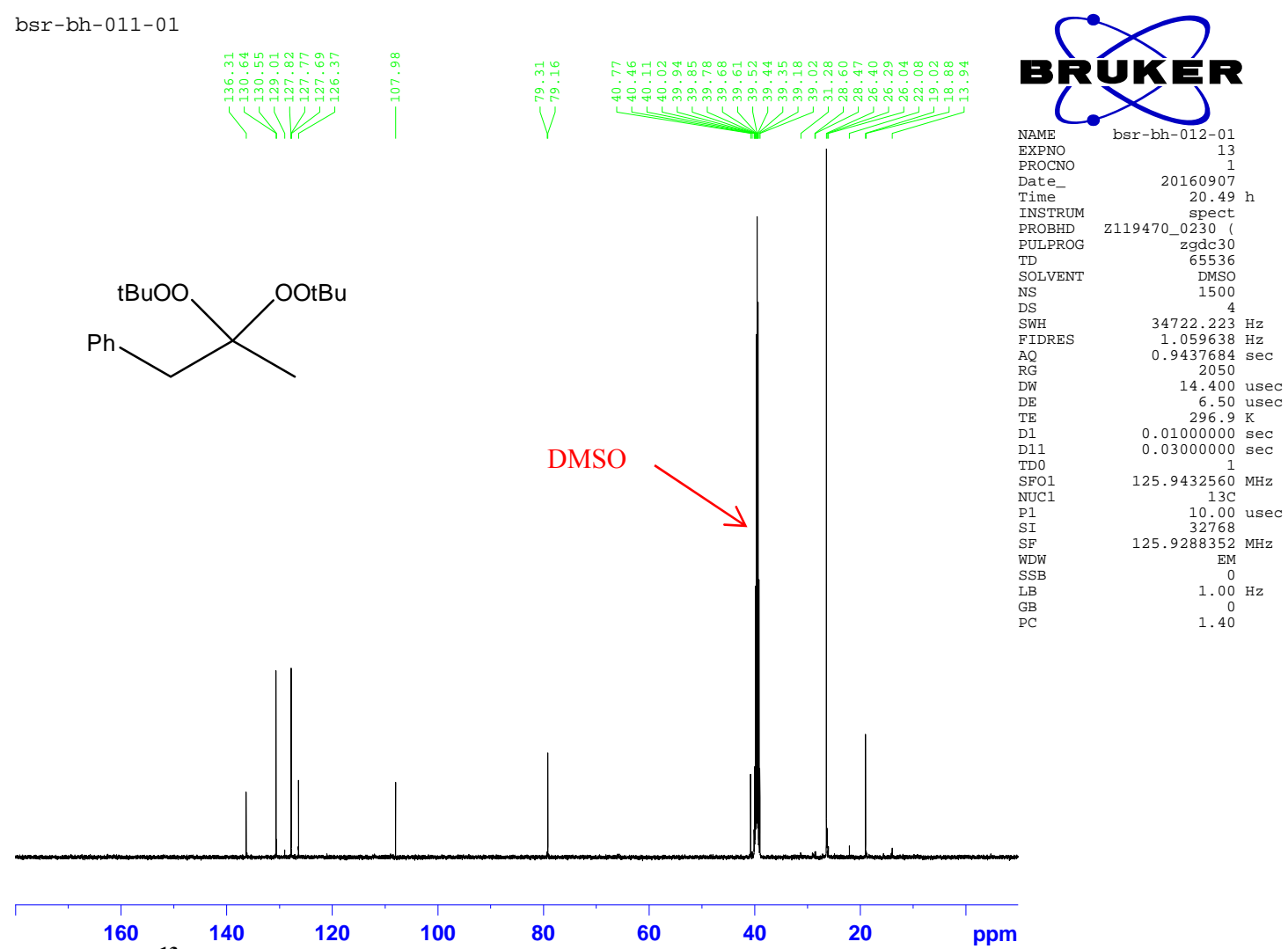

Figure S9: ${ }^{13} \mathrm{C}-\mathrm{NMR}$ (DMSO-d $\mathrm{d}_{6}, 125 \mathrm{MHz}$ ) of compound $3 \mathrm{~b}$. 


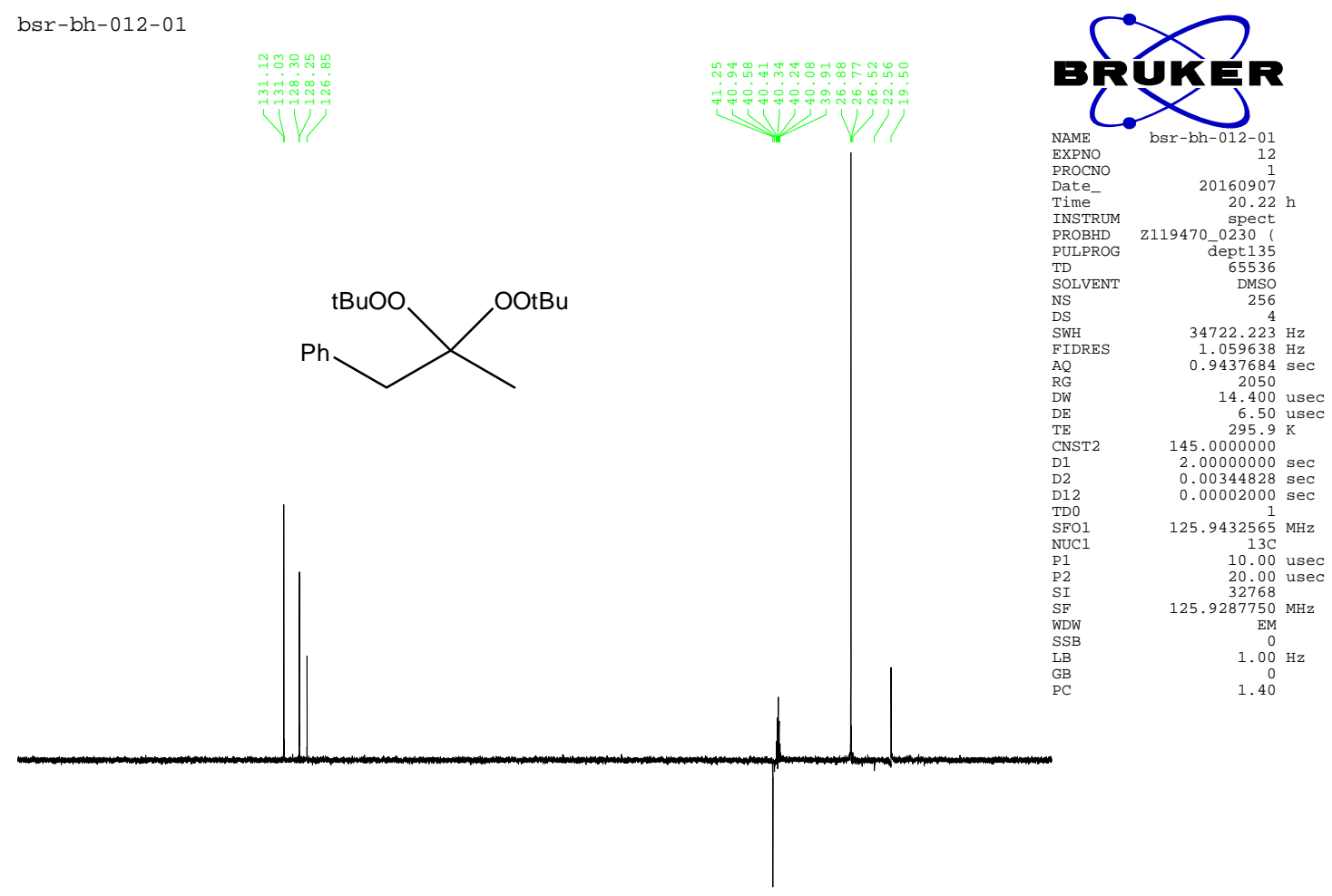

\begin{tabular}{llllllll|l|l|}
160 & 140 & 120 & 100 & 80 & 60 & 40 & 20 & $\mathrm{ppm}$
\end{tabular}

Figure S10: DEPT 135-NMR (DMSO-d 6 , $125 \mathrm{MHz}$ ) of compound $3 \mathrm{~b}$.

bsr - bh- $013-01$
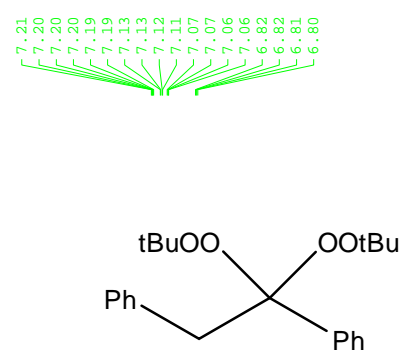

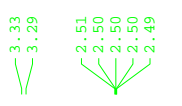

DMSO

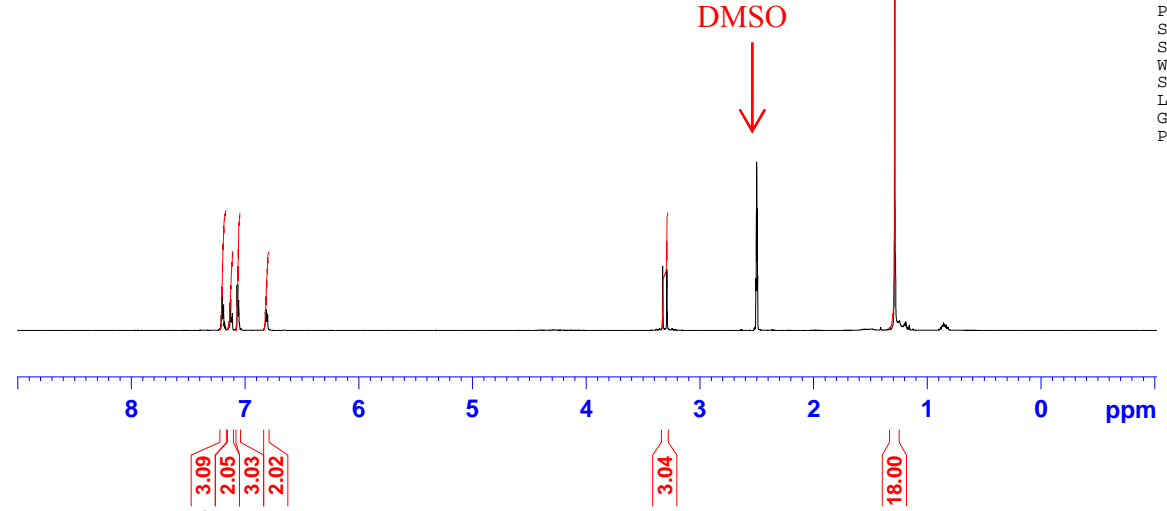

Figure S11: ${ }^{1} \mathrm{H}-\mathrm{NMR}$ (DMSO-d 6 , $500 \mathrm{MHz}$ ) of compound 3c. 


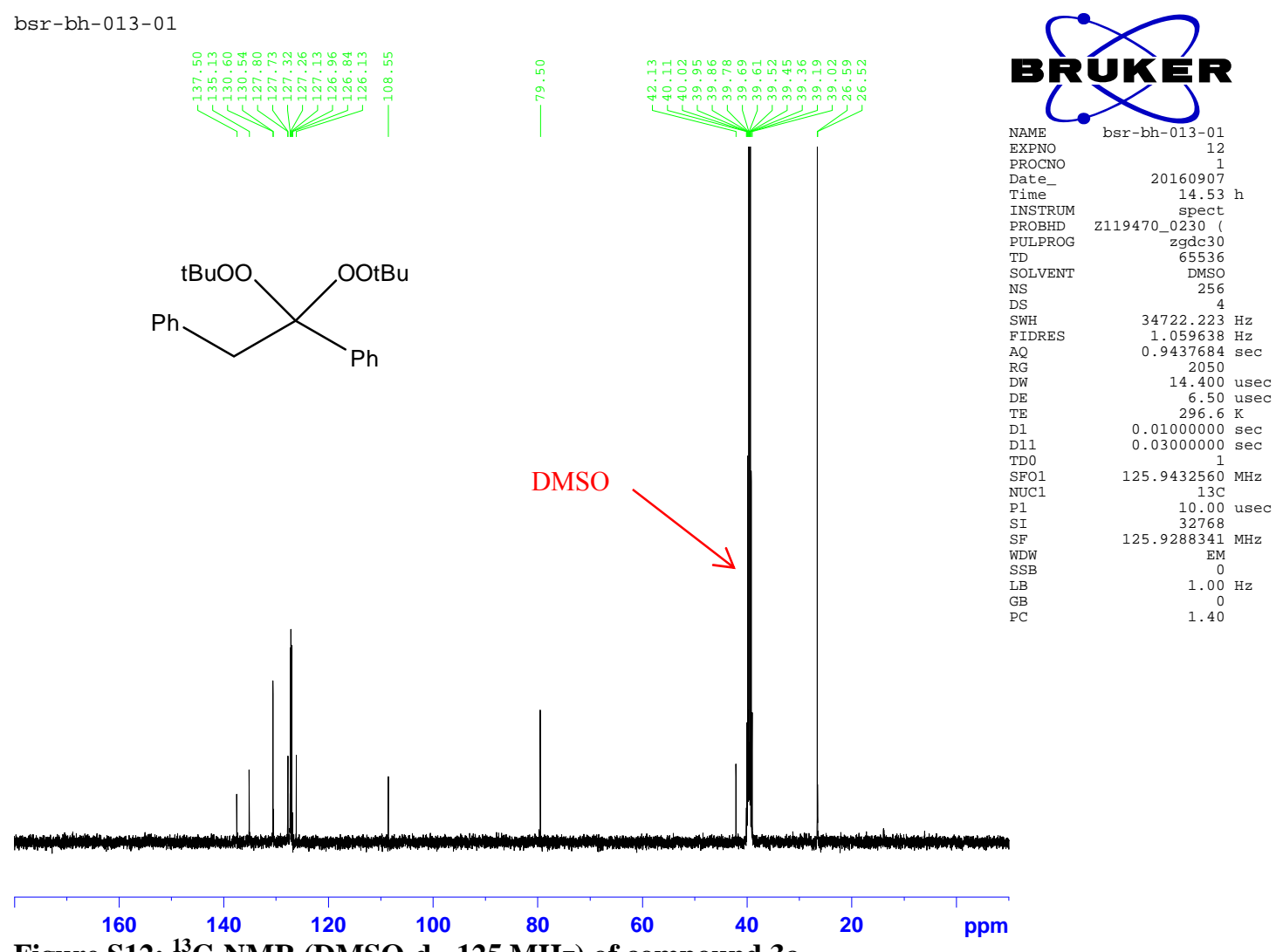

Figure S12: ${ }^{13} \mathrm{C}-\mathrm{NMR}$ (DMSO-d $\mathrm{d}_{6}, 125 \mathrm{MHz}$ ) of compound 3c.

bsr - bh- $-13-01$
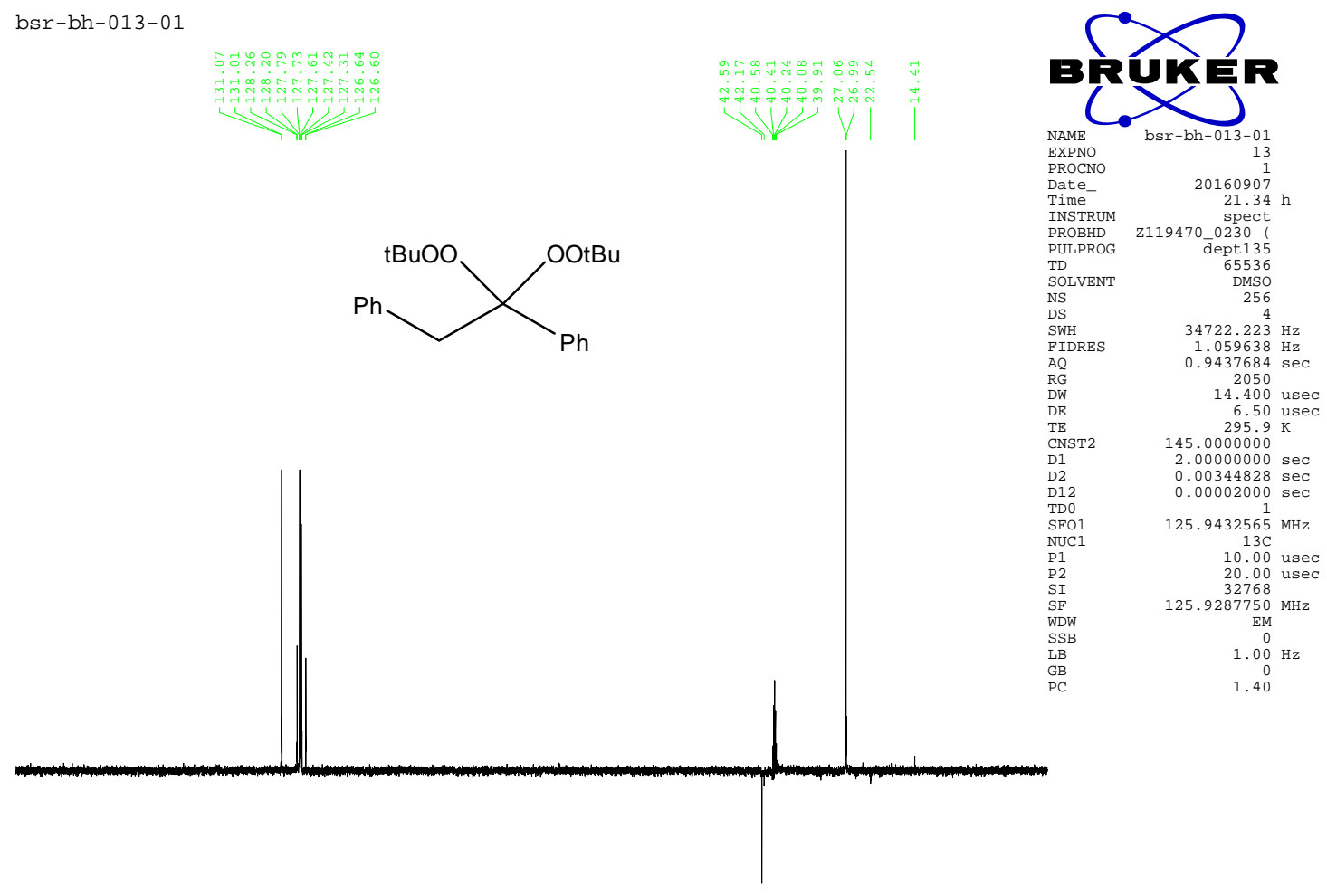

$295.9 \mathrm{~K}$

2.000000000 sec

$0.00344828 \mathrm{sec}$

$25.9432565 \mathrm{MHZ}$

10.00 usec
20.00 usec

$32768 \mathrm{MHZ}$

0
$1 . \oplus 0$
0

\begin{tabular}{|llllllllll}
\hline 160 & 140 & 120 & 100 & 80 & 60 & 40 & 20 & $\mathrm{ppm}$
\end{tabular}

Figure S13: DEPT 135-NMR (DMSO-d 6 , $125 \mathrm{MHz}$ ) of compound 3c. 


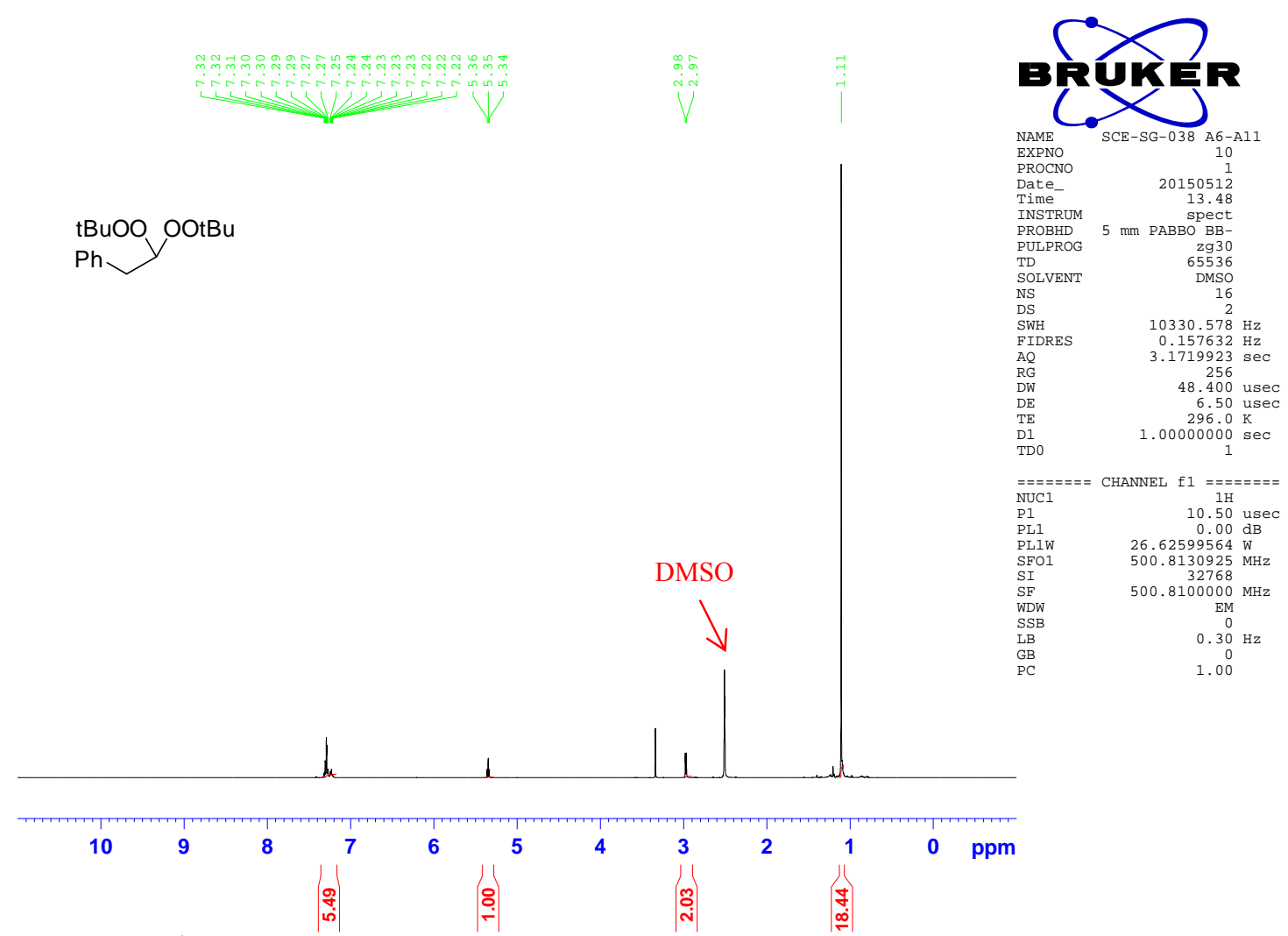

Figure S14: ${ }^{1} \mathrm{H}-\mathrm{NMR}$ (DMSO-d $\mathrm{d}_{6}, 500 \mathrm{MHz}$ ) of compound $3 \mathrm{~d}$.

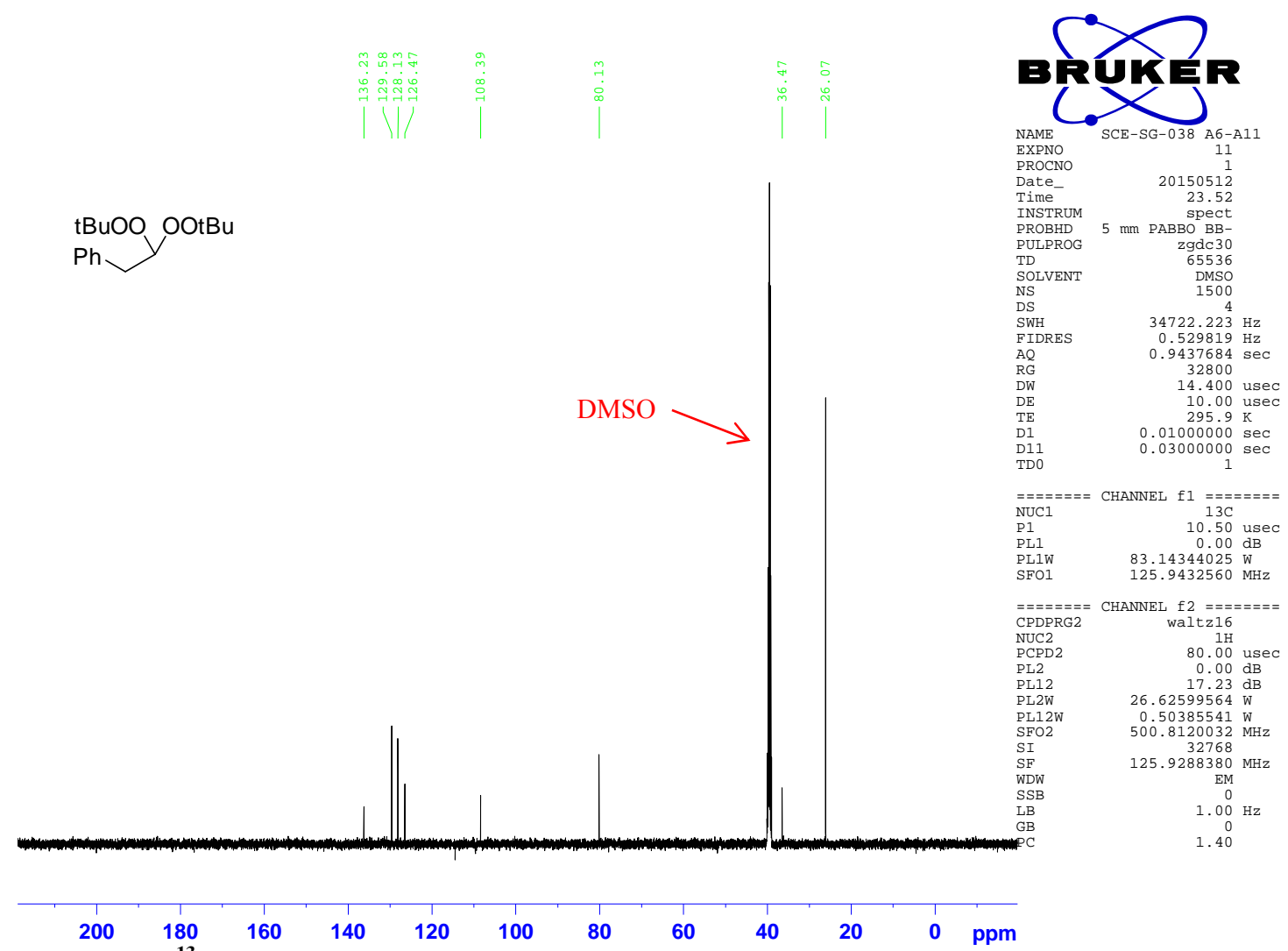

Figure S15: ${ }^{13} \mathrm{C}-\mathrm{NMR}$ (DMSO-d 6 , $125 \mathrm{MHz}$ ) of compound 3d. 


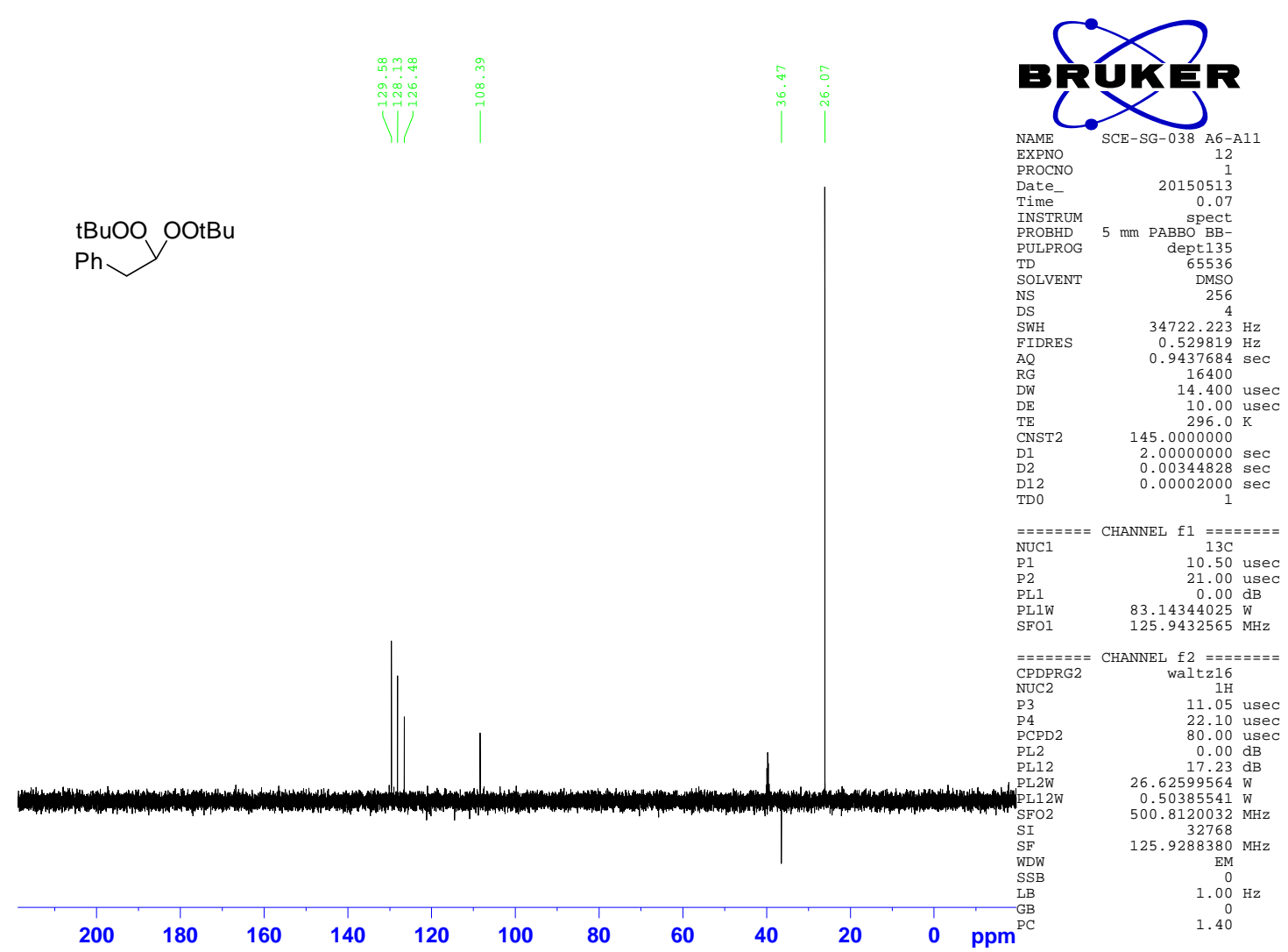

Figure S16: DEPT 135-NMR (DMSO-d 6 , $125 \mathrm{MHz}$ ) of compound 3d.

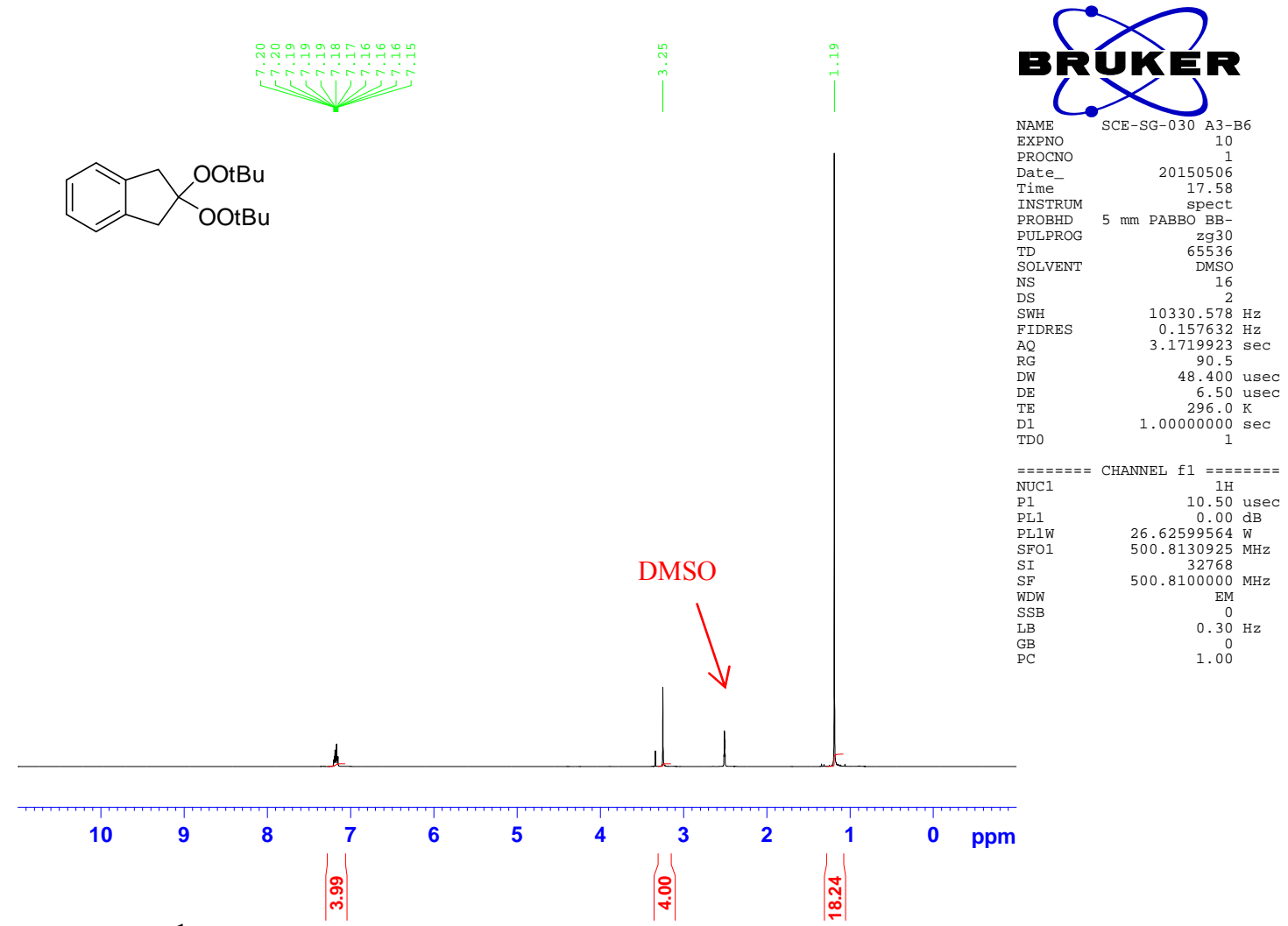

Figure S17: ${ }^{1} \mathrm{H}-\mathrm{NMR}$ (DMSO-d 6 , $500 \mathrm{MHz}$ ) of compound $6 \mathrm{a}$. 


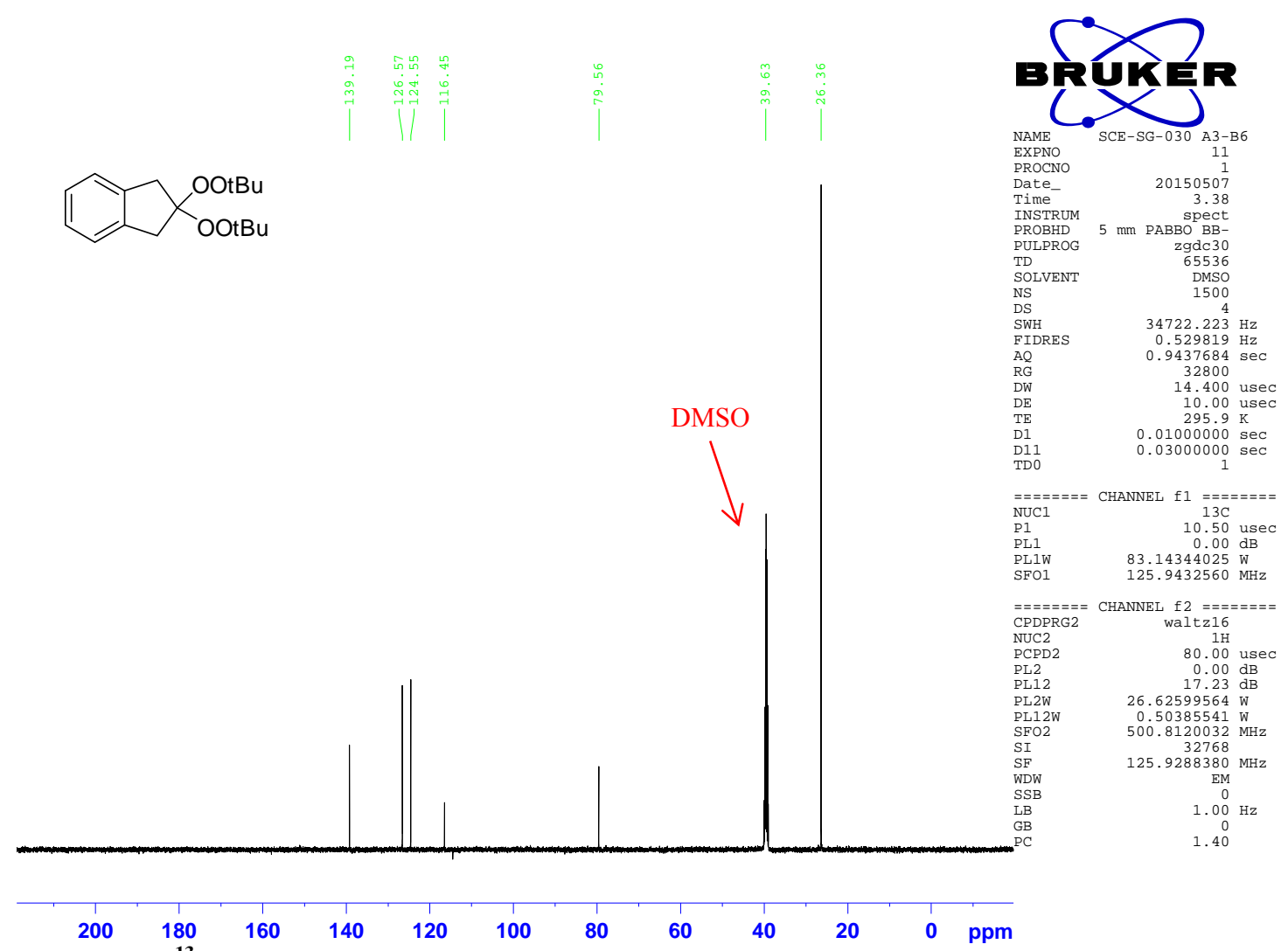

Figure S18: ${ }^{13} \mathrm{C}-\mathrm{NMR}$ (DMSO-d 6 , $125 \mathrm{MHz}$ ) of compound $6 \mathrm{a}$.

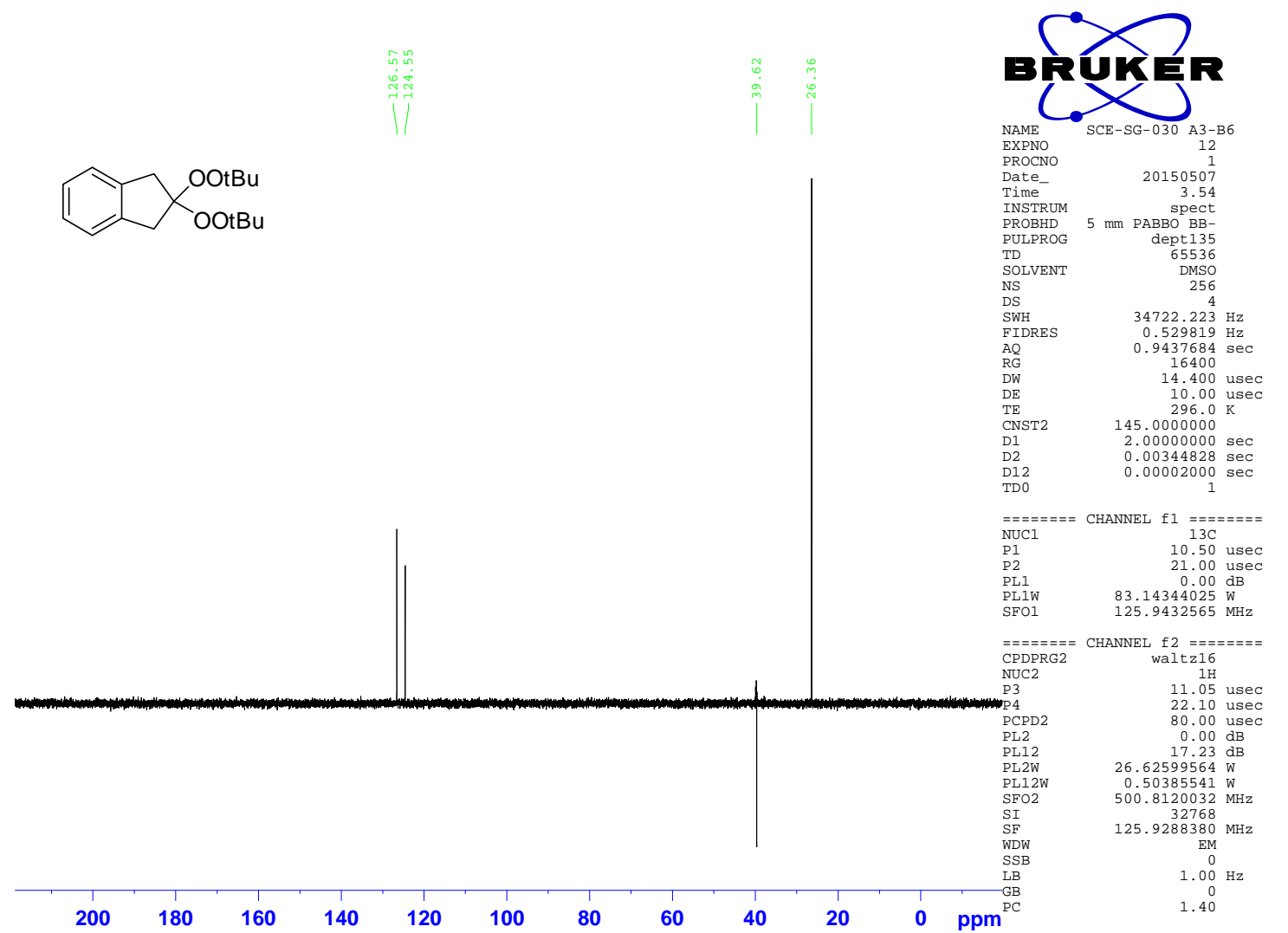

Figure S19: DEPT 135-NMR (DMSO-d ${ }_{6}, 125 \mathrm{MHz}$ ) of compound $6 \mathrm{a}$. 

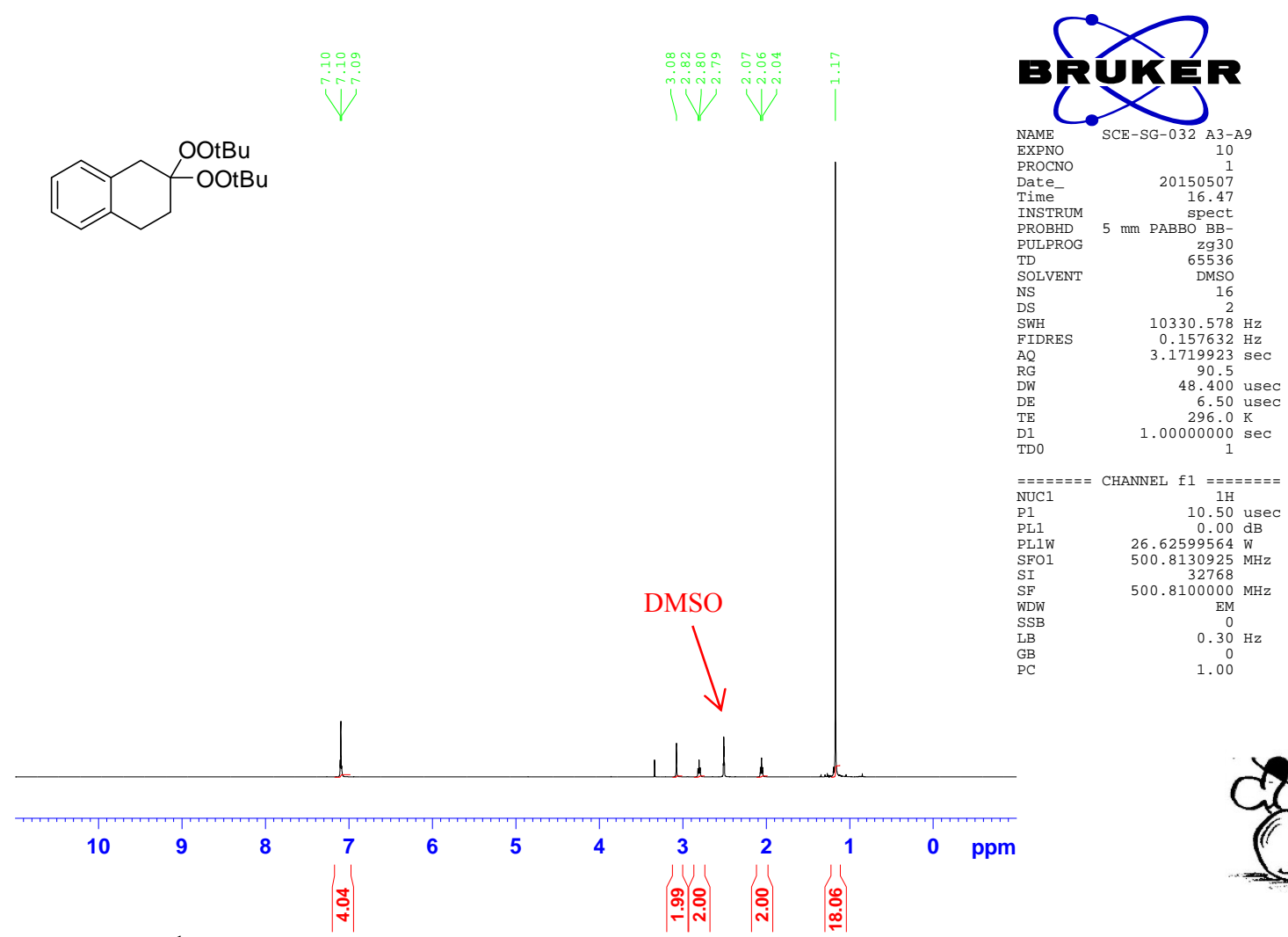

Figure S20: ${ }^{1} \mathrm{H}-\mathrm{NMR}$ (DMSO-d $\mathrm{d}_{6}, 500 \mathrm{MHz}$ ) of compound $6 \mathrm{~b}$.

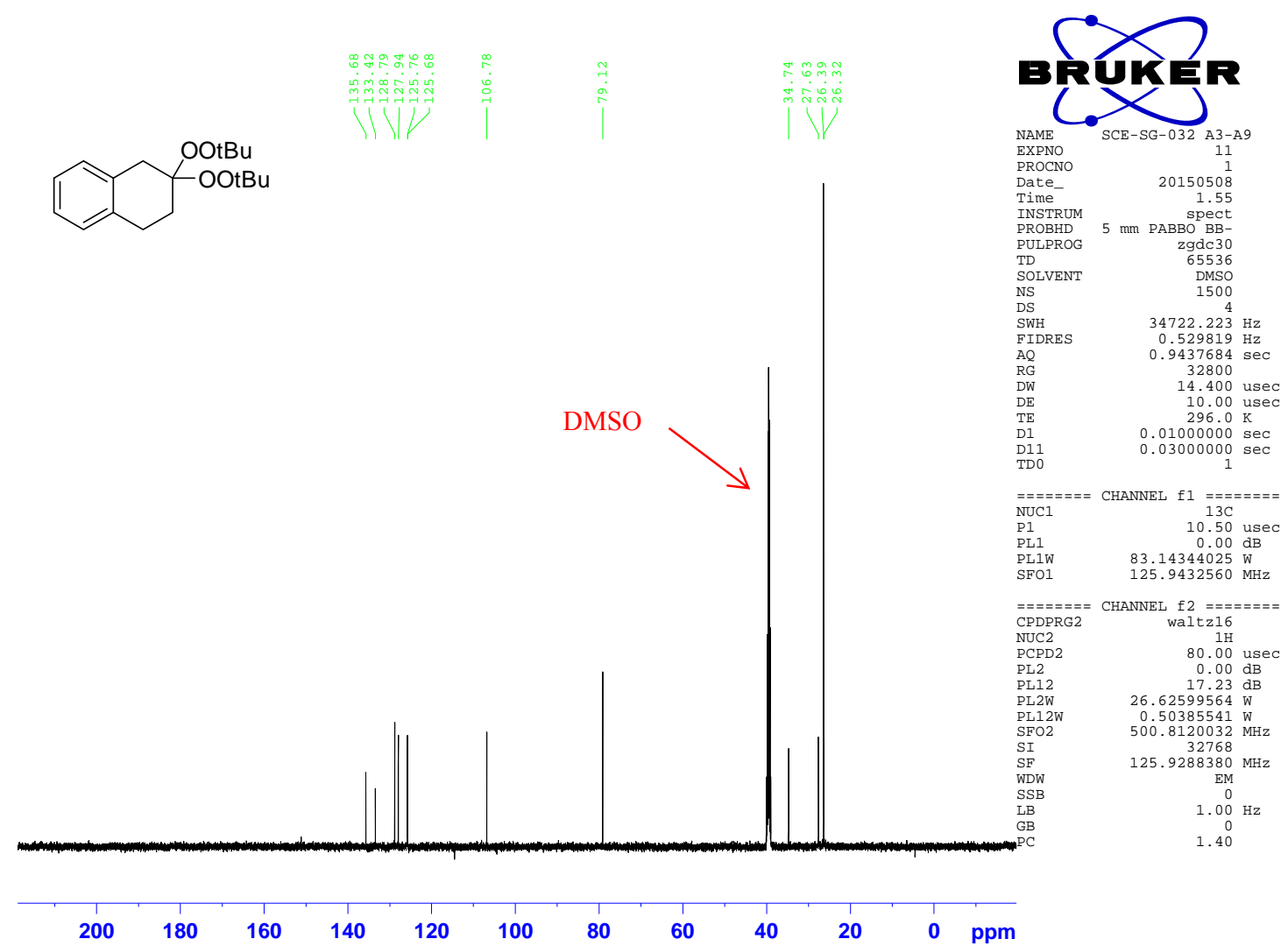

Figure S21: ${ }^{13} \mathrm{C}-\mathrm{NMR}$ (DMSO-d $\mathrm{d}_{6}, 125 \mathrm{MHz}$ ) of compound $6 \mathrm{~b}$. 


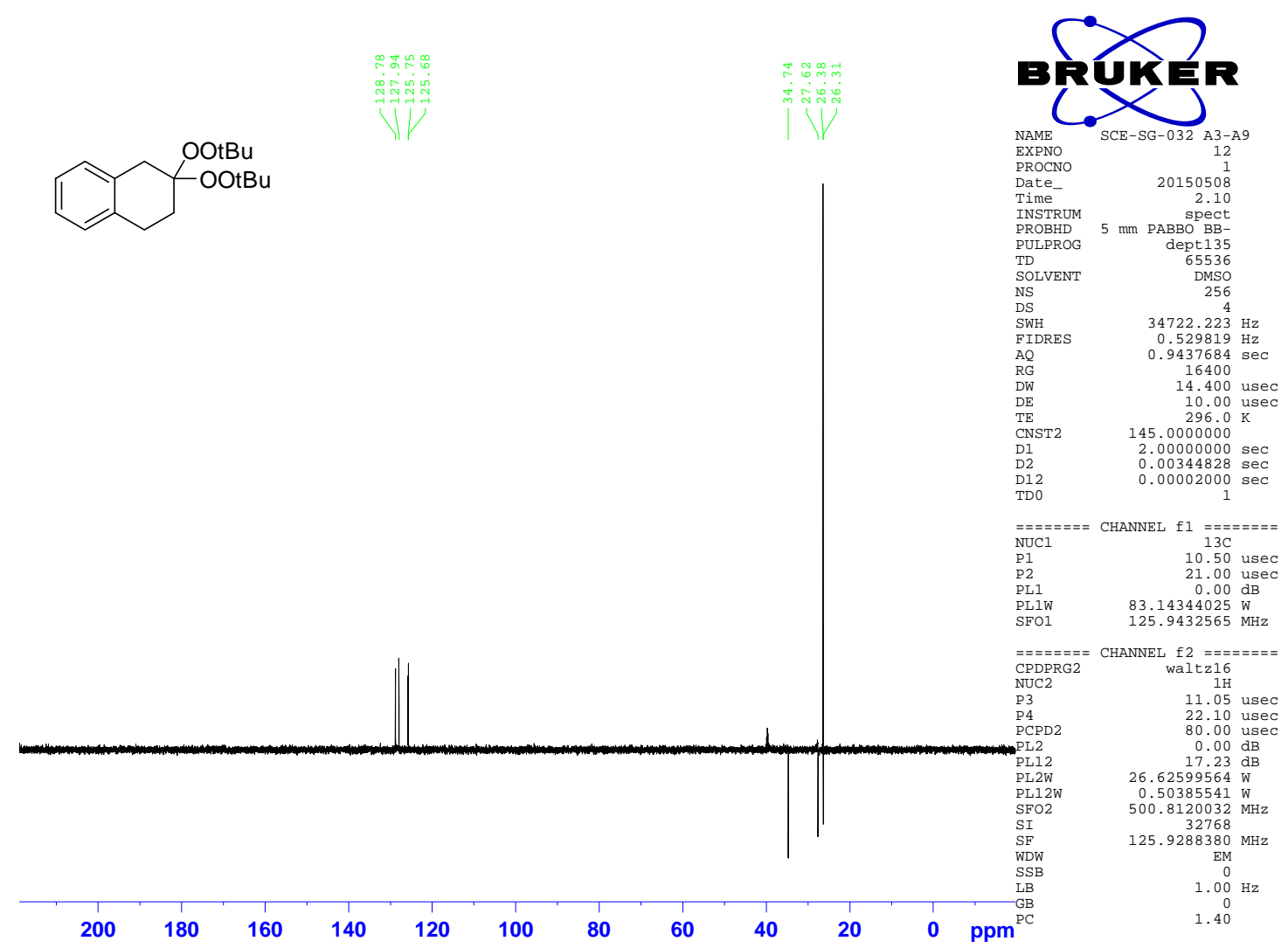

Figure S22: DEPT 135-NMR (DMSO-d 6 , $125 \mathrm{MHz}$ ) of compound $6 \mathrm{~b}$.

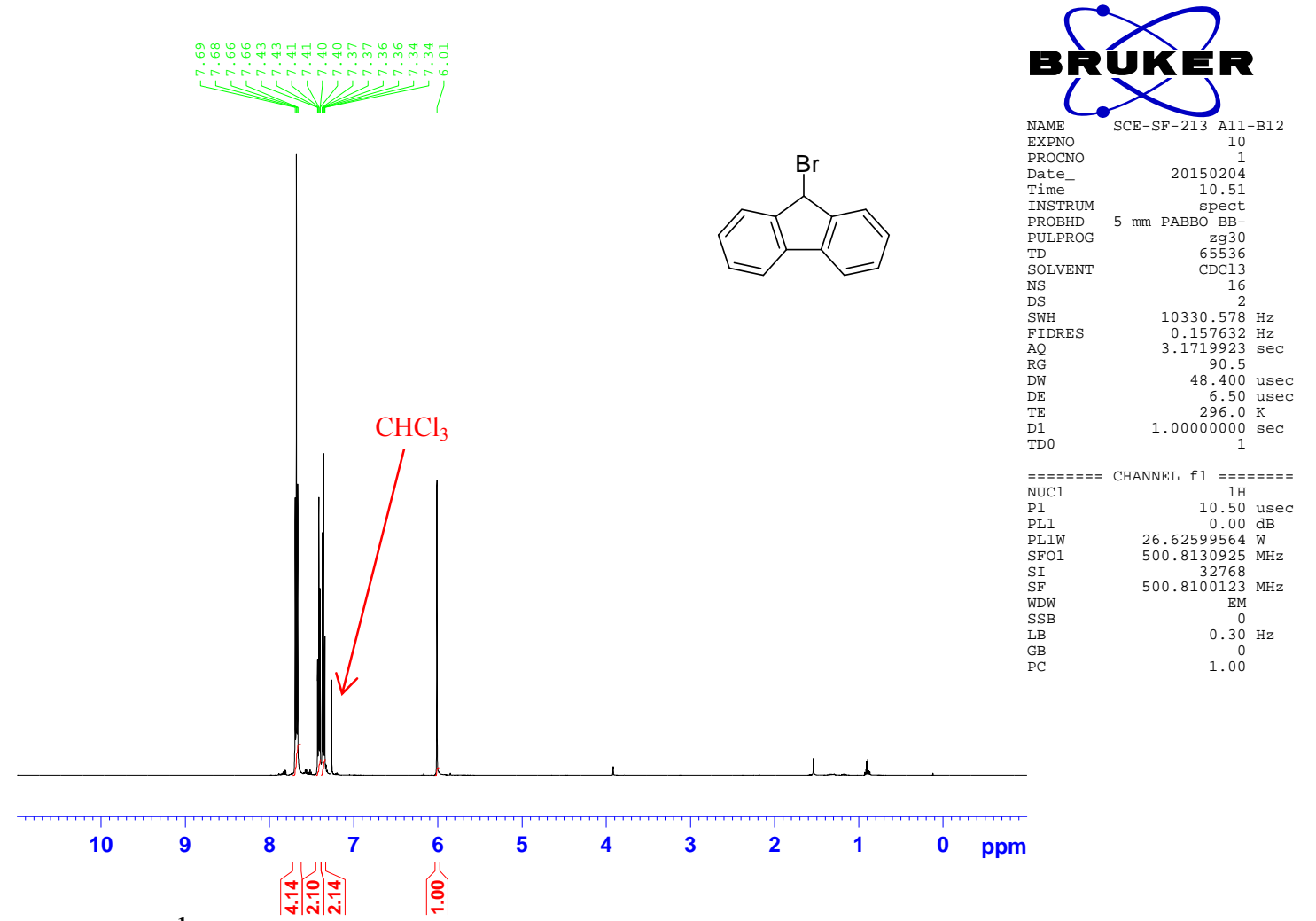

Figure S23: ${ }^{1} \mathrm{H}-\mathrm{NMR}\left(\mathrm{CDCl}_{3}, 500 \mathrm{MHz}\right)$ of compound 8. 

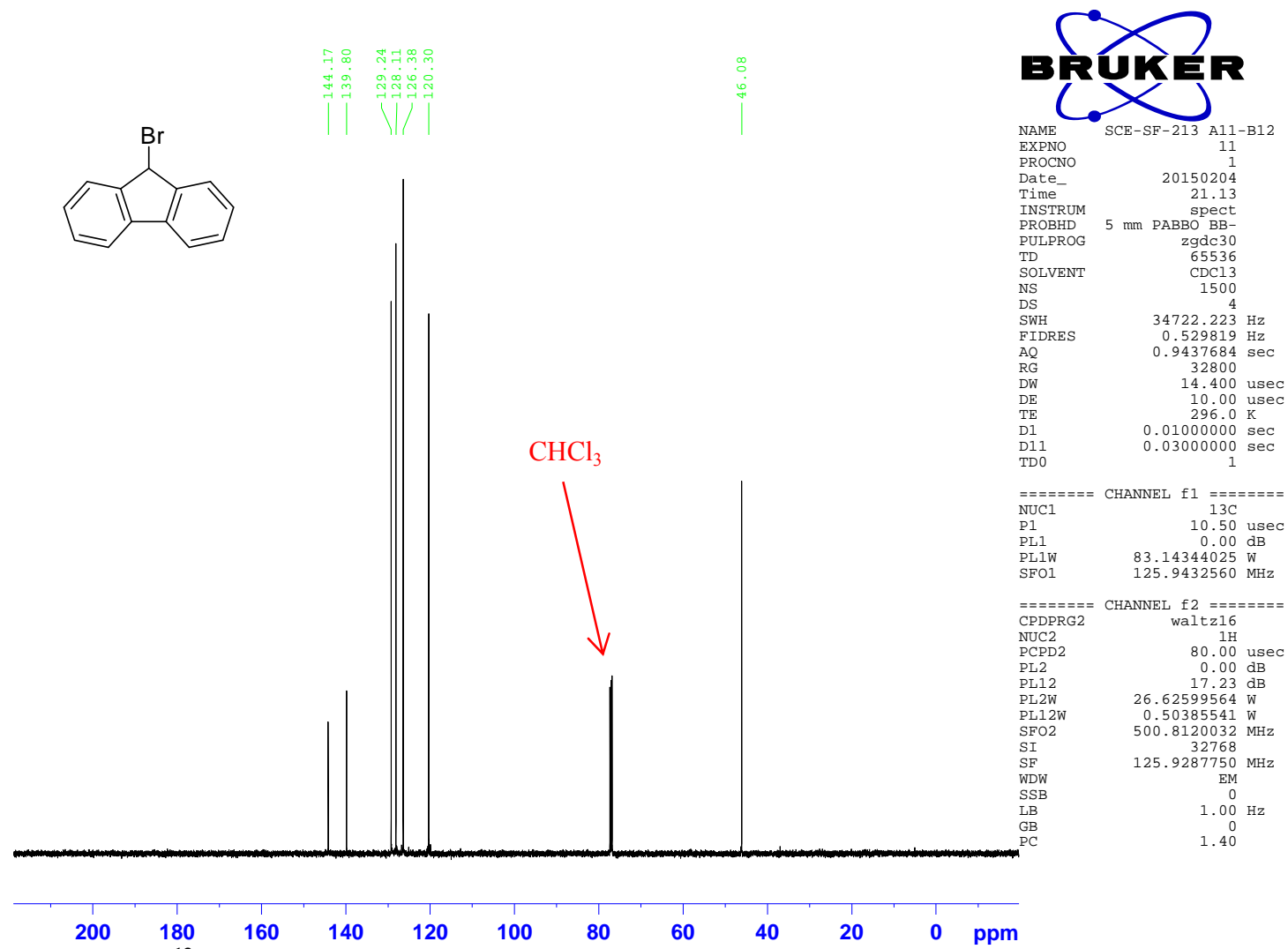

Figure S24: ${ }^{13} \mathrm{C}-\mathrm{NMR}\left(\mathrm{CDCl}_{3}, 125 \mathrm{MHz}\right)$ of compound 8.

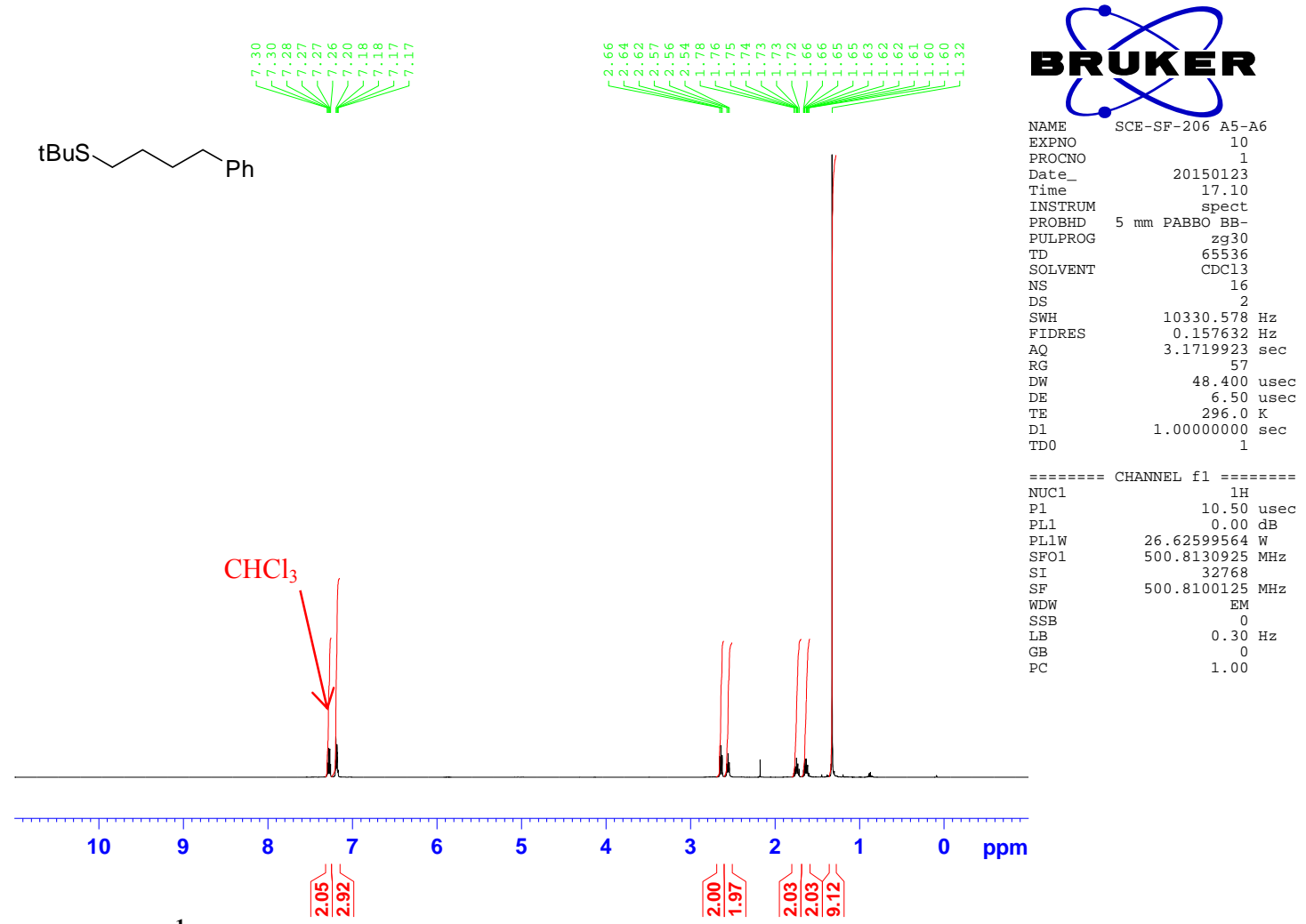

Figure S25: ${ }^{1} \mathrm{H}-\mathrm{NMR}\left(\mathrm{CDCl}_{3}, 500 \mathrm{MHz}\right)$ of compound 9. 


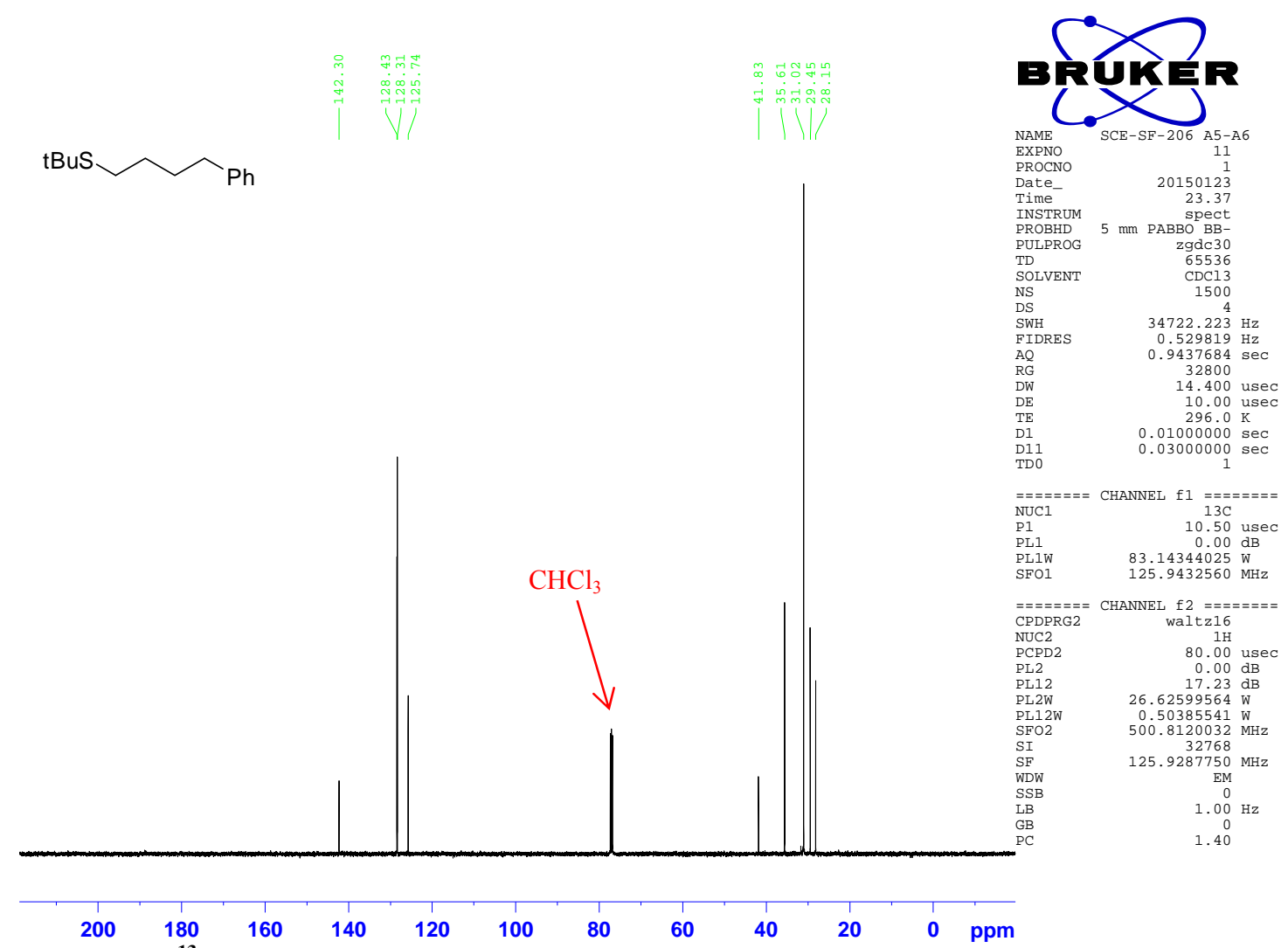

Figure S26: ${ }^{13} \mathrm{C}-\mathrm{NMR}\left(\mathrm{CDCl}_{3}, 125 \mathrm{MHz}\right)$ of compound 9.

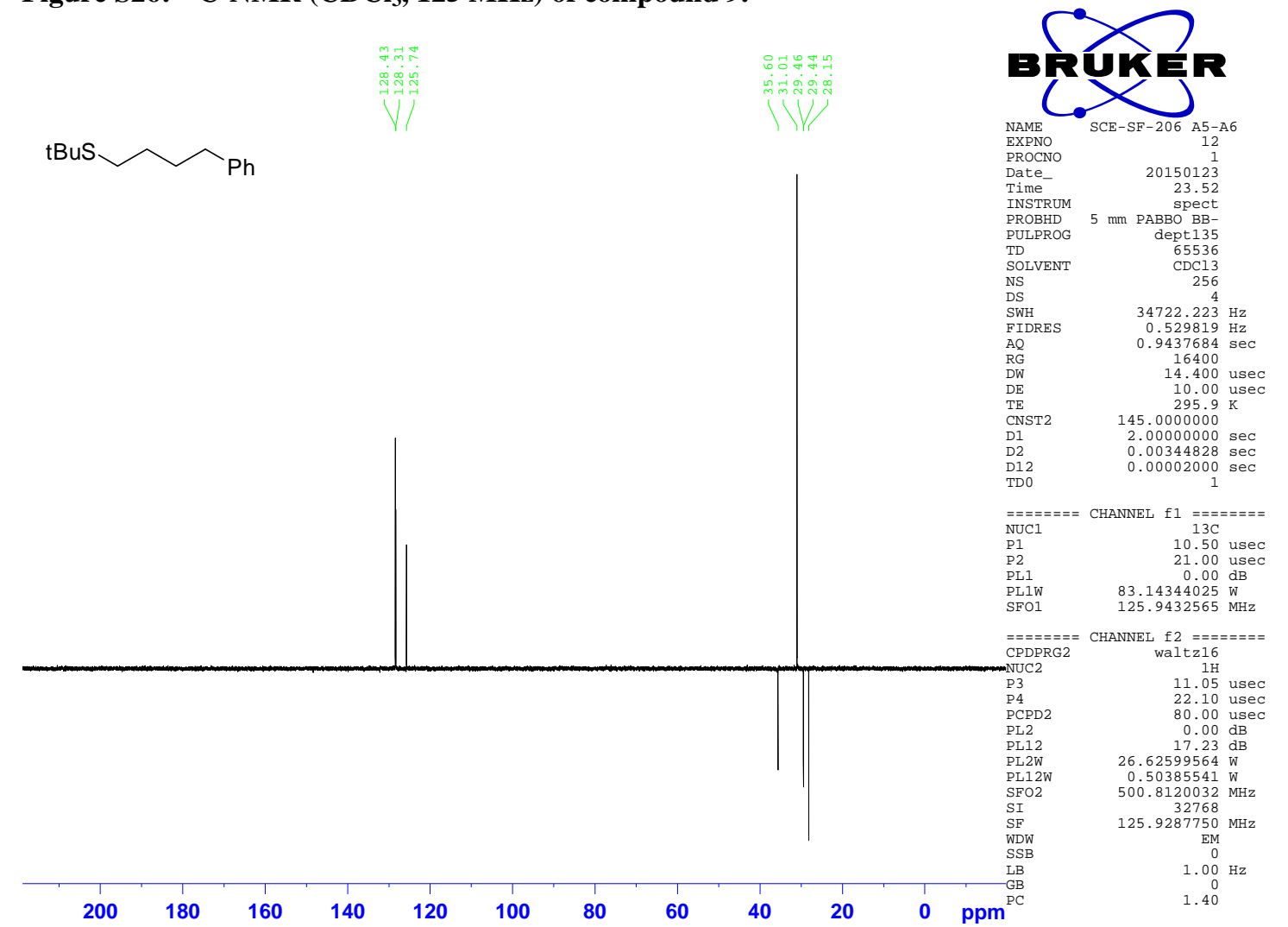

Figure S27: DEPT 135-NMR ( $\left.\mathrm{CDCl}_{3}, 125 \mathrm{MHz}\right)$ of compound 9. 


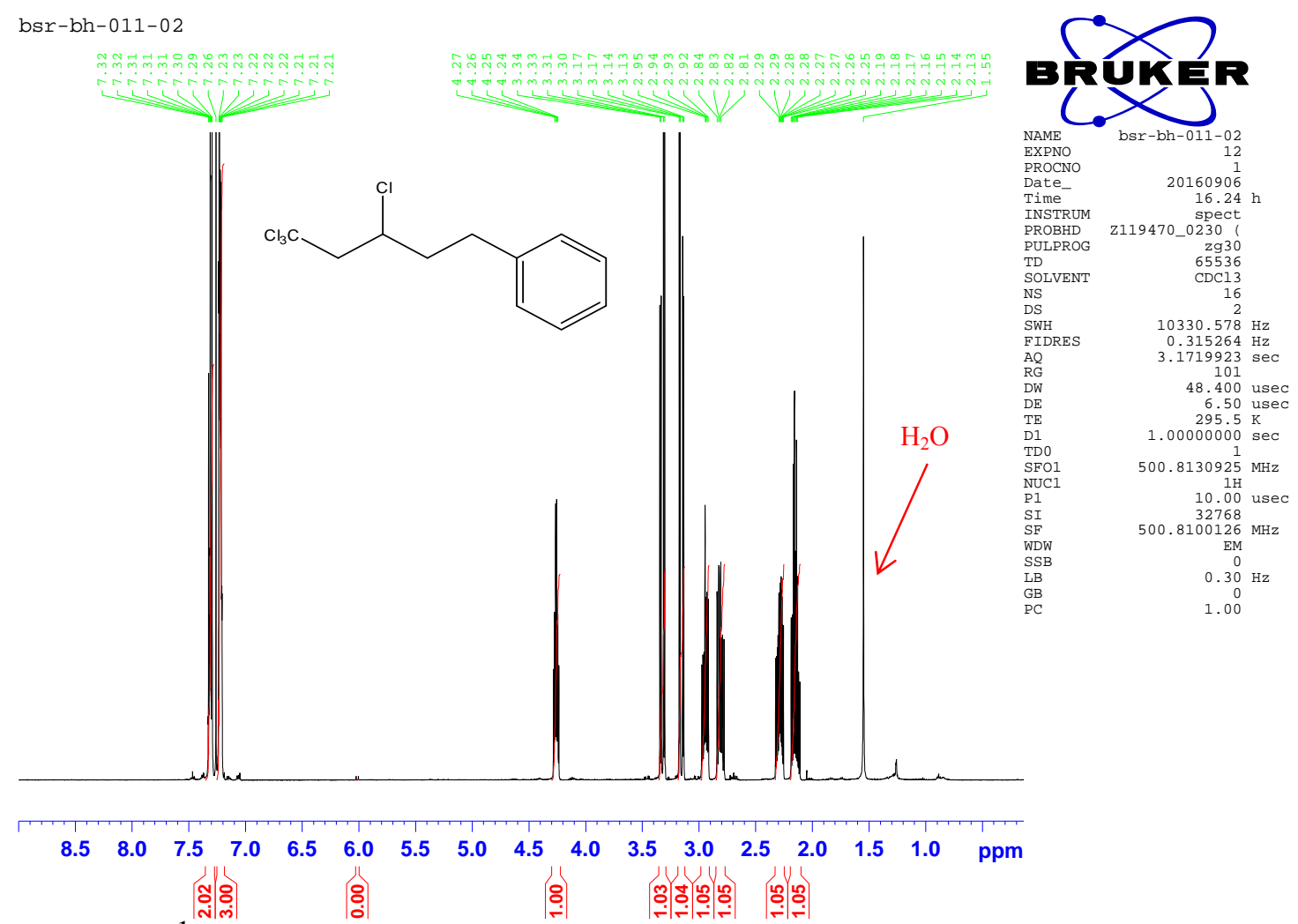

Figure S28: ${ }^{1} \mathrm{H}-\mathrm{NMR}\left(\mathrm{CDCl}_{3}, 500 \mathrm{MHz}\right)$ of compound 10.

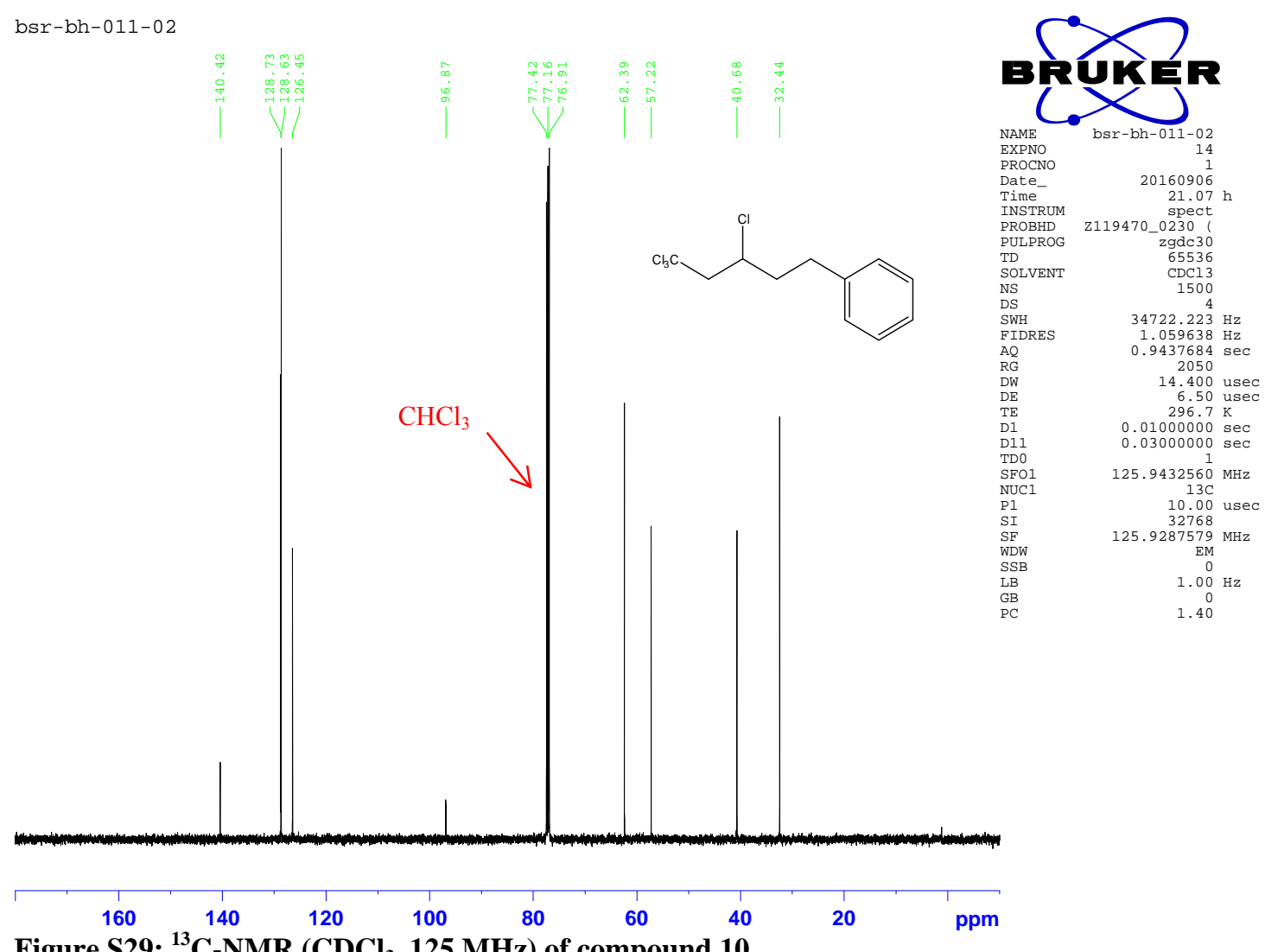

Figure S29: ${ }^{13} \mathrm{C}-\mathrm{NMR}\left(\mathrm{CDCl}_{3}, 125 \mathrm{MHz}\right)$ of compound 10. 


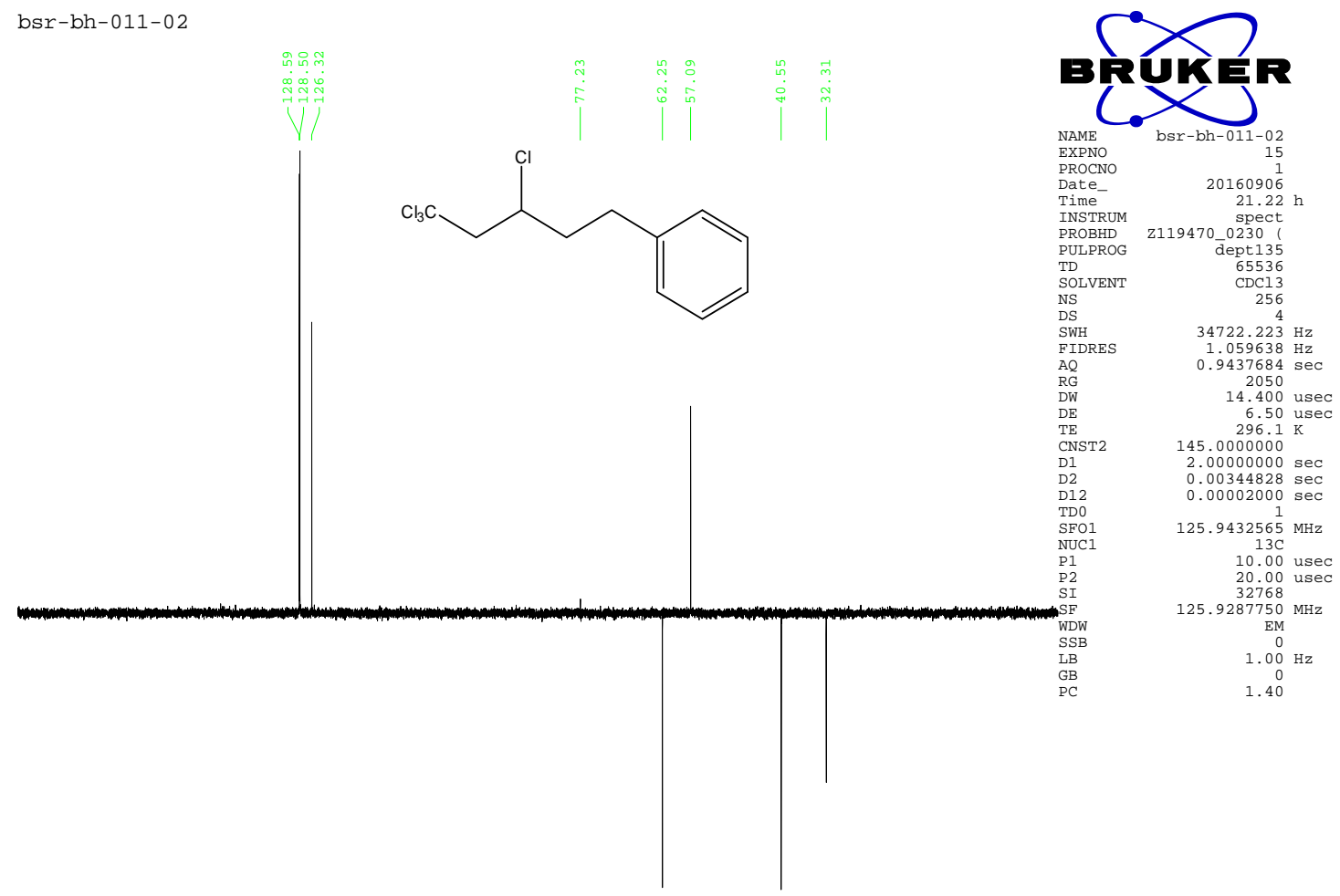
160
$\begin{array}{lll}140 & 120 & 100\end{array}$
80
$60 \quad 40$
20
ppm

Figure S30: DEPT 135-NMR (CDCl $3,125 \mathrm{MHz})$ of compound 10.

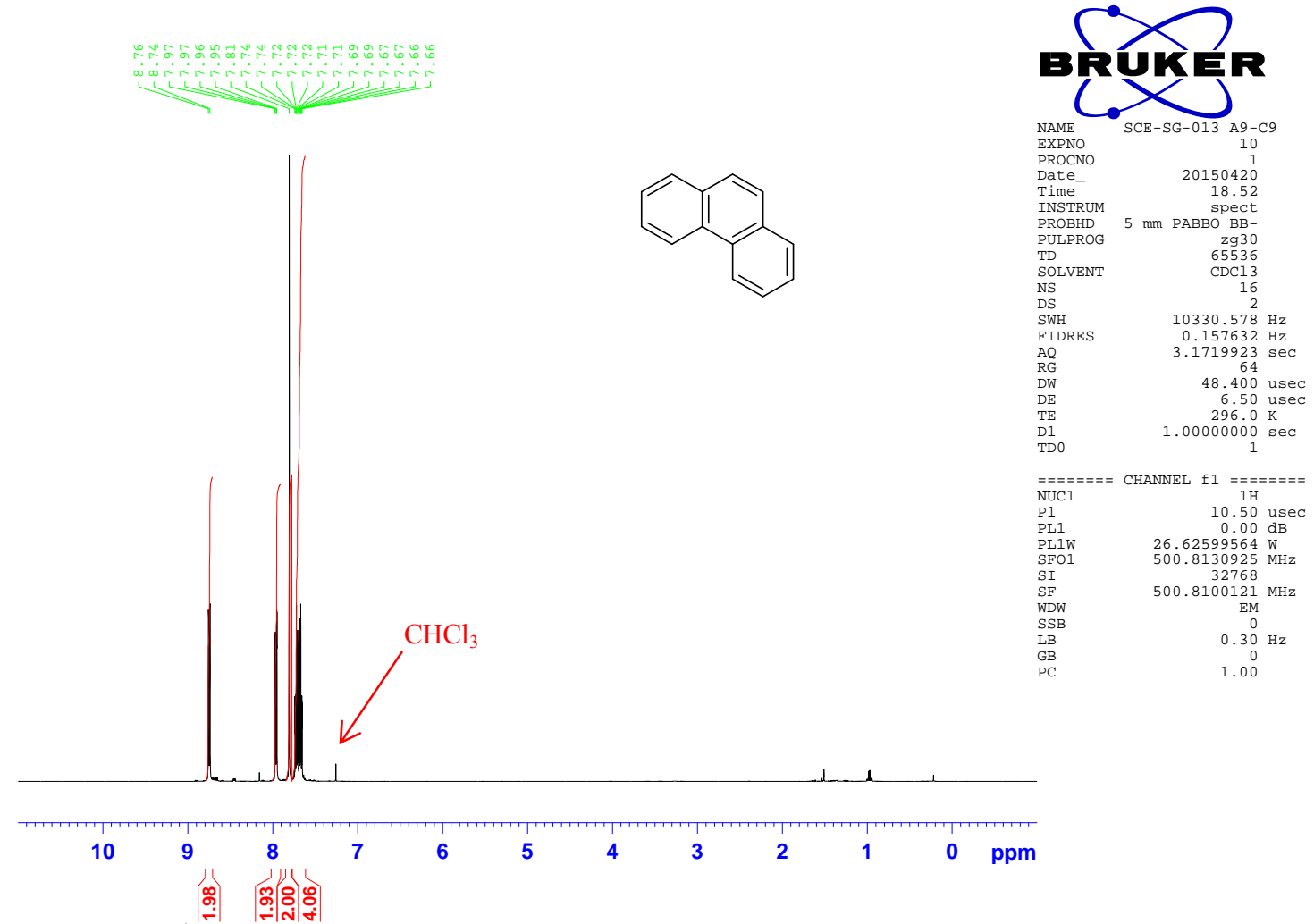

Figure S31: ${ }^{1} \mathrm{H}-\mathrm{NMR}\left(\mathrm{CDCl}_{3}, 500 \mathrm{MHz}\right)$ of compound 11. 

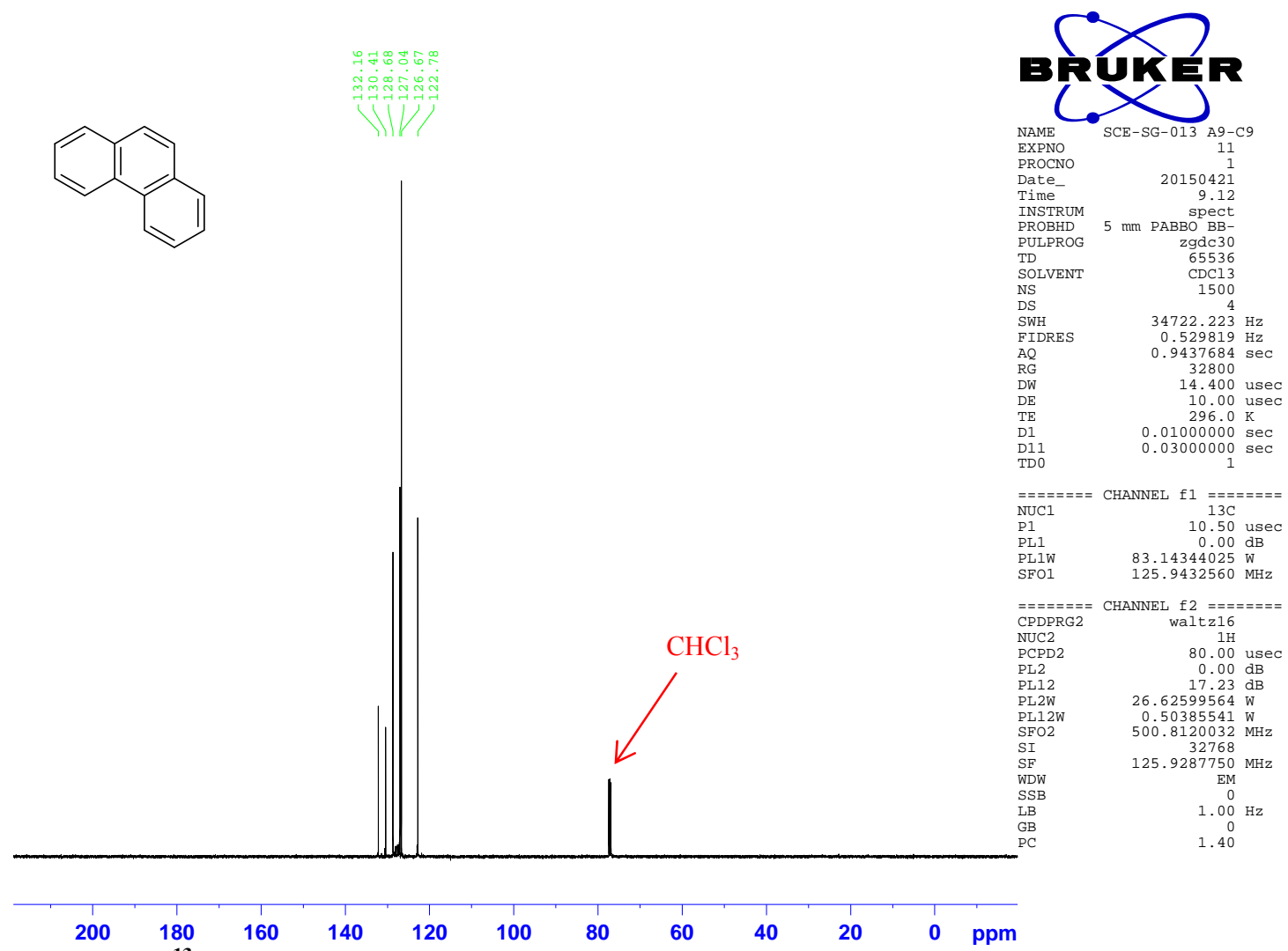

$========$ CHANNEL f 1 1 =======
NUC1 $13 \mathrm{C}$

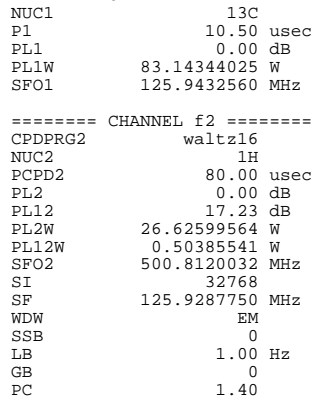

Figure S32: ${ }^{13} \mathrm{C}-\mathrm{NMR}\left(\mathrm{CDCl}_{3}, 125 \mathrm{MHz}\right)$ of compound 11.

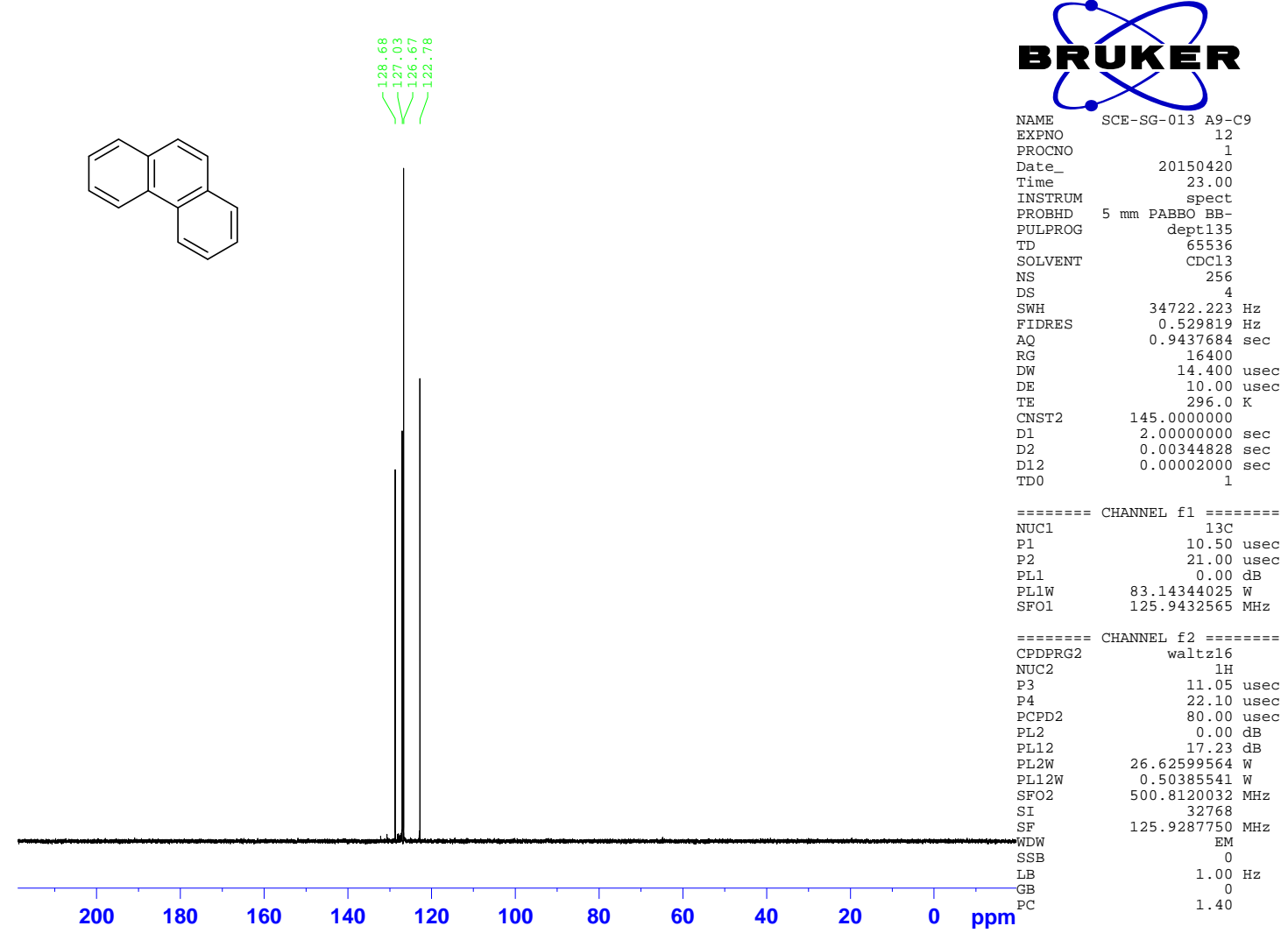

Figure S33: DEPT 135-NMR $\left(\mathrm{CDCl}_{3}, 125 \mathrm{MHz}\right)$ of compound 11. 


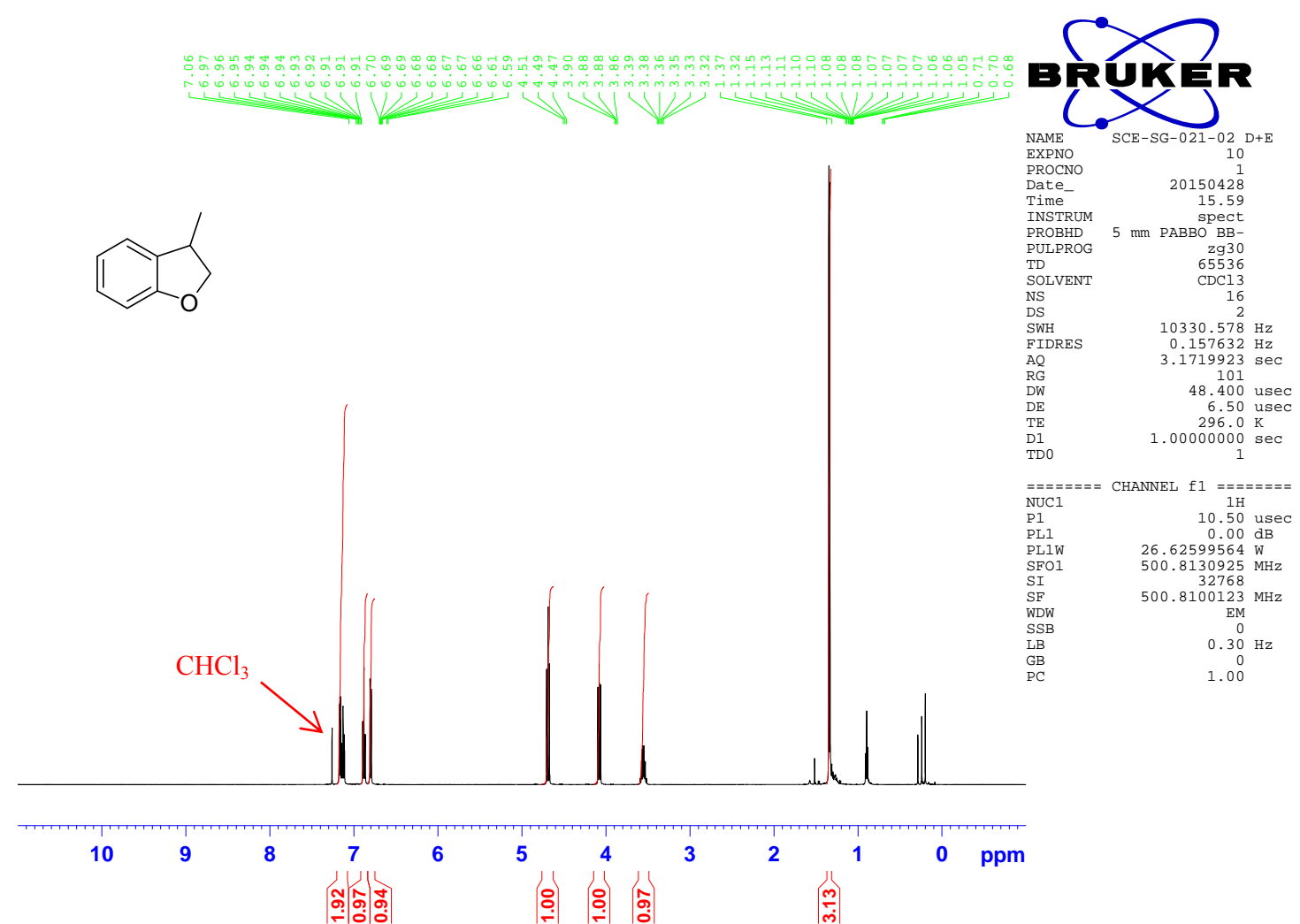

Figure S34: ${ }^{1} \mathrm{H}-\mathrm{NMR}\left(\mathrm{CDCl}_{3}, 500 \mathrm{MHz}\right)$ of compound 13.

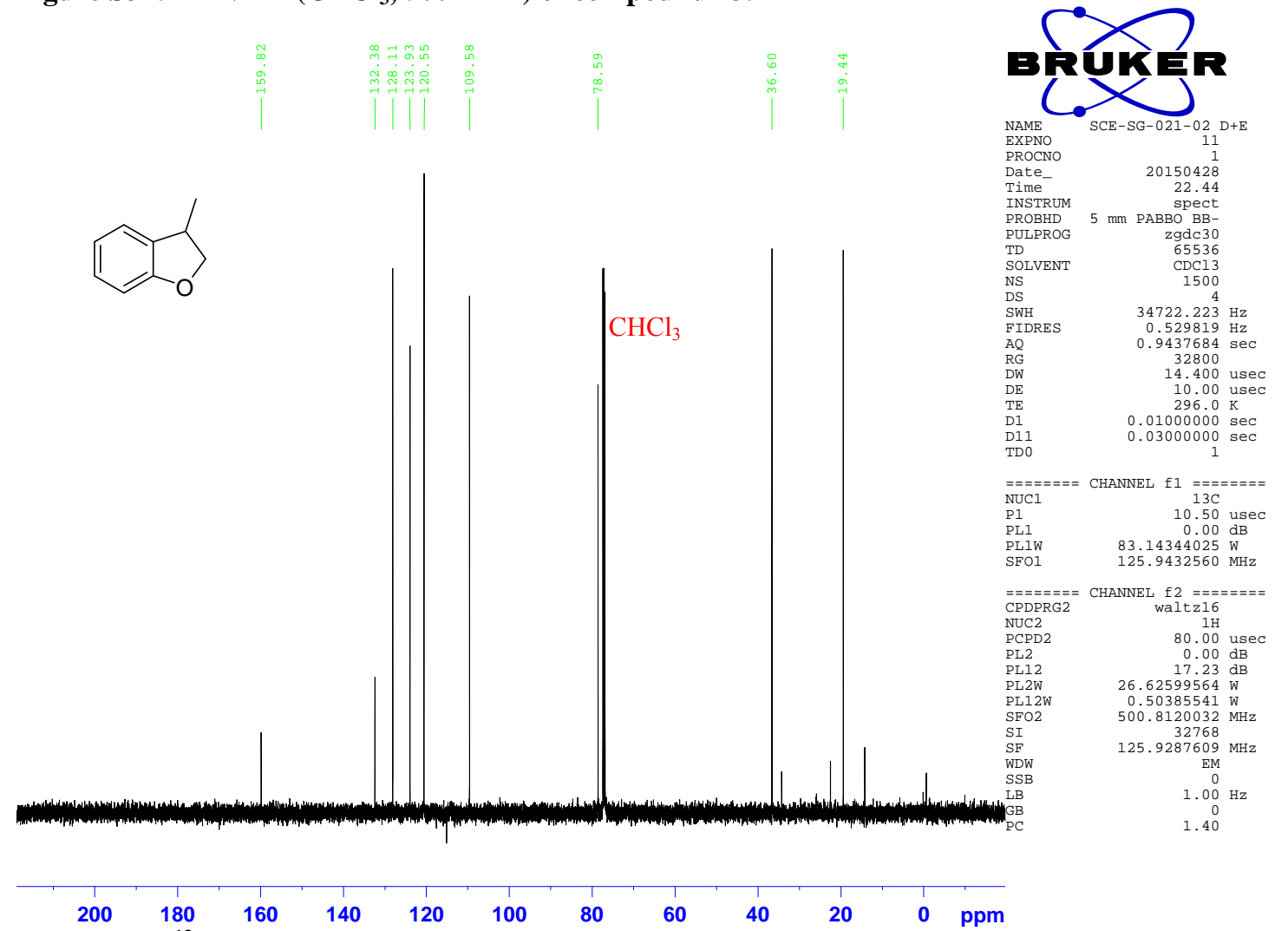

Figure S35: ${ }^{13} \mathrm{C}-\mathrm{NMR}\left(\mathrm{CDCl}_{3}, 125 \mathrm{MHz}\right)$ of compound 13. 


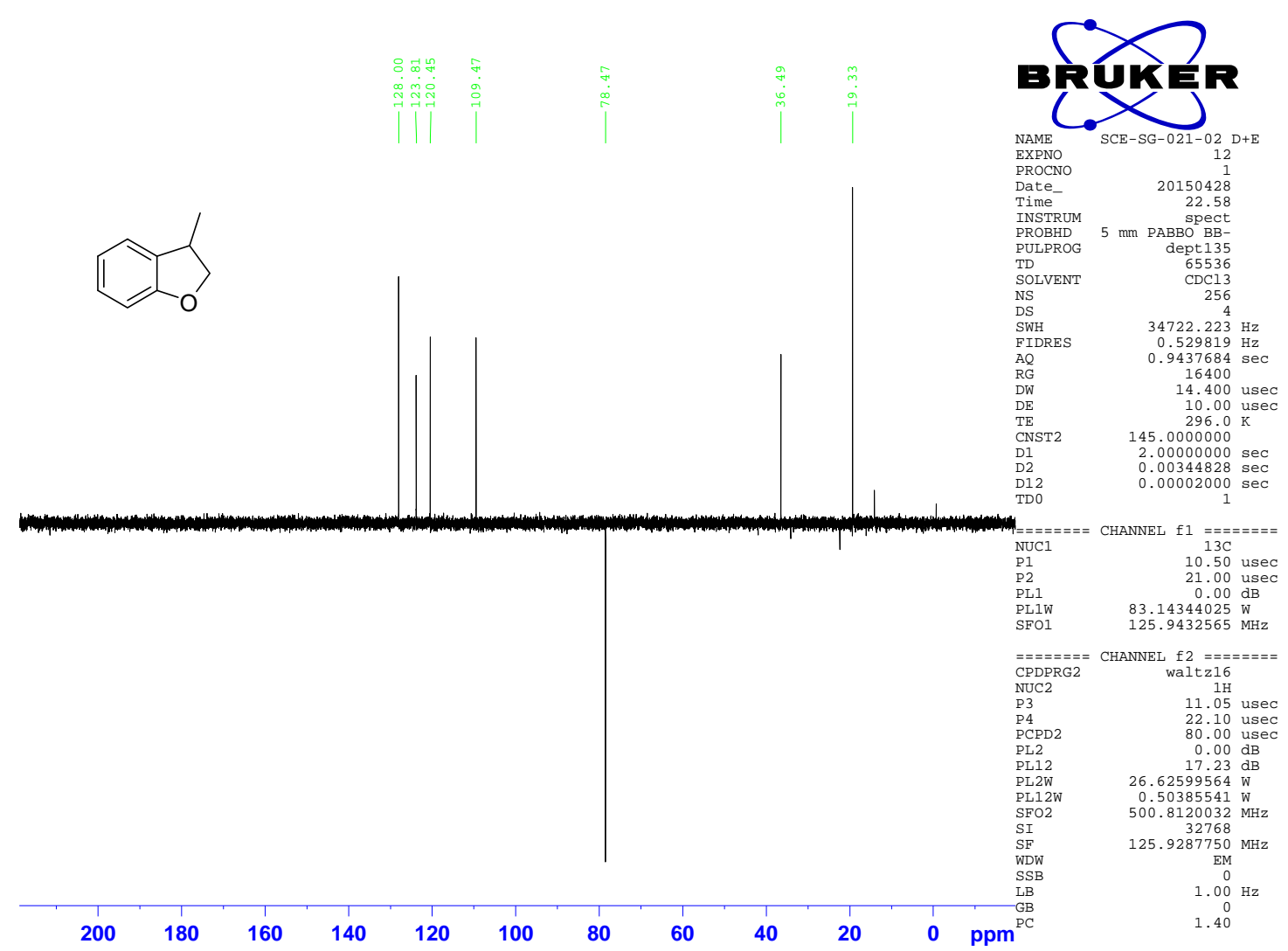

Figure S36: DEPT 135-NMR ( $\left.\mathrm{CDCl}_{3}, 125 \mathrm{MHz}\right)$ of compound 13.

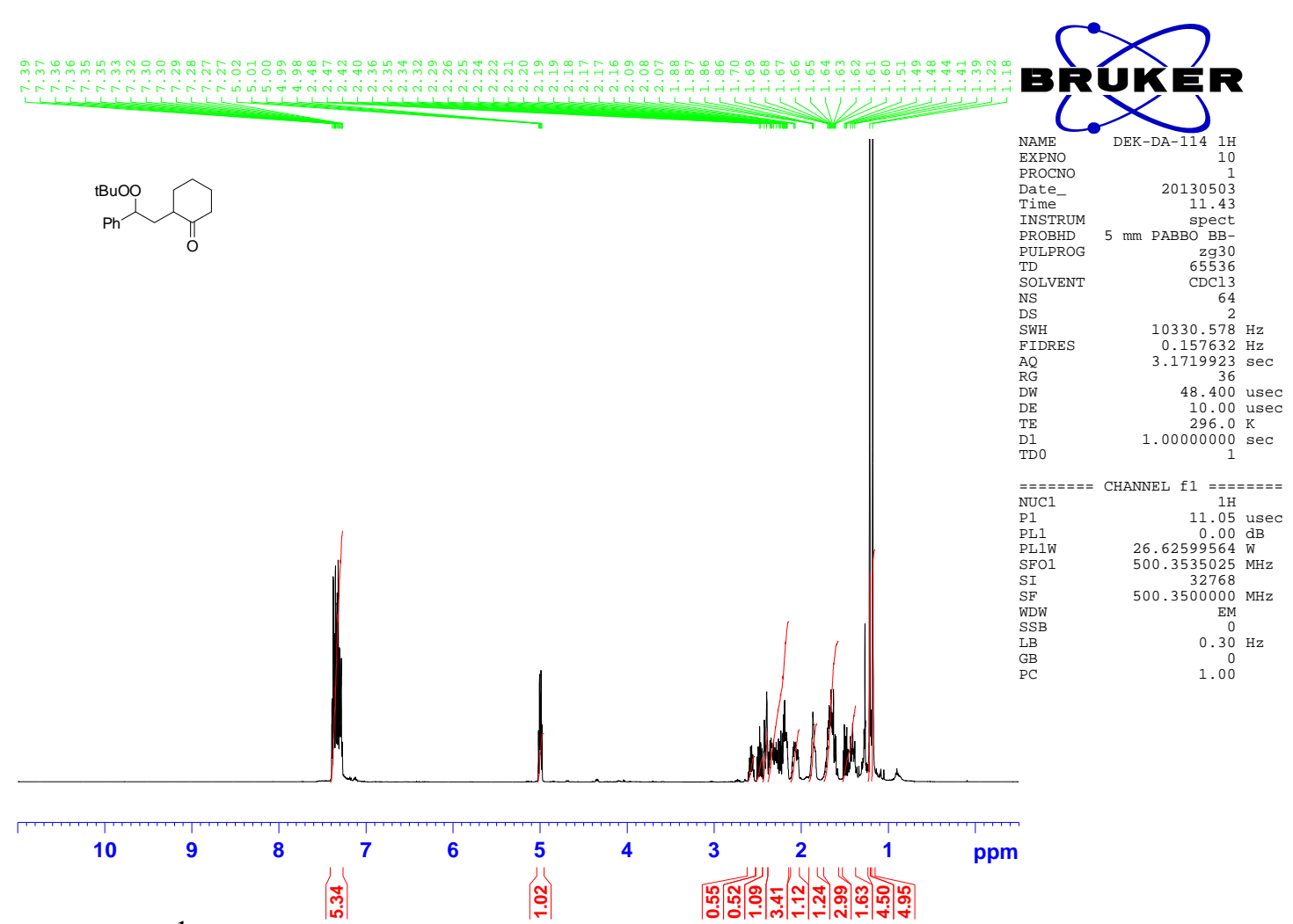

Figure S37: ${ }^{1} \mathrm{H}-\mathrm{NMR}\left(\mathrm{CDCl}_{3}, 500 \mathrm{MHz}\right)$ of 2-(2-(tert-butylperoxy)-2-phenylethyl)cyclohexan-1one. 


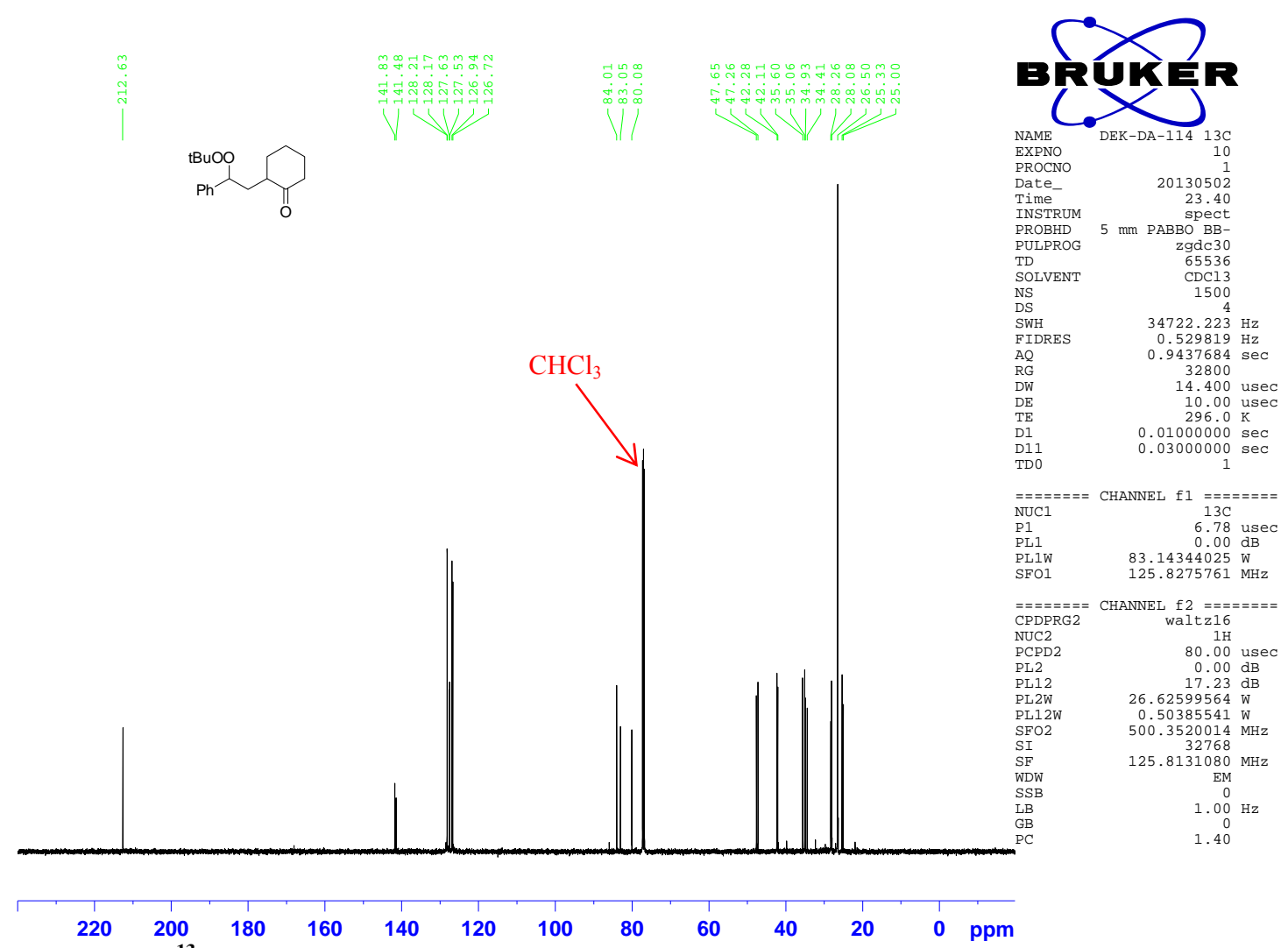

Figure S38: ${ }^{13} \mathrm{C}-\mathrm{NMR}\left(\mathrm{CDCl}_{3}, 125 \mathrm{MHz}\right)$ of 2-(2-(tert-butylperoxy)-2-phenylethyl)cyclohexan-1one.

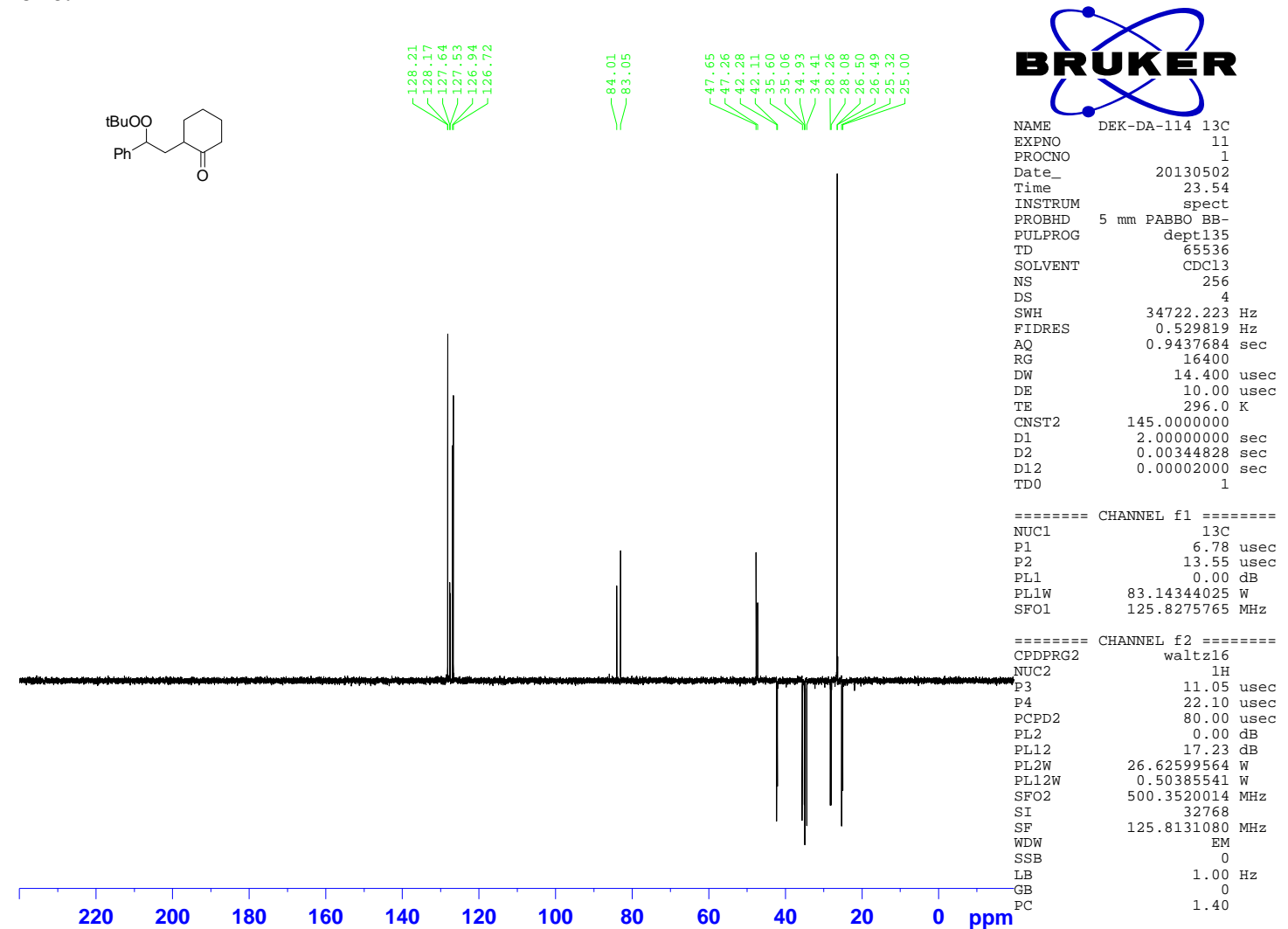

Figure S39: DEPT 135-NMR ( $\left.\mathrm{CDCl}_{3}, 125 \mathrm{MHz}\right)$ of 2-(2-(tert-butylperoxy)-2phenylethyl)cyclohexan-1-one. 


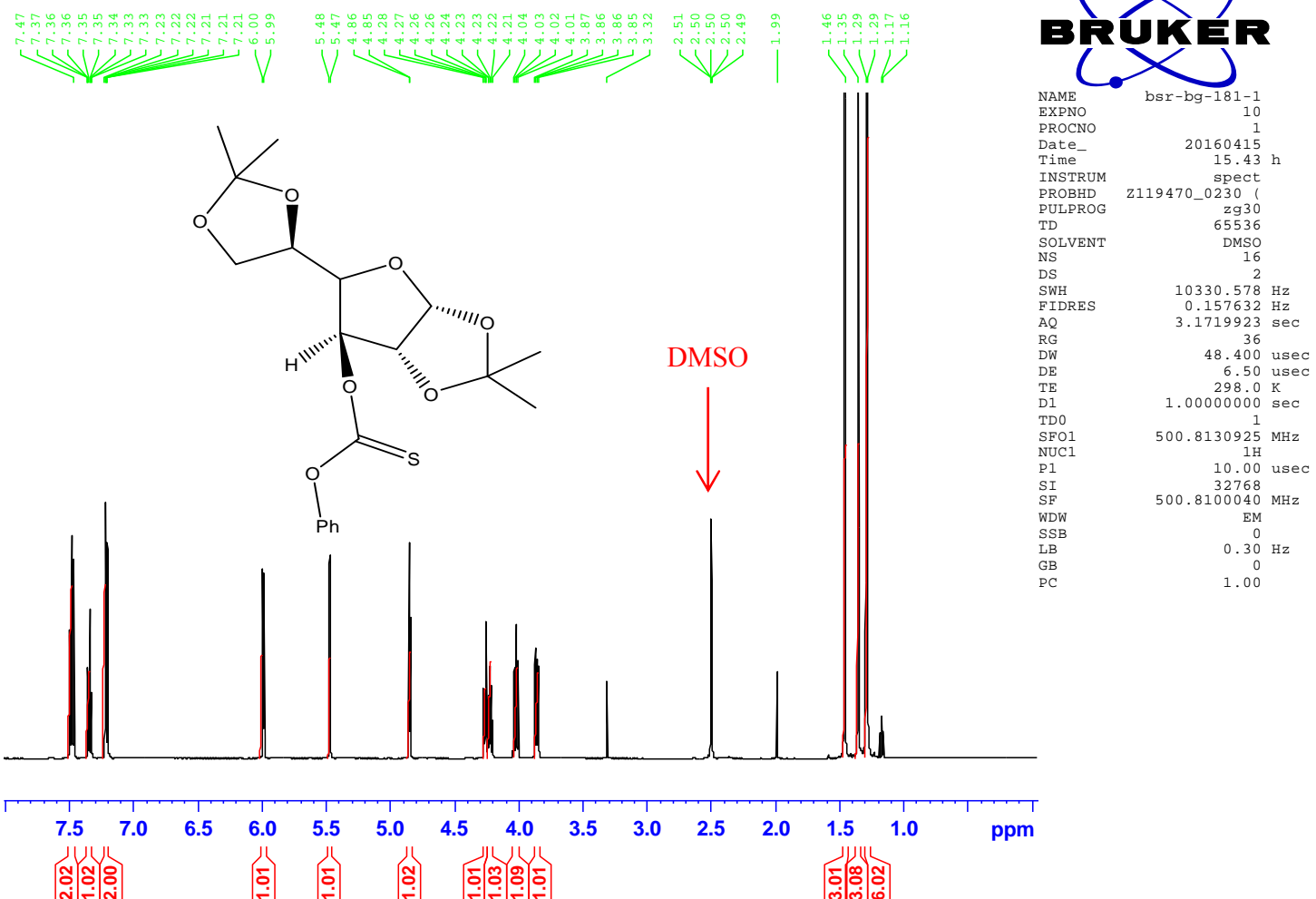

Figure S40: ${ }^{1} \mathrm{H}-\mathrm{NMR}$ (DMSO-d 6 , $500 \mathrm{MHz}$ ) of compound 14.
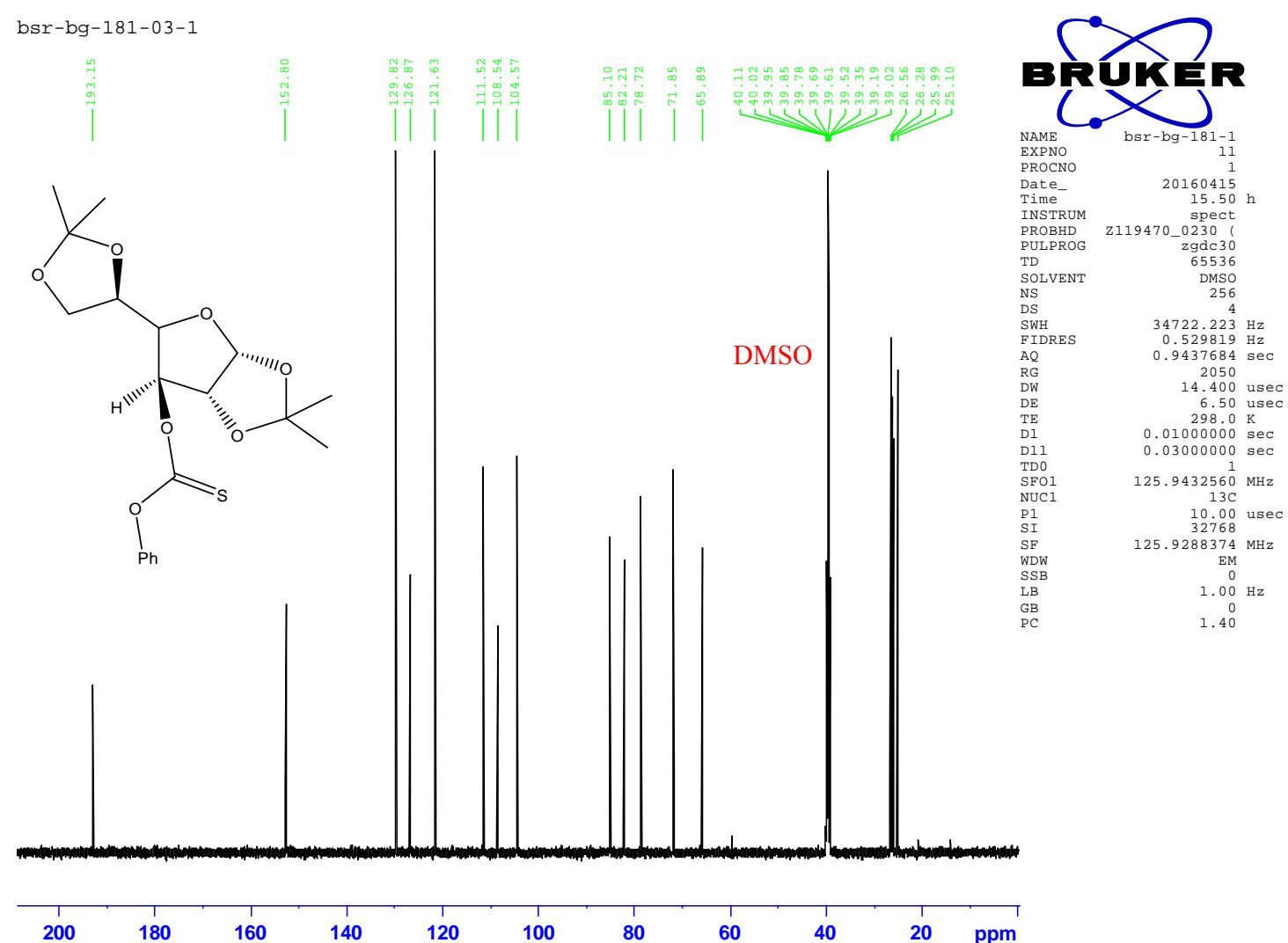

Figure S41: ${ }^{13} \mathrm{C}-\mathrm{NMR}$ (DMSO-d 6 , $125 \mathrm{MHz}$ ) of compound 14. 


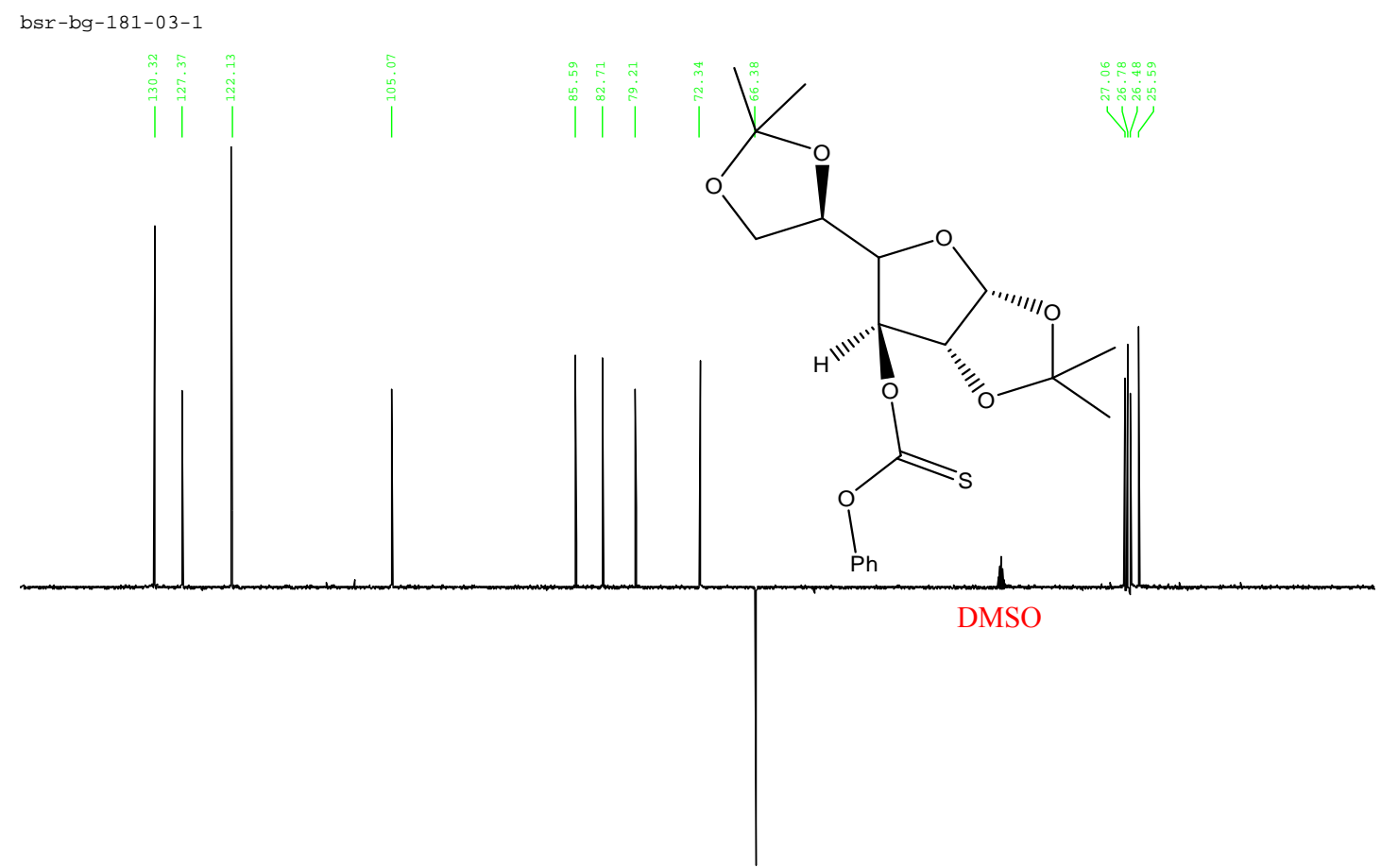

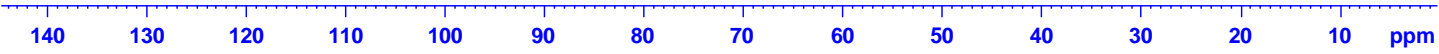

Figure S42: DEPT 135-NMR (DMSO-d 6 , $125 \mathrm{MHz}$ ) of compound 14.

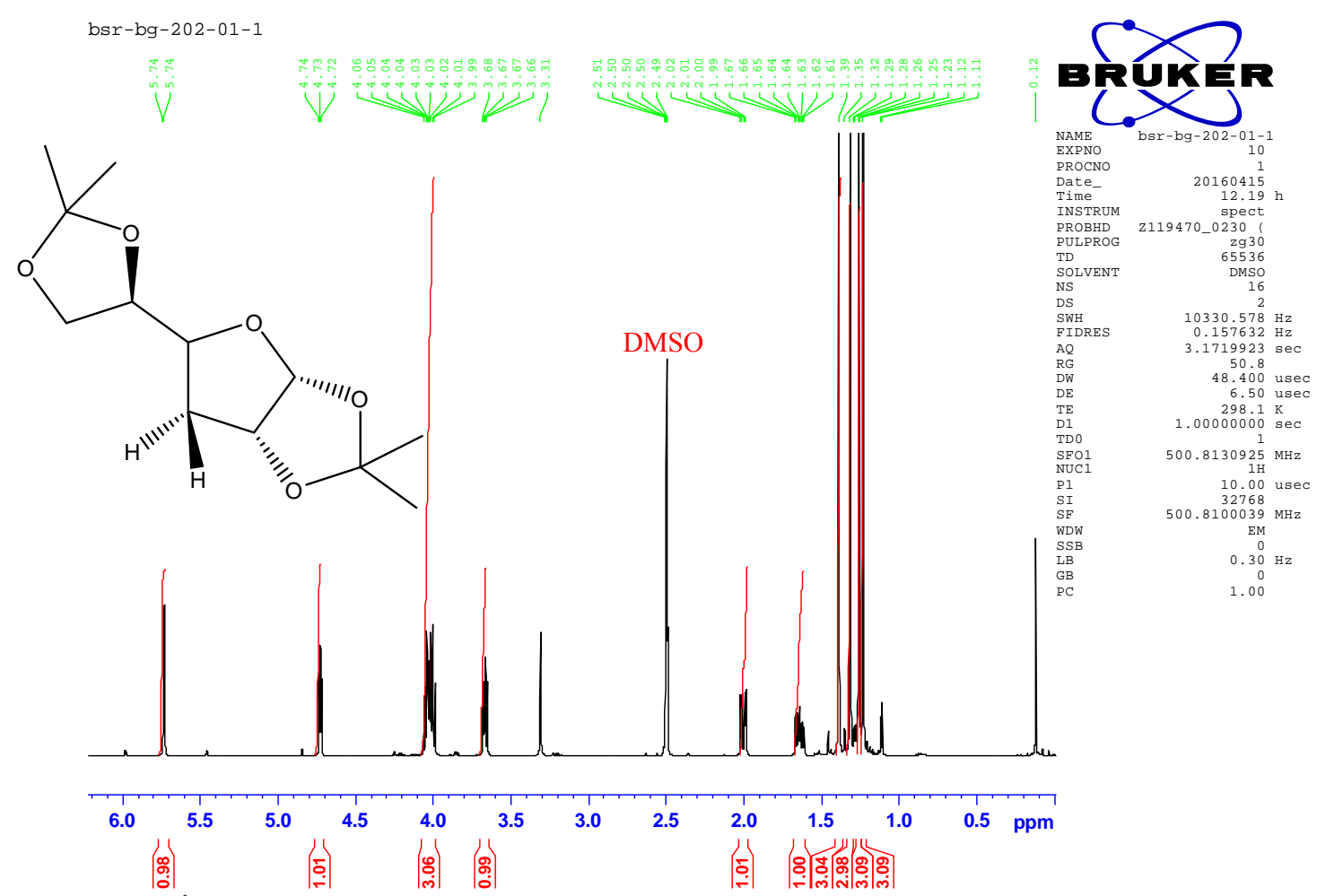

Figure S43: ${ }^{1} \mathrm{H}-\mathrm{NMR}$ (DMSO-d ${ }_{6}, 500 \mathrm{MHz}$ ) of compound 15. 

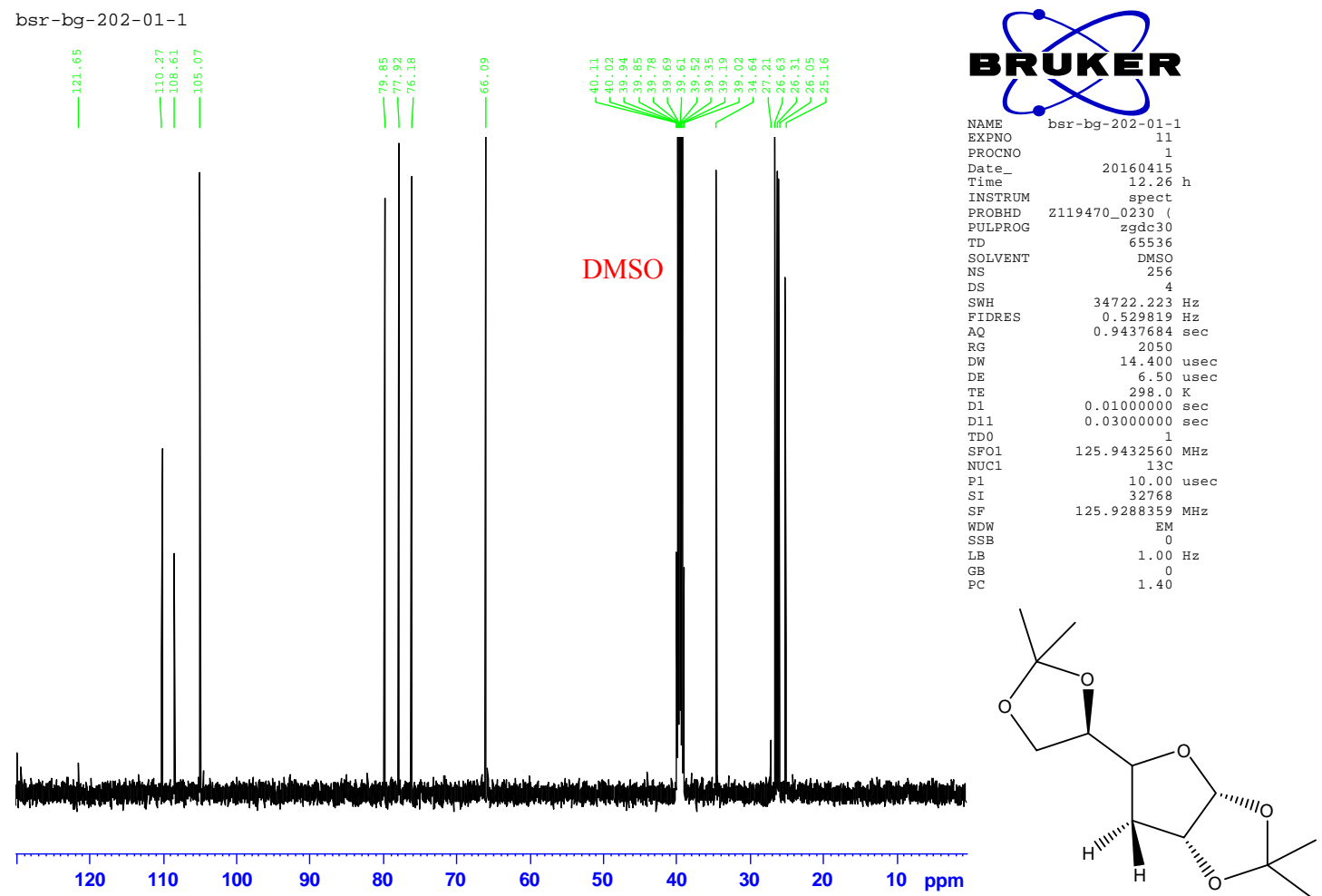

Figure S44: ${ }^{13} \mathrm{C}-\mathrm{NMR}$ (DMSO-d 6 , $125 \mathrm{MHz}$ ) of compound 15.

bsr-bg-202-01-1

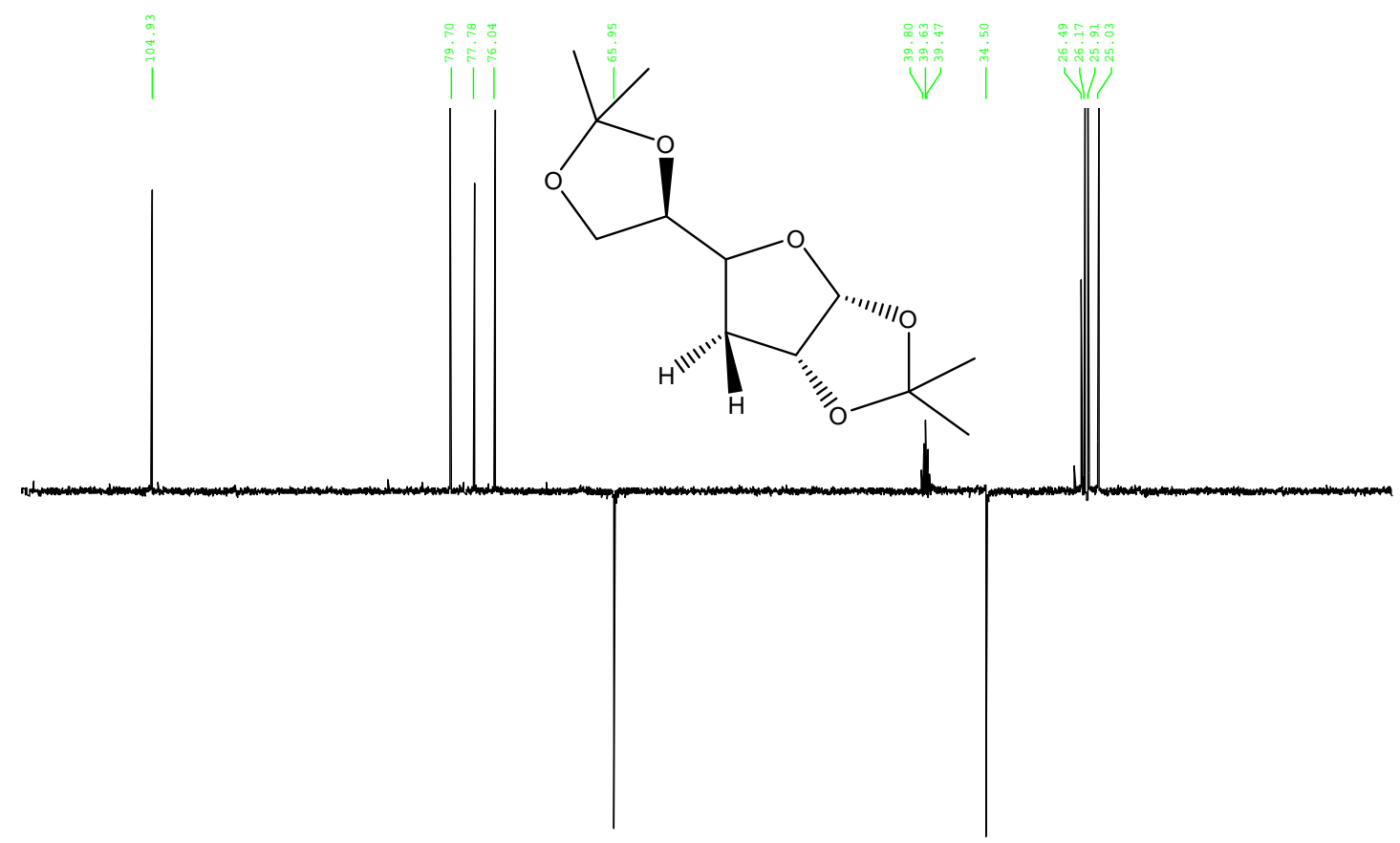

Figure S45: DEPT 135-NMR (DMSO-d ${ }_{6}, 125 \mathrm{MHz}$ ) of compound 15. 


\section{Supporting References}

(1) Gottlieb, H. E.; Kotlyar, V.; Nudelman, A. J. Org. Chem. 1997, 62, 7512.

(2) Terent'ev, A. O.; Kutkin, A. V.; Troizky, N. A.; Ogibin, Y. N.; Nikishin, G. I. Synthesis 2005, 2005, 2215.

(3) Matsuyama, K.; Sugiura, T.; Minoshima, Y. J. Org. Chem. 1995, 60, 5520.

(4) Pramanik, S.; Ghorai, P. Org. Lett. 2013, 15, 3832.

(5) Organic Peroxides, 1966; UK Patent No. GB19640004687 19640204

(Montecatini Societa Generale Per L'industria Mineraria E chimica).

(6) Colombo, L.; Sacrini, E.; Colombo, V.; Organic Peroxides; Montecatini Edison S. p. A., M., Ed. Italy, 1973; Vol. Italian Patent Number IT19700020830 19700219.

(7) Roy, B. G.; Maity, J. K.; Drew, M. G. B.; Achari, B.; Mandal, S. B. Tetrahedron Lett. 2006, 47, 8821.

(8) de Almeida, L. S.; Esteves, P. M.; de Mattos, M. C. S. Tetrahedron Lett. 2015, 56, 6843.

(9) Pereira, S.; Srebnik, M. J. Am. Chem. Soc. 1996, 118, 909.

(10) Curran, D. P.; Totleben, M. J. J. Am. Chem. Soc. 1992, 114, 6050.

(11) Dahlen, A.; Petersson, A.; Hilmersson, G. Org. Biomol. Chem. 2003, 1, 2423.

(12) Lopez, R. M.; Hays, D. S.; Fu, G. C. J. Am. Chem. Soc. 1997, 119, 6949.

(13) Schweitzer-Chaput, B.; Demaerel, J.; Engler, H.; Klussmann, M. Angew. Chem. Int. Ed. 2014, 53, 8737.

(14) Schweitzer-Chaput, B.; Kurtén, T.; Klussmann, M. Angew. Chem. Int. Ed. 2015, $54,11848$. 